Wentia 2 (1959) 1-96

\title{
HEATHS AND INLAND DUNES OF THE VELUWE
}

A STUDY ON SOME OF THE RELATIONS EXISTING BETWEEN VEGETATION, SOIL AND MICROCLIMATE

PH. STOUTJESDIJK

(Biol. Station "Weeversduin", Oostvoorne)

\section{CONTENTS}

INTRODUCTION . . . . . . . . . . . . . . . . . . . . 2

GHapter 1. Stratification OF THE SOIL UNDER Heath VEgetations . . . . 3

a. The typical heath podsol . . . . . . . . . . . . . . . . 3

b. Heath podsols found outside the Netherlands . . . . . . . . . . . 4

c. Formation of the heath podsol . . . . . . . . . . . . . . 5

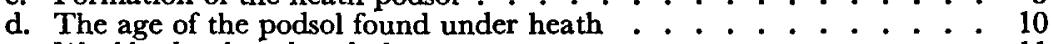

e. Weakly developed podsols . . . . . . . . . . . . . ... 11

f. Brown podsolic soils . . . . . . . . . . . . . . . . . . . . . 11

g. Transition between heath podsol and brown podsolic soil . . . . . 12

h. Transition between podsol and gley . . . . . . . . . . . . 12

i. Regeneration of heath podsol . . . . . . . . . . . . . . . 13

j. Red sand . . . . . . . . . . . . . . . . . . . . . . . . 14

k. Concluding remarks . . . . . . . . . . . . . . . . . . 18

Ghapter II. The heAth Vegetation . . . . . . . . . . . . . . . 18

a. Plant communities found on the heath . . . . . . . . . . . 18

b. Exposition effects on the heath vegetation . . . . . . . . . . . . 20

c. Gyclic development of the heath vegetation . . . . . . . . . . . . 22

d. Heaths with Deschampsia flexuosa . . . . . . . . . . . . 25

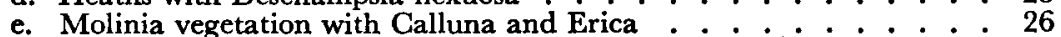

f. Equilibrium of plant communities . . . . . . . . . . . . . 27

g. Human and biotic influences. . . . . . . . . . . . . . . . 28

h. Biological notes on heath plants . . . . . . . . . . . . . . . . 31

CHAPTER III. INLAND DUNES . . . . . . . . . . . . . . . . . . 35

a. Landscape forms which owe their origin to wind erosion . . . . . . 35

b. Vegetation of blown-out plains . . . . . . . . . . . . . . 40

c. Colonization of the fixed inland dunes . . . . . . . . . . . 41

d. Hills covered with oak shrub. . . . . . . . . . . . . . . . . 45

e. Growth rings . . . . . . . . . . . . . . . . . . . . 46

f. Biological notes on inland dune plants. . . . . . . . . . . . . . 48

IHAPTER IV. Microclimatological measurements . . . . . . . . . . . 51

a. Variation width of the temperature in the heath soil. $. . .^{*} \cdot .^{-} \quad .51$

b. Heath-soil temperatures in parts with different exposition . . . . . 55

c. Nocturnal air temperatures in and above the heath . . . . . . . . 56

d. Air temperatures in periods with strong insolation. . . . . . . . 61

e. The effect of the relief on night temperatures measured above a heath 65

f. Humidity within the heath vegetation. . . . . . . . . . 66

g. The changes which the humidity undergoes during the night . . . . 69

h. Evaporation . . . . . . . . . . . . . . . . 70

i. Light intensity in the heath vegetation . . . . . . . . . . . . . 72

j. Heat balance of the heath vegetation . . . . . . . . . . . . 73

k. Temperatures of inland dune sand . . . . . . . . . . . . . . . 75

1. Air temperatures above the dunes . . . . . . . . . . . . 76

m. Dew formation. . . . . . . . . . . . . . . . . . . . 80 
n. Light reflection of the bare dune sand . . . . . . . . . . . 81

o. Heat emission by dune sand . . . . . . . . . . . . . . . . . 81

p. Water relations of inland dune vegetation . . . . . . . . 82

q. The effect of exposition on the temperatures of the soil . . . . . 84

r. Influence of the IJsselmeer. . . . . . . . . . . . . . 89

chapter v. Concluding remarks on the Relations between vegetation AND HABITAT. . . . . . . . . . . . . . . . . . . . . 89

a. The heath vegetation . . . . . . . . . . . . . . . . . 89

b. Inland dunes . . . . . . . . . . . . . . . . . 92

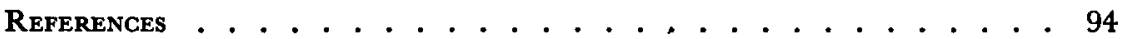

\section{INTRODUGTION}

The Veluwe is a stretch of high ground in the central part of the Netherlands, north of the river Rhine and south of the IJssel Meer, i.e. the former Zuiderzee, and the polders reclaimed from the latter.

Geologically the area consists of three formations:

1. ridges which owe their origin to the pressure of the land ise, and which consist of sands deposited as river sediments in preglacial times;

2. a fluvioglacial formation; on some of these plains small but steep hills are found;

3. aeolian sediments: löss and cover-sands (cf. VINK, 1949); they were deposited in the late-glacial period.

Löss is found in the S.E. corner of the area, and cover-sands form extensive areas, inside the area as well as on the lower ground to the west of it. The greater part of the cover-sand areas on the Veluwe have fallen a victim to wind erosion, and in this way extensive stretches of inland dunes have been formed.

Compared with the rest of the Netherlands the Veluwe shows a rather strong relief, and rises locally to over $100 \mathrm{~m}$ above sea level. In the greater part of the area the surface lies far above the ground water.

Data with regard to the climtate of the area have been given by BRAAK (1929-1947). Only those which seem to be of interest from the point of view of the present study, are mentioned here.

On the greater part of the Veluwe the rainfall is rather high; this is due to the fact that its elevation too is rather high in comparison with the rest of the Netherlands. Apeldoorn has a yearly rainfall of $802 \mathrm{~mm}$. The lowest rainfall has been recorded along the coast of the IJsselmeer (Putten $745 \mathrm{~mm}$ ). The difference is most marked between the beginning of March and the end of July; it stands out even more clearly when instead of the rainfall figures the number of days with more than $0.1 \mathrm{~mm}$ precipitation are compared.

The amount of sunshine is probably negatively correlated with the amount of rainfall. For the influence which is exercised by the IJsselmeer on air temperature and humidity, cf. Chapter Iv.r.

$\mathrm{Up}$ to the second half of the 19th century the main landscape types were dry heaths and inland dunes. In the second part of the 19th century and in the beginning of this century extensive areas were 
planted with Scotch pine. However, on the heaths as well as on the inland dunes several areas thousands of acres in extent were spared. This study is concerned with some aspects of the original vegetation.

The estimated positions of sampling spots and of soil sections are usually given in coordinates of the Dutch Ordnance Map 1:50000.

\section{CHAPTER I}

\section{STRATIFICATION OF THE SOIL UNDER HEATH VEGETATIONS}

\section{a. THE TYPIGAL HEATH PODSOL}

What we mean by this term, is perhaps best illustrated by the description of a typical example, e.g. the following one.

$\mathrm{A}_{0} \quad 0-4 \mathrm{~cm}$ mixture of black humus with sand

$\mathrm{A}_{1}$ 4-7 cm dark humous sand

$A_{2} \quad 7-17 \mathrm{~cm}$ grey bleached sand

$A_{3}$ 17-25 cm a black, soft humous layer separated from the next lower one by a hard, firmly concreted lamina with a felt of thin roots just above it

$B_{1} \quad 25-35 \mathrm{~cm}$ sand consisting of strongly cemented grains; colour changing from black brown on top to brown at the bottom; one darker vein in it; difficult to penetrate with a spade

$\mathbf{B}_{2}$ 35-59 cm marbly; colour changing from brown to light yellow; showing an undulating fibre; main direction horizontal

$59-69 \mathrm{~cm}$ light yellow sand showing a weak fibre

C 69- light yellow sand

Fine sand throughout the whole section; roots sporadically penetrating below the horizon between $A_{3}$ and $B_{1}$.

Locality: Elspeetsche Heide.

A stratification of this type was found in most cover-sands and in part of the fluvioglacial soils; rarely on praeglacial soil.

\section{Position of sampling spots}

Elspeetsche Heide

Ermelosche Heide

Houtdorper Veld

Gerritsfles "

Kootwijksche Zand

Eder Heide

$\begin{array}{ll}481,6 & 183.1 \\ 478.3 & 174.7 \\ 474.5 & 177.5 \\ & \\ 473.2 & 178.5 \\ 463.8 & 185.6 \\ 452.7 & 176.7\end{array}$

481,6

478.3

174.7

177.5

178.5

176.7

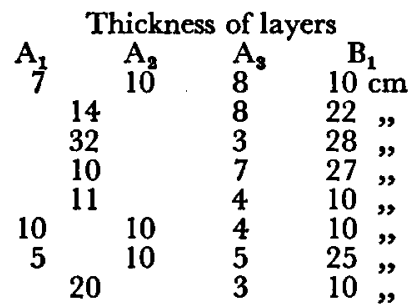

The thickness and other properties of the different layers vary considerably. The colour of the bleached sand ranges from almost white to dark grey. The thickness of this layer varies between $11 \mathrm{~cm}$ and $32 \mathrm{~cm}$. However, in a few places we found bleached sand layers up to $80 \mathrm{~cm}$ thick. In such cases it seems probable that a gradual aeolian deposition of sand has taken place, even though the sections show no boundary line between autochtonous bleached sand and sand that was deposited at a later date. The black humous layer $A_{3}$ varies in thickness from 3 to $8 \mathrm{~cm}$. The concretion layer is sometimes absent, but the boundary line between $A_{3}$ and $B$ may nevertheless be very 
sharp. However, podsols with a gradual transition between $\mathrm{A}$ and $\mathrm{B}$ are found as well. The $B_{1}$ layer varies in thickness from 10 to $28 \mathrm{~cm}$. This hardpan is always very compact, as the particles are often cemented together; it is difficult to penetrate with a spade, although never as hard as stone. The pan probably hampers the downward movement of water. Yet, as a rule, the soil above it does not become waterlogged even after prolonged rainy periods. Exceptions were found exclusively on places where the soil had become covered with a layer of aeolian sand, or where the layer of bleached sand proved to be very thick. Extensive areas of heath with an impermeable hardpan underneath, are not known to us from the Netherlands. It seems that such soils have formerly been present, but that they have now been reclaimed.

In connection with the statement of VeENENBos (1953) that the hardpan found in soils on higher ground can not be regarded as a zone in which iron is accumulated, the data of Table 1 are of interest. The analyses were kindly made by $\mathrm{Mr}$. O. H. Blaauw in such a way that the total amount of 'iron in the sample was determined.

TABLE 1

Iron content and loss on ignition (humus) in some layers of heath podsol and in a red soil.

\begin{tabular}{|c|c|c|c|c|}
\hline \multicolumn{2}{|c|}{ Locality } & Layer & Iron & $\begin{array}{c}\text { Loss on } \\
\text { ignition }(\%)\end{array}$ \\
\hline 474,5 & 177,4 & $\begin{array}{l}\mathbf{A}_{\mathbf{2}} \\
\mathbf{A}_{\mathbf{3}} \\
\mathbf{B}_{\mathbf{1}}\end{array}$ & $\begin{array}{l}0,04 \\
0,04 \\
0,55 \\
0,33\end{array}$ & $\begin{array}{r}0,5 \\
11.4 \\
4,1 \\
0.7\end{array}$ \\
\hline 469,1 & 175,2 & $\begin{array}{l}\mathrm{A}_{\mathbf{2}} \\
\mathbf{B}_{1}\end{array}$ & $\begin{array}{l}0,09 \\
0,65\end{array}$ & $\begin{array}{l}8,7 \\
6.7\end{array}$ \\
\hline 464,8 & 181,2 & $\mathrm{~A}_{\mathrm{z}}$ & 0,09 & 8,0 \\
\hline $\begin{array}{l}465 \\
465,4 \\
469,4\end{array}$ & $\begin{array}{l}182 \\
182,6 \\
172,9\end{array}$ & $\begin{array}{c}\mathbf{B}_{1} \\
\mathbf{B}_{1} \\
\operatorname{Red} \text { soil }\end{array}$ & $\begin{array}{l}0,34 \\
0,94 \\
0,87\end{array}$ & $\begin{array}{l}6,6 \\
4,9 \\
3,1\end{array}$ \\
\hline
\end{tabular}

b. Heath podsols found outside the Netherlands

WEIss $(1929,1933)$ has given detailed descriptions and analyses of heath podsols in Denmark. The stratification is down to details similar to that of the sections studied by us. The thickness of the different layers is of the same order as that found by us. The raw-humus layer, however, is about $10 \mathrm{~cm}$ thick. However, it should be noted that the name raw humus is used by Weiss for a soil that contains but $50 \%$ organic material. The pan is often impermeable to such a degree that water stagnates on the soil surface. In summer, on the other hand, the topsoil may be very dry.

FARRow (1925) gives a picture of a heath podsol from the Brecklands (Norfolk), which is very similar to that found in the Netherlands. According to RoBIsson (1949) on the Bagshot sands in South England a heath podsol is found with an impermeable hardpan. 
The black-humus layer above the hardpan proper seems to be very characteristic for the heath podsol, and separates it from other podsols. As compared with the other podsols the heath podsol, moreover, seems to consist of layers which are more strongly differentiated, and separated from each other by sharper boundary lines. Descriptions are given by Robinson (1949), TAmm (1920, 1921, 1933), Aaltonen $(1935,1939)$.

\section{c. Formation of the heath PODSOL}

The heath podsol is usually considered a form of the podsol in general. In that case its development is supposed to have followed the same line as that of other podsols. In the development of a heath podsol a weakly podsolizing climate has acted in combination with special edaphic factors and with a special vegetation. A soil with a low base content and with a sufficient porosity seems to be essential. A vegetation which produces an acid litter, is a necessary factor.

Another point of importance must be the amount of water used by the vegetation. The less water is used by the vegetation, the more is available for leaching the soil (VliEgER, 1941). The water economy of the heath vegetation is discussed below.

In the writer's opinion the low summer temperatures of the heath soil should also be taken into consideration. It is true that these low summer temperatures alternate with relatively high winter temperatures, and that the mean year-temperature is about the same as that of other soils in the same region. Yet for chemical processes the mean temperature is not decisive, as the following consideration shows. Let a reaction at a temperature of $10^{\circ} \mathrm{C}$ have a reaction rate 1 . With a $\mathrm{Q}_{10}=3$ the reaction rate becomes 0.33 at $0^{\circ} \mathrm{C}$, and 3 at $20^{\circ} \mathrm{C}$. Therefore, one hour at $0^{\circ} \mathrm{C}$ and one hour $20^{\circ} \mathrm{C}$ give a mean reaction rate of 1.66 , whereas at $10^{\circ} \mathrm{C}$ the reaction rate would have remained 1.0. This, of course, applies to biological processes as well, and here the effect may even be more marked as below a certain temperature biological activities stop altogether.

On the mechanism of podsolization no unanimity has been reached yet. The colloid-chemical theory of Mattson (cf. M. E. Gustaffson, 1933) has recently been criticized from various sides. According to Mattson the sesquioxides form electronegative sols with humus compounds which at a greater depth, where the $\mathrm{p}_{H}$ is higher,are flocculated. However, the question whether the conditions in the soil are actually concordant with those postulated by Mattson, is often answered in the negative (cf. VeENENBos, 1953; VAN SaHUYLENBorgh \& SÄNGER, 1949). According to DeB (1949), the conditions in the flucial zone of a podsol are unable to effect the flocculation of a $\mathrm{FeOH}_{3}$ sol obtained by peptization with humus compounds. Deb postulates a microbiological process for the deposition of iron. In this case iron could move, according to him, either as a colloid or, as Gallagher (1943) supposed, as a complex salt of oxalic acid. Gallagher could imitate a podsolization by percolating a solution of oxalic acid through a column of soil taken from the B-zone of a podsol 
(he obtained this result without making use of microbiological processes).

Most studies on podsolization have paid special attention to the physico-chemical processes which take place in the soil. These studies have given us a general insight in the podsolization process. However, they can not (yet) explain details of structure and morphology of the stratification.

Data with regard to phenomenological relations existing between the factors time, climate, soil and vegetation and the properties of the podsol stratification are scarce. However, some hypotheses have been brought forward, e.g. that of W. BEYERINCK (1941). Beyerinck supposed that the thickness of the layer of bleached sand might be determined either by the depth to which the soil dries up during the summer, or by the depth to which frost penetrates the soil in winter.

We tried to find in the literature data with regard to the development of heath podsols under different conditions, as we hoped that the studies of our predecessors might throw some light on these relations. However, we did not find data which would enable us to disentangle the influence of the soil from that of the climate. We therefore decided to compare heath podsols formed under different micro climatic conditions. For this purpose we studied soil sections on the north and south slopes of smaller hills and ridges. Small hills and narrow ridges were chosen in order to exclude as far as possible differences in the soil conditions.

TABLE 2

Thickness of the different layers of the heath podsol in slopes with different exposition.

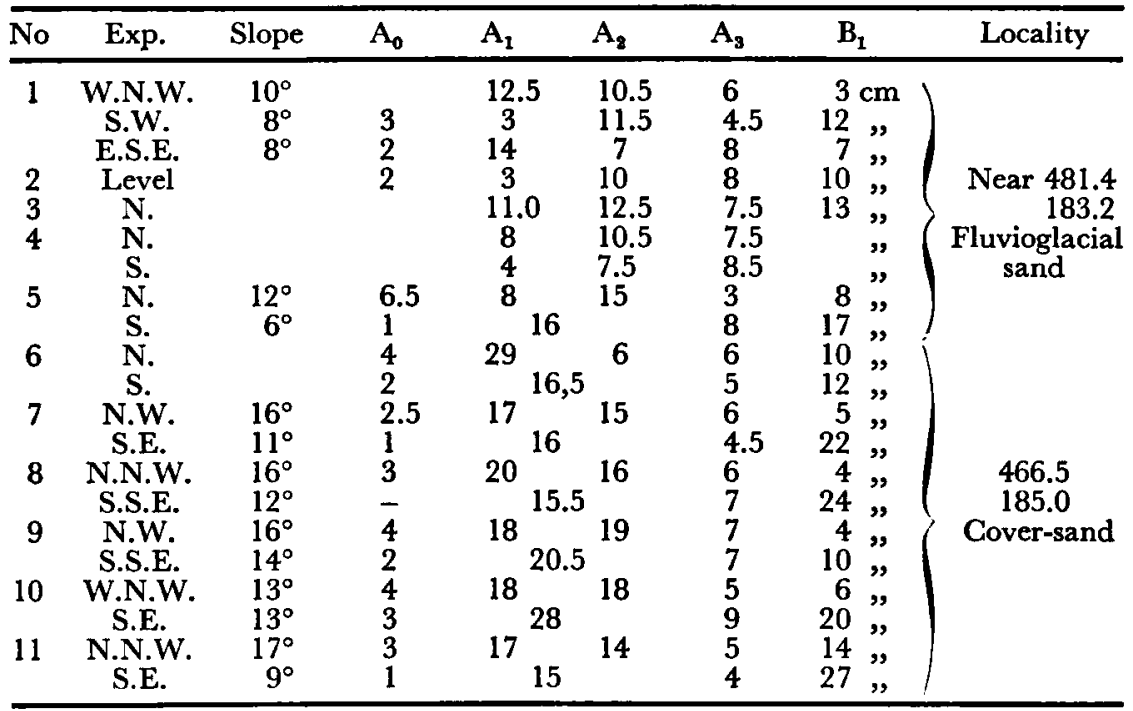

The slopes studied by us were situated on cover-sand as well as on fluvioglacial sand with gravel. One of the pairs of sections is described below; the rest of the data are presented in Table 2. 
Hill, diameter $30 \mathrm{~m}$, height $4 \mathrm{~m}$.

Section on SSE slope; inclination $8^{\circ}$. Section taken halfway the slope.

0-3 cm darkbrown raw humus

3-10 cm grey-coloured bleached sand; pebbles up to $3 \mathrm{~cm}$ occur regularly

10-20 cm black, strongly humous sand; concretion lamina $2 \mathrm{~mm}$ thick

$20-42 \mathrm{~cm}$ hardpan, darkbrown to brown, rapidly passing into:

$42-62 \mathrm{~cm}$ yellow sand, with a few dark veins and spots; yellow sand.

All layers consist of medium fine sand with some pebbles.

Section on NNW slope; inclination $10^{\circ}$. Section taken halfway the slope.

0-2 cm brown raw humus

2-12 cm dark coloured, strongly humous bleached sand with some pebbles

$12-21 \mathrm{~cm}$ light grey bleached sand with some pebbles

$21-28 \mathrm{~cm}$ black humous sand descending with a few tongues up to $10 \mathrm{~cm}$ deep in the next layer

$28-31 \mathrm{~cm}$ brown to orange-brown hardpan; locally, where tongues of the overlying layer intrude, up to $10 \mathrm{~cm}$ thick

$31-41 \mathrm{~cm}$ light yellow sand with a brownish hue

$41-76 \mathrm{~cm}$ light yellow sand with fine fibres

Light yellow sand.

One difference stands out very clearly: the layer of bleached sand is much thicker on the north slopes than it is on south slopes or on flat ground.

Another difference, which is not so well-marked and not so consistent as the first one, is the weaker development of the B-layer on the north slope. The B-layer is here often somewhat reddish-brown, while on the south slope it is dark brown. Anyway it is remarkable that a thicker layer of bleached sand is not correlated with a thicker illuvial zone. The top layers of the soil on the north slope contain much more humus. The bleached sand s.s., i.e. the greyisch layer with the white quartz grains, is on the north slope not much thicker than it is on the south slope. The difference between het north slope and the flat ground is much more pronounced than that between the south slope and the flat ground. This can be correlated with radiation data. The same thick layer of bleached sand was found in depressions where probably water collected, and on a gentle western slope near Hoog Buurlo at the bottom of an old stream valley.

The primary difference between a north slope and a south slope is found in the different amount of irradiation received per unit of surface. This metereological factor acts on the soil mainly via the vegetation. The best way to obtain an idea of vegetation conditions on north and south slopes before and during the development of the podsol is to study the unpodsolized slopes of old inland dunes. Details of these vegetations are given below. For our present purpose it seems sufficient to note that on the north slope the moss layer is very lush and thick, and that the development of the sour humus proceeds at a fast rate. On the south slope the corresponding vegetation is not closed, and consists mainly of lichens and smaller mosses and liverworts. The shrub layer on both slopes is dominated by Calluna; on the north slope its density is somewhat lower than it is on the south slope. 
It is the interplay of the above described climatic conditions with those created by the type of vegetation, that acts on the soil.

Soil temperatures are higher on the south slope than on the north slope, first because of the different exposition, secondly because the isolating layers of moss and raw humus, are on the north slope thicker than on the south slope. Soil temperatures are known to have an important effect on the amount and on the composition of the humus that is formed (JENNY, 1930), and also on the weathering of minerals in the soil (JENNY, 1934). Differences in water economics of north and south slopes may also be of importance. On the south slope transpiration and evaporation certainly are higher than on the north slope. Therefore, less water will move in a downward direction on the southern slope, and on such a slope in dry periods the soil solution (or some elements of it) may become more concentrated. Rainfall may be heavier on the slope facing the wind (the south or south-westslope), than on the slope facing the opposite direction (Geiger, 1950). Especially with strong winds this difference may become important. In comparing slopes with $20^{\circ}$ inclination Geiger found that with windforces of over $5 \mathrm{~m} / \mathrm{sec}$. the wind-exposed one received about $20 \%$ more rain per unit of surface than the leeward one. This, of course, counteracts the effect of radiation. W.BEYERINCK (1941) has brought forward the idea that the thickness of the layer of bleached sand might depend either on the average depth to which the soil does (did) dry out in summer or on that to which the frost does (did) penetrate. The first supposition does not fit in with our data; the second might do, but it should be borne in mind that the influence of exposition is on the north slope counteracted by the isolating layer of raw humus.

In our opinion the most simple explanation of the observed facts is that the thickness of the layer of bleached sand depends on the degree of leaching. Leaching will be the stronger the more water percolates. Further the amount of humus and its acidity must be of importance.

That the greater thickness of the layer of bleached sand (on north slopes) is not due to the fact that more wind-blown sand has been deposited on these slopes, is proved by sections obtained in the fluvioglacial area, where the bleached sand contains a fair amount of gravel, and where no traces of aeolian transport are found in the vicinity. Further, that more soil would be washed away from the south than from the north slopes, can not explain the observed facts either, as in this case both slopes should have a thinner eluvial layer than is found in flat ground.

Messrs Lumens and Van der Valk made an analysis of some of the properties found in two pairs of sections studied by us. The results are summarized in Table 3.

In the discussion of their results the following points are brought forward:

The iron content was determined as the amount of iron soluble in a solution of tartaric acid and ammonium tartrate with a $\mathrm{p}_{\mathrm{H}}$ of 5.0. 
In this way the mobile iron only is supposed to be determined.

The organic material is determined both as loss on ignition and by wet oxidation with potassium bichromate. The latter determination starts from the assumption that only $86.9 \%$ of the organic material

TABLE 3

Chemical data of podsols on north and south slopes. Soil: coversand.

\begin{tabular}{|c|c|c|c|c|c|c|c|c|}
\hline $\begin{array}{l}1 \\
\text { Layer and } \\
\text { thickness } \\
\text { in } \mathrm{cm}\end{array}$ & $\begin{array}{c}2 \\
\text { Water } \\
\text { content } \\
\%\end{array}$ & $\begin{array}{c}3 \\
\text { Loss } \\
\text { on } \\
\text { ignition } \\
\% \\
\%\end{array}$ & $\begin{array}{c}4 \\
\text { Organic } \\
\text { material } \\
\text { Allison } \\
\%\end{array}$ & $\begin{array}{c}5 \\
2 / 3\end{array}$ & $\begin{array}{c}6 \\
2 / 4\end{array}$ & $\begin{array}{c}7 \\
\mathbf{P}_{\mathrm{H}}\end{array}$ & $\begin{array}{c}8 \\
\mathrm{Fe} \\
\mathrm{mg} / \mathrm{g}\end{array}$ & \\
\hline $\begin{array}{lr}\mathrm{A}_{0} & 3 \\
\mathrm{~A}_{1} & 17 \\
\mathrm{~A}_{2} & 13 \\
\mathrm{~A}_{3} & 8 \\
\mathrm{~B}_{1} & 12 \\
\mathrm{~B}_{2} & 25 \\
\mathrm{C}^{2} & \end{array}$ & $\begin{array}{l}1,54 \\
1,54 \\
0,26 \\
3,23 \\
1,54 \\
0,80 \\
0,18\end{array}$ & $\begin{array}{r}9,3 \\
1,5 \\
11,2 \\
3,3 \\
1,5 \\
0,5\end{array}$ & $\begin{array}{r}10,5 \\
1,5 \\
9,6 \\
2,9 \\
1,7 \\
\end{array}$ & $\begin{array}{l}0,165 \\
0,17 \\
0,29 \\
0,46 \\
0,53 \\
0,36\end{array}$ & $\begin{array}{r}0,15 \\
0,17 \\
0,34 \\
0,53 \\
0,47 \\
-\end{array}$ & $\begin{array}{l}3,82 \\
4.05 \\
4,55 \\
4,45 \\
4,92 \\
5,0 \\
5,0\end{array}$ & $\begin{array}{l}\mathbf{0 , 8 7 5} \\
0,26 \\
0,45 \\
2,25 \\
0,80 \\
0,92\end{array}$ & 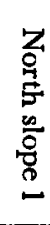 \\
\hline $\begin{array}{lr}\mathrm{A}_{0} & 4 \\
\mathrm{~A}_{1} & 18 \\
\mathrm{~A}_{2} & 14 \\
\mathrm{~A}_{\mathrm{a}} & 8 \\
\mathrm{~B}_{1} & 12 \\
\mathrm{~B}_{2} & 15 \\
\mathrm{C}^{2} & \end{array}$ & $\begin{array}{l}1,13 \\
0,30 \\
2,34 \\
1,50 \\
0,62 \\
0,22\end{array}$ & $\begin{array}{l}7,4 \\
1,3 \\
9,2 \\
4,5 \\
1,2 \\
0,4\end{array}$ & $\begin{array}{l}9,2 \\
1,7 \\
7,9 \\
3,5 \\
0,7 \\
0,2\end{array}$ & $\begin{array}{l}0,15 \\
0,23 \\
0,26 \\
0,33 \\
0,52 \\
0,55\end{array}$ & $\begin{array}{l}0,12 \\
0,18 \\
0,30 \\
0,43 \\
0,89 \\
0,11\end{array}$ & $\begin{array}{l}3,82 \\
4,09 \\
4,34 \\
4,51 \\
4,76 \\
4,88 \\
5,16\end{array}$ & $\begin{array}{l}1,125 \\
0,95 \\
0,40 \\
1,40 \\
0,55 \\
1,05\end{array}$ & 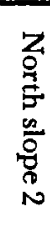 \\
\hline $\begin{array}{ll}\mathrm{A}_{0} & 1 \\
\mathrm{~A}_{1} & 16 \\
\mathrm{~A}_{2} & \\
\mathrm{~A}_{3} & 10 \\
\mathrm{~B}_{1} & 20 \\
\mathrm{~B}_{2} & 14 \\
\mathrm{C}^{2} & \end{array}$ & $\begin{array}{l}0,55 \\
\\
1,65 \\
0,92 \\
0,33 \\
0,22\end{array}$ & $\begin{array}{l}3,1 \\
\\
5,3 \\
3,0 \\
1,2 \\
0,4\end{array}$ & $\begin{array}{l}3,0 \\
\\
4,0 \\
2,4 \\
0,7 \\
0,4\end{array}$ & $\begin{array}{l}0,18 \\
\\
0,31 \\
0,31 \\
0,28 \\
0,55\end{array}$ & $\begin{array}{l}0,18 \\
\\
0,41 \\
0,38 \\
0,47 \\
0,55\end{array}$ & $\begin{array}{l}4,0 \\
4,09 \\
4,53 \\
4,88 \\
4,94 \\
5,23\end{array}$ & $\begin{array}{l}0,93 \\
0,52 \\
1,85 \\
0,65 \\
0,875\end{array}$ & 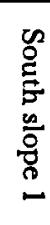 \\
\hline $\begin{array}{lr}\mathbf{A}_{0} & 1 \\
\mathrm{~A}_{1} & 12 \\
\mathrm{~A}_{2} & \\
\mathrm{~A}_{3} & 4 \\
\mathrm{~B}_{1} & 8 \\
\mathrm{~B}_{2} & 15 \\
\mathbf{C}^{2} & \end{array}$ & $\begin{array}{l}1,07 \\
1,39 \\
1,34 \\
0,46 \\
0,25\end{array}$ & $\begin{array}{l}5,7 \\
5,2 \\
4,1 \\
1,3 \\
0,5\end{array}$ & $\begin{array}{l}6,4 \\
4,8 \\
3,3 \\
0,9 \\
0,3\end{array}$ & $\begin{array}{l}0,19 \\
0,27 \\
0,33 \\
0,36 \\
0,50\end{array}$ & $\begin{array}{l}0,17 \\
0,29 \\
0,41 \\
0,51 \\
1,25\end{array}$ & $\begin{array}{l}4,0 \\
4,06 \\
4,56 \\
4,76 \\
4,78 \\
5,26\end{array}$ & $\begin{array}{l}1,95 \\
\\
0,54 \\
1,40 \\
0,35 \\
0,75\end{array}$ & 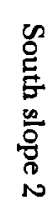 \\
\hline
\end{tabular}

can be oxidized. This assumption is based on a comparison of the results obtained in a special case by means of this method with those obtained by a more thorough investigation. The percentage of 86.9 can not, of course, be expected to hold good for every type of soil. Apparently this percentage is too low for the upper layers of the section. That for the deeper layers loss on ignition gives considerably higher values than wet oxidation, may be due to the fact that in these layers after drying at $105^{\circ} \mathrm{G}$ much water is still bound.

We may add the following remarks. The method of determination used for iron gives the amount of iron which at the moment the analysis is made, may take part in the podsolization process. It gives no information with regard to the total amount of iron that has actually been 
washed out or precipitated during the podsolization process. However, even for the mobile iron the $B$ set of layers is an accumulation zone as compared with the adjoining layers.

The total amount of organic matter in the section obtained on the north slope is much higher, roughly about two times as high, than in the section obtained on the south slope. The bleached sand of the north slope has a low content of organic material.

That on the south slope a somewhat higher humus content was found in the bleached sand, is probably due to the fact that here the $A_{1}$ and $A_{2}$ horizons were not sampled separately.

In the air-dry soil the ratio between water content and organic material in the lower layers is higher than it is in the higher ones. This may be due either to a more complete colloidal dispersion of the humus in the former, or it may be that in these layers more water is bound hygroscopically by other colloids.

The higher $p_{B}$ of the raw humus and the higher $p_{H}$ values which in general are found in the soil on the south slope, are in accordance with the assumption that the tendency to form an acid litter and an acid soil is the stronger, the more humid and cool the conditions are.

By some authors the heath podsol is considered to be essentially different from other podsols. MUELLER (1924) assumed that the hardpan of the heath podsol was an old "tundrabank" formed immediately after the last glaciation. Mueller was fascinated by the similarity existing between a tundra vegetation with its permanently frozen subsoil, which keeps the upper part of the soil waterlogged, and a heath with its impermeable hardpan, acid soil and raw humus covering. Mueller concludes to the glacial age of the podsol on the base of the following reasoning: if in a plain with a podsolized soil in postglacial time an erosion valley is formed, the bottom of such a valley is found to be not podsolized. This, of course, is no sufficient proof that the podsol was formed before the erosion valley. The more likely explanation is that in the valley the soil properties were such that podsolization could not take place.

According to FlorschüTz (1941) the bleached sand is an aeolean deposit. This conclusion cannot be of general validity, as layers of bleached sand of the same kind are found in fluvioglacial soils that can be recognized as such by the presence of coarse sand and gravel, and in fine sands which have a composition which, however, does not exclude a gradual aeolian deposition.

\section{d. The age of THE PODSOL FOUND UNDER heAth}

VAN Giffen (1941) concluded from archaeological data that the heath podsol has been formed at the transition of Neolithicum and Bronze age. The work of WATERBOLK (1953) gave further support to this opinion. According to Waterbolk the podsol formed in the Bronze age obtained its present appearance only after Roman times.

Florschütz (l.c.) concluded from a pollen analysis of layers of sand that were either covering peat or covered by peat, that a continuity existed between the pollen spectra of the peat and those of the sand. 
Even when we are not convinced that this proves the gradual deposition of the bleached sand, his data can be used in another way. We may assume that in the illuvial part of the podsol no new pollen entered after the hardpan had been formed, as the deposits of humus and sesquioxides act as a barrier to pollen moving downward. We may also assume that it takes a considerable time for the pollen to reach the relevant depth, which means that podsel formation may have started considerably after the period indicated by the pollen content of the layer in which the hardpan was formed. Finally, a very accurate dating by the relative amounts of pollen is, in our opinion, not possible for sand. First, there is selective weathering and transport of pollen. Secondly, the pollen analysis of material from a sampling spot where trees have grown, cannot give as good a picture of the mean flora of an area as material from a treeless bog does. The pollen grains in the hardpan can be used as guide fossils only, and no exact dating by means of the pollen spectrum is possible. Another point of importance is that the pollen content of one of our sections which certainly was not formed by aeolean deposition, showed similar traits as the soils studied by Florschütz. This section contained in the hardpan pollen of Tilia, Alnus, and Corylus. The soil must have been fluvioglacial, as the bleached sand contained gravel up to the top. In this case it is clear that the pollen must have been washed down into the soil.

When we bear in mind the limited value that, in our opinion, can be attached to the result of pollen analyses of sand, no objections can be raised to the assumption that the heath podsols dated as Atlantic by Florschütz must actually be younger.

The fact that by Florschütz and others under peat podsols were found, which certainly are older than Atlantic, has been discussed by VAN ZeIST (1955).

\section{e. WeAKLy DeVELOPED PODSOLS}

On cover-sand the heath podsol usually is strongly developed. Weakly developed podsols are found on resting inland dunes of great age and in the vicinity of red sand.

A description of such a section follows.

0-22 cm bleached sand, light grey, gradually passing into:

22-24 cm black humous sand, gradually passing into:

$24-36 \mathrm{~cm}$ soft, brown sand with lighter spots

36- yellow sand showing a fine fibre.

The whole section consists of fine cover-sand without any coarser material.

\section{f. BRown PoDsolic soll}

As brown podsolic soil (cf. Veenenbos 1.c.) we classified stratifications like the following one:

\footnotetext{
0- $11 \mathrm{~cm}$ strongly humous, almost black sand, gradually passing into:

11- $22 \mathrm{~cm}$ medium brown sand with a transition in a downward direction to lightbrown sand

$21-50 \mathrm{~cm}$ lightbrown to yellow

$50-100 \mathrm{~cm}$ yellow sand becoming somewhat lighter.
} 
Throughout the whole section medium fine to coarse sand was found mixed with a little gravel. The upper $20 \mathrm{~cm}$ are somewhat loamy.

This section is characterized by a still more gradual transition between the different layers than the former one. The dark fibre is absent. The A zone varies in colour from greyish to almost black, but it is always much darker grey than typical bleached sand.

The alluvial zone varies in colour from light brown or somewhat reddish-brown to dark brown.

Localities: Positions:

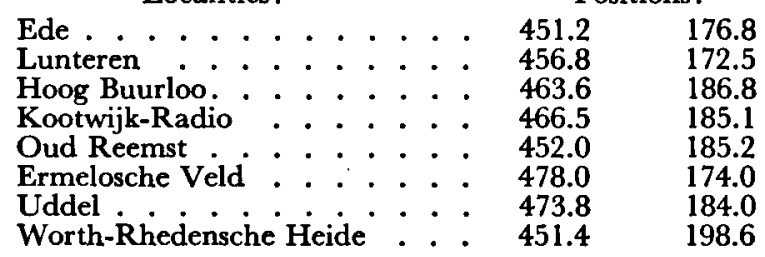

On most preglacial soils in the area studied by us, a brown podsolic stratification has been found. On the other hand, this kind of stratification has very rarely been met in other soils (on löss and lösslike soils).

g. Transition between heath podsol and BRown podsolic soil Especially in fluvioglacial soil a stratification as that described below is found.

0-13 cm black, very humous sand, not sharply separated from:

$13-21 \mathrm{~cm}$ very dark brown sand, not cemented together, rather rapidly passing $21-45 \mathrm{~cm}$ into:

$21-45 \mathrm{~cm}$ brown to very lightbrown sand, between 21 and $25 \mathrm{~cm}$ showing a coarse 45-90 cm nearly white, slightly yellowish sand, showing a coarse but weak fibre

The soil throughout the whole section consists of fine sand, especially between $40-60 \mathrm{~cm}$ with some pebbles. Roots of Calluna penetrate to a depth of $32 \mathrm{~cm}$.

The differences with the typical heath podsol are the absence of a sharply humous $A_{3}$ layer, the higher humus content of $A_{1}$ and $A_{2}$ and the soft $B$ zone. Soils with this kind of stratification sometimes contain an amount of loam that is already perceptible in the field. Often, however, the difference in composition with stronger podsolized soils was imperceptible to us in the field.

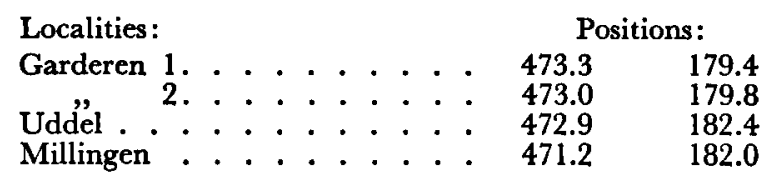

h. Transition between heath podsol and gley

These transitions can be seen most beautifully in the lower parts of the undulating cover-sand landscape. The ridges are beyond the 
reach of the ground water, while the valleys are under its influence.

On the top of the ridges typical heath podsols are found.

At a lower level the stratification looks as follows:

$0-2 \mathrm{~cm}$ raw humus

2-14 cm grey bleached sand

$14-17 \mathrm{~cm}$ black humous sand

17-23 cm brown to reddish brown sand, weakly cemented together, with a few darker veins in it

$23-50 \mathrm{~cm}$ reddish brown to light yellow sand

50- light yellow sand with a few faint veins in the upper decimeters.

At the bottom of a valley:

$0-1 \mathrm{~cm}$ raw humus

1-11 cm black humous sand not sharply separated from:

$11-50 \mathrm{~cm}$ somewhat reddish lightbrown to yellow sand

$50-65 \mathrm{~cm}$ yellow sand

$65-80 \mathrm{~cm}$ yellow sand with rust-coloured spots.

Both sets of layers consist of fine cover-sand.

\section{i. Regeneration of heath PODsol}

MÜLLER (1887) has drawn the attention to the fact that under oak woods and under heath two very different types of soil are found, viz. respectively "mull" and "mor". He suggests that development of one soil type to the other and vice versa may be possible.

Dimblesy (1952) found that where birch invaded a heath, a desintegration of the raw humus took place, and a mull soil developed. The hardpan became partly disintegrated.

On the Veluwe birches prefer places where the stratification is disturbed. Therefore we found it difficult to make sure that the stratification under birch was not due to a disturbance of the original heath soil. On a place where this probably was not so, the sections showed the following composition:

a. Under birch:

$0-20 \mathrm{~cm}$ grey sand

$20-25 \mathrm{~cm}$ brown to yellow sand; locally with a few fibres.

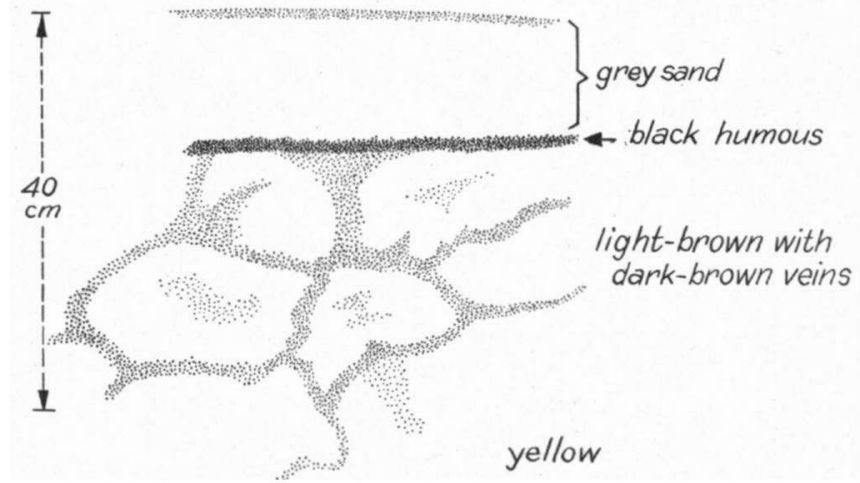

Fig. 1. Stratification under oak shrub interpreted as a heath podsol regenerating into a brown podsolic soil. 
b. Beyond the vertical projection of the crowns of the birches:

$0-20 \mathrm{~cm}$ bleached sand

20-24 cm black-brown, strongly humous sand

$24-44 \mathrm{~cm}$ brown sand with darker veins

44-69 cm yellow sand with brown spots and darker veins.

Under oak shrub it sometimes looks as if a heath podsol is reconverted into a typical forest soil (Fig. 1). That the development would have taken place in the opposite direction, is not probable. The presence of rests of a rather sharply defined black layer $\left(A_{3}\right)$ seems to indicate rather a heath podsol in a state of breakdown than a forest soil that is changing into a heath podsol.

The presence of the subspontaneous Prunus serotina brings about a rapid destruction of the raw humus and a loosening of the top soil.

j. ReD SAND

In many parts of the cover-sand area a brick red soil type is found. A description of a typical section is given below:

$0-2 \mathrm{~cm}$ raw humus

2-22 cm grey humous sand

$22-57 \mathrm{~cm}$ greyish red to red sand

$57-77 \mathrm{~cm}$ bright brick red sand

$77-82 \mathrm{~cm}$ transition from red to yellow sand

below $82 \mathrm{~cm}$ yellow sand.

The red sand contains magnetic-iron concretions of irregular shape and size, and up to $5 \mathrm{~mm}$ in diam. Pieces of charcoal are found down to a depth of $1 \mathrm{~m}$. Moermañ (1947) gives a list of places on the Veluwe as well as elsewhere in the Netherlands where this soil has been found. The red colour seems to have been developed exclusively in coversand.

Moerman supposes that the formation of the red soil is due to a form of primitive agriculture. The ash brought by primitive man on their fields as a fertilizer, would have been the active element. This would explain also the presence of charcoal.

According to Faveljee the red compound is $\gamma \mathrm{Fe}_{2} \mathrm{O}_{3}$, which is formed by oxidation under alkaline conditions. He supposes that such conditions may be created by the burning of wood.

We found the red sand in two different situations, viz.:

1. In a weakly undulating landscape, the red sand was found in pieces of ground of a capricious form several aresc in extent. The red sand proved to alternate with brown and yellow sands. The stratification of the red sand was as described above. The charcoal pieces could be identified as oak charcoal.

The brown sand was of a reddish brown colour, but the stratification proved to be the same as that of the red sand. Gradual transitions were found. The yellow sand proved to be weakly podsolized. In all sections the soil proved to be of a rather loose structure. Charcoal was found in the red soil as well as in the other soil types.

Several burial mounds are found in this area. In other parts of the area rests of a typical heath podsol occur. The whole area looks as if it has been egalized by wind erosion, with rests of the original 
heath podsol preserved. This, however, is a mere hypothesis as we cannot give a plausible explanation for the development of the landscape. However, the great depth to which the charcoal is found, supports the supposition of an aeolian deposition, especially as in the heath digging animals by whose activities the stratification might be disturbed, are rare.

Near Boeschoten an area is found with red sand showing the same stratification as that described above. Oak charcoal is found in this sand as well as magnetic concretions. Here too several burial mounds are found. In the vicinity weakly podsolized yellow sand is present. This piece of ground lies near an area with resting inland dunes.

North of Garderen a stretch of fine sandy soil is found on the west side of a fluvioglacial plain. The stratification is partly that of the red sand described before, but partly the soil shows the following stratification:

$0-10 \mathrm{~cm}$ greyish brown sand

$10-25 \mathrm{~cm}$ brownish yellow sand with grey spots

$25-35 \mathrm{~cm}$ yellow sand with a few greyish spots

$35-50 \mathrm{~cm}$ light yellow sand with sporadically grey spots

below $50 \mathrm{~cm}$ yellow sand.

Fine cover-sand throughout the whole section.

Here too, associated with the red soil a group of burial mounds is found.

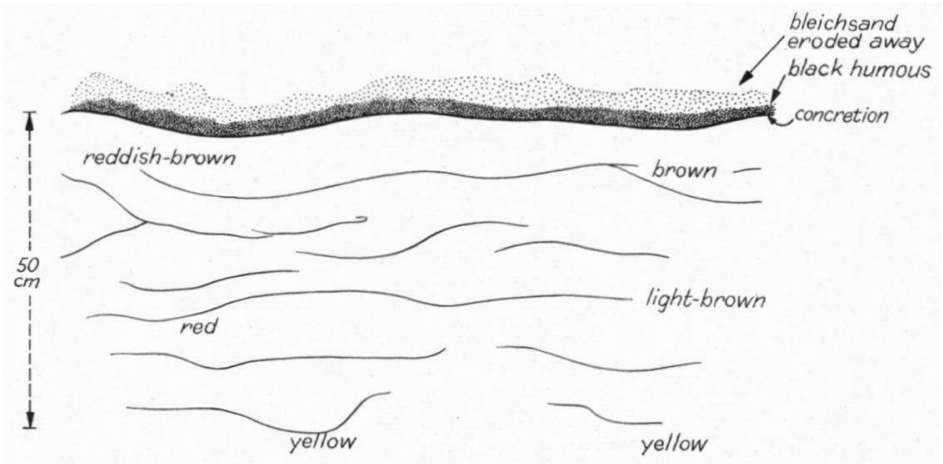

Fig. 2. Transition between red sand and a typical heath podsol.

2. The other situation in which red sand was found, is the following: In several aeolian sand areas patches of red sand are found together with rests of a typical heath podsol. The red soils are situated at the same level as the podsol, and red sand and heath podsol are distributed irregularly over the area. Transitions between red sand and heath podsol too are found. In Fig. 2 a truncated podsol is shown, which gradually passes into a red-sand stratification. The concretion layer, which forms the border line between the zones A and B of the podsol, is present in the red-sand part too, and dark veins extend uninterrupted from the podsol into the red sand. Magnetite concretions were found both in the red and in the brown part of the section, and a few pieces of charcoal too were present. The charcoal could be identi- 
TABLE 4

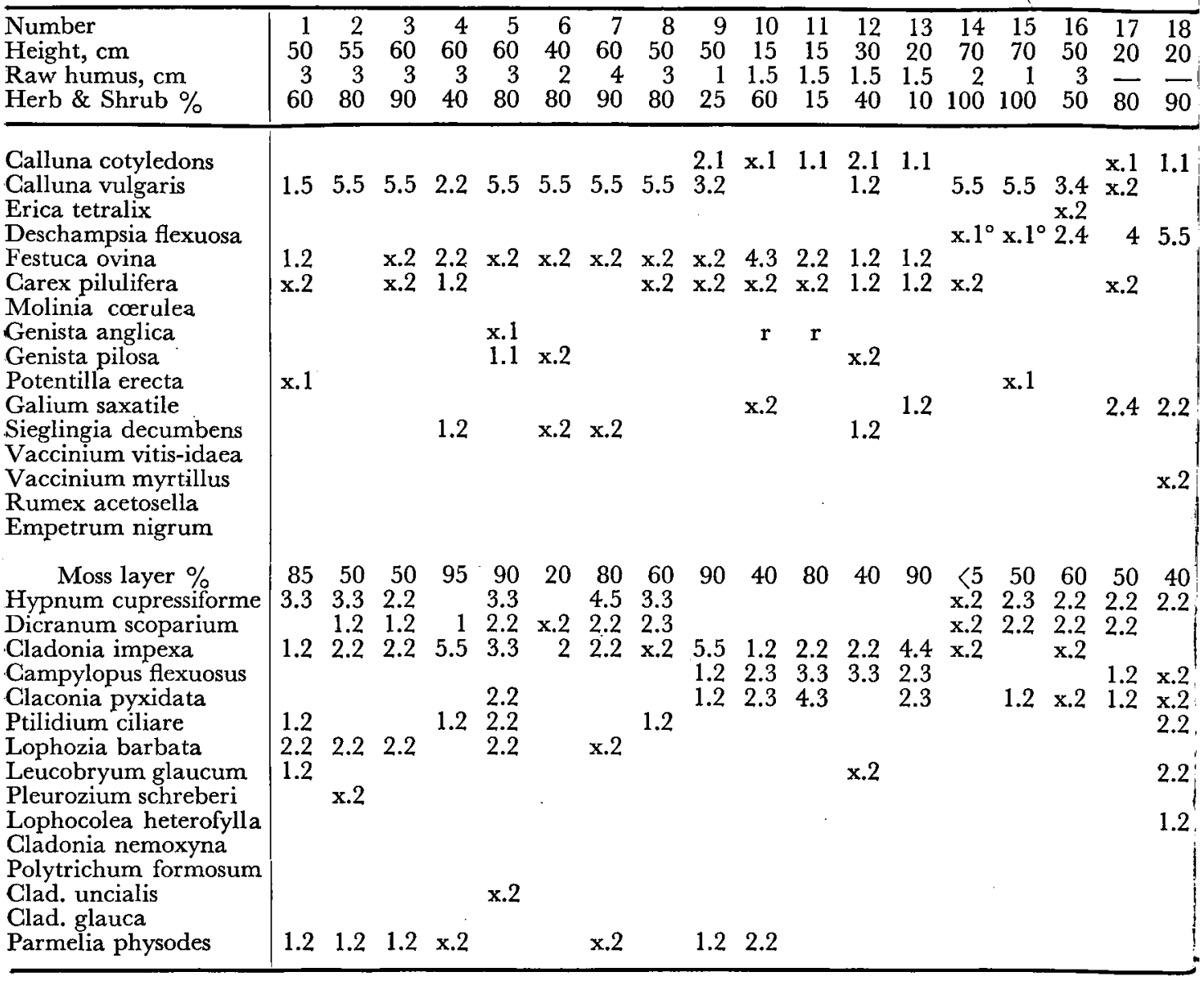

Localities and other remarks:

1. $469,6173,0$, red soil. $2,3,4,5,10,11,12,13.469,8$ 175,3 (appr.), weakly developed podsol in very old fixed inland dune sand.

2. Pinus silvestris 1, 4. Agrostis canina 2. 4, 5. Agrostis canina x.2. Cladonia - - mitis 1.2 6, 7, 8. 466,8 179,3 (appr.), weakly developed podsol. 6 Pohlia spec.x.2, Dicranum spurium x.2.

Eurvirts fleds,

9. $466,4177,8$ weakly developed podsol. 14, 15, 19 463,6 186,8 Brown podsolic soil with strongly humous A horizon.

15. Up to $4 \mathrm{~cm}$ decaying grass-rests under moss layer.

16 , 17, 18. 198,3 451,3. brown podsolic soil.

18. Rubus spec. x.1, Numerous rests of Calluna under layer of $4 \mathrm{~cm}$ Deschampsia; On spots with Campylopus and Cladonia pyxidata, only $1 \mathrm{~cm}$ decayed grass rests.

19. 463,6 186,8 Agrostis canina x.2. Brown podsolic soil.

20. 469,3 180,2, fine löss-like sand with a brown podsolic stratification. Carex arenaria $\times .2$, Pinus silvestris $\mathrm{xl}$, Lophocolea heterophylla $x .2$.

21. $463,6186,8$, brown podsolic soil.

22. $466,1178,1$, heath podsol with $3 \mathrm{dm}$ of acolian sand.

23. $466,9178,1$, valley of a brooklet filled with aeolian sand.

24. $451,5198,4$, valley between hills that owe their origin to the pressure of the 
Mature heath vegetations

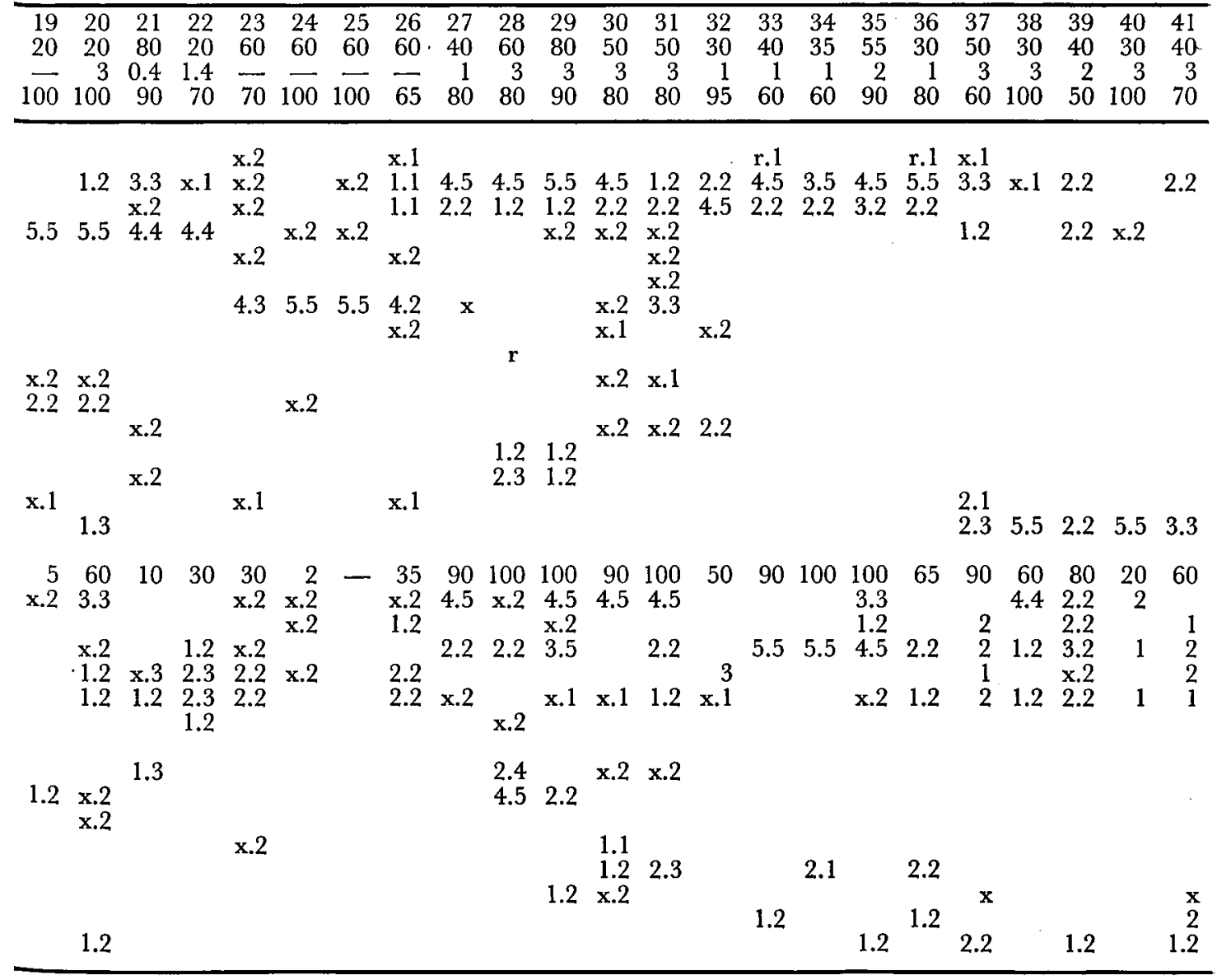

land-ice. Cover-sand, $7 \mathrm{~cm}$ grass rests, $A_{01} 3 \mathrm{~cm}$ black amorphous humus, $A_{1} 10 \mathrm{~cm}, A_{2} 25 \mathrm{~cm}, A_{3} 3 \mathrm{~cm}, B 12 \mathrm{~cm}$.

25. $463,8185,8$, cover-sand with heath podsol in valley, $3 \mathrm{~cm}$ grass rests, $2 \mathrm{~cm}$ amorphous black humus.

26. $463,4185,4$, old erosion valley: at the bottom: sand with gravel, brown podsolic stratification; higher: cover-sand with heath podsol, bleached sand at $60 \mathrm{~cm}$ depth.

28. $472,5187,1$, podsolized fine cover-sand.

29. 469,2 186,2, sand with much gravel; heath podsol.

30,31 . 456,0 187,4, impermeable heath podsol covered with $80 \mathrm{~cm}$ aeolian sand with weakly developed heath podsol.

30. Juncus squarrosus $\mathbf{x} .2$.

32. $480,5175,2$, transition stratification, somewhat loamy; Trichophorum caespitosum 1.2, Pinus silvestris 5.1, Carex stolonifera x.2, Erica seedlings 1.1.

33. $480,3183,5$, heath podsol.

34. $476,5182,1$, transition stratification.

35. $480,4183,8$, heath podsol.

36. 473,3 179,2, transition stratification; Cladonia furcata x.2; Cornicularia aculeata $\times .2$

37-41. 469 180,6, soil weakly podsolized, recently covered with aeolian sand. Size of plots $10 \times 10 \mathrm{~m}$. 
fied as pine charcoal; tracheids, woodrays and resin canals were well preserved.

A description of a different section is given below:

0-10 $\mathrm{cm}$ bleached sand of which the upper layers are eroded away

10-14 cm black, strongly humous sand; concretion lamina $1 \mathrm{~mm}$ thick

14-34 $\mathrm{cm}$ darkbrown to lightbrown sand with an undulating fibre

34-67 cm brownish yellow sand with thick brown veins

67-74 cm greyish-brown red sand

$74-94 \mathrm{~cm}$ red sand with much charcoal particles

94-104 cm marbled sand passing into almost white sand.

Locality: "Hulshorster zand".

The red sand appears in the section as an oblong patch $2 \mathrm{~m}$ in length. Here the formation of red sand has apparently nothing to do with the podsolization process. Pine charcoal is present in the red sand but also in the yellow sand above it. In some spots charcoal is present in great quantity, but without a trace of red sand. The pine charcoal is probably of the same age as that found in the so-called Usselo-layer.

\section{k. Concluding Remarks}

Under dry heath the soil may show different types of stratification. A typical heath podsol apparently did develop only in such places where the soil was fit for it. This is seen best in the fluvioglacial formation, where the stratification may differ considerably from point to point. VLIEGER (194I) already stated that on brown podsolic very old heaths may be found.

\section{CHAPTER II}

\section{THE HEATH VEGETATION}

\section{a. Plant communities found on the heath}

In studying the composition of the vegetation, no fully objective method was used.

Sampling was done according to the method of Braun-Blanquet in spots which we regarded as typical, an impression we obtained after thoroughly searching a wider area.

The Calluna heaths of the Veluwe are divided by us in a few types, each of which is characterized by the frequent occurrence or codominance of another species. In Table 4 samples of these heath types are brought together. We tried to restrict our study to samples of mature heath vegetations, but for heaths rich in Erica this was not possible. As mature we classify vegetations which show no signs of human interference, such as burning, mowing and sod-cutting. For most of the stands it could be ascertained that there had been no human interference during the last 25 years.

Some of the vegetations that were included in the table, contain hardly any Calluna at all. They did, however, originate from Calluna heath, and will probably be reconverted into the latter, as will be argued further on. 
1. Heaths without a co-dominant or with Festuca ovina

These heaths are found on:

a. resting inland dunes with an ancient, weakly podsolized soil;

b. red sand;

c. resting inland dunes of more recent origin.

2. Vegetations of which Deschampsia flexuosa forms an important component, or where the latter becomes dominant

A characteristic species is Galium saxatile. Erica is rare.

This kind of vegetation is found on the following soil types, viz.:

$a$. on preglacial sand with a brown podsolic stratification; extensive heath complexes belong to this type;

b. on red sand;

c. on very fine, almost löss-like sand with a brown podsolic stratification;

d. on podsolized soil covered with a layer of aeolian sand.

No stagnation of water above the hardpan was observed.

This kind of vegetation apparently finds its optimum on a soil which to a considerable depth is of loose structure.

3. Vegetations of which Molinia forms an important component, and in which it may become dominant

This kind of vegetation was found on the following soil types, viz.:

a. where an impermeable hardpan is covered with a thick layer of aeolian sand;

b. on aeolian sand with the ground-water level at a depth of $1.5 \mathrm{~m}$;

$c$. at the bottom of deep erosion valleys, either on podsolized soil or on soil with a brown podsolic stratification. Where the soil is podsolized, the layer of bleached sand is thicker than normal, viz. up to $70 \mathrm{~cm}$. No stagnation of water above the hardpan was noted.

This kind of vegetation contains many plant species that are characteristic of dry soil, like Festuca ovina, Genista anglica, Calluna vulgaris, Hieracium umbellatum. Ecologically it differs strongly from the Molinia vegetation found at the bottom of shallow pools which dry out in summer and where in winter the groundwater rises above the soil surface. The latter vegetation is found at a lower level than the vegetation with Erica tetralix, while the former is replaced by the Erica vegetation in wetter spots.

4. Heaths in which Vaccinium myrtillus and V. vitis-idaea occur frequently

In most of the heaths of the Veluwe the two Vaccinium species are but rarely found. An exception, however, forms the area round Apeldoorn. Here both Vaccinium species occur regularly in the heath, and locally they may become an important part of the vegetation. The soil types in this area differ widely; they may be:

a. preglacial soil with a brown podsolic stratification;

b. fluvioglacial soil with a heath podsol stratification;

c. cover-sand with a heath podsol stratification. 
PH. STOUTJESDIJK

No difference with the soils outside this area could be found.

The explanation of this exceptional situation may be a climatological one. Apeldoorn receives the highest rainfall of the Veluwe. The rain gauge is situated somewhat east of the area where Vaccinium is most numerous, and where probably rainfall is highest. In this connection it is of interest that Böcher (1943) found V. myrtillus "of common occurrence only in acid woods and on northern heath slopes" and explains this by the high humidity and the low summer temperatures of these habitats.

Hegi calls $V$. myrtillus "trockenscheu".

Furthermore the area round Apeldoorn is characterized by a very rank growth of Calluna. Regardless of the soil type Calluna reaches here a height of $1 \mathrm{~m}$. We may draw attention to the fact that Calluna in Western Ireland and in Cornwall reaches over $2 \mathrm{~m}$ in height.

\section{Heaths with much Erica}

Erica is usually present on soil with a heath podsol stratification.

Vegetations with much Erica are found on soils with the transitional stratification.

On fluvioglacial soil irregular areas are found, completely dominated by Erica. Here the soil is distinctly loamy with a stratification like this one:

$0-18 \mathrm{~cm}$ black humous, fine sand; loamy especially in the lower half of the layer 18-36 cm very darkbrown to lightbrown fine sand, loamy especially in the upper half of the layer

$36-46 \mathrm{~cm}$ light brown to yellow sand hardly containing any loam, showing a coarse fibre

$46-65 \mathrm{~cm}$ yellow sand showing a weak fibre.

Of interest in this respect is that for reclaiming purposes Erica heaths were considered best; next best was heath with much Deschampsia.

\section{Heaths rich in Empetrum}

Empetrum is rare on the heaths of the Veluwe. Empetrum obviously finds its optimum on $\mathrm{N}$-slopes of resting inland dunes. It occurs more regularly in heaths on weakly podsolized fine sand. A vegetation in which Empetrum is a co-dominant, is tabulated in Table 4 . In the system of Tüxen this heath may be classified as Calluneto-Genistetum Empetrosum. The soil is weakly podsolized, covered with a layer of recent aeolian sand and shows the following stratification:

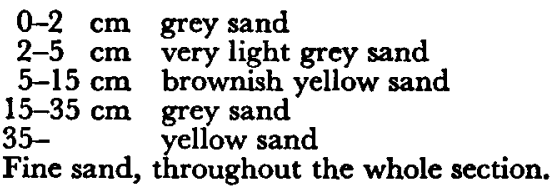

\section{b. EFfect of the exposition ON THE heATH VEgetation}

The effect of exposition on the heath vegetation is demonstrated by Table 5 . Compared are the vegetation of north and south slopes on three different soil types, viz. resting inland dune soil of long 
HEATHS AND INLAND DUNES OP THE VELUWE

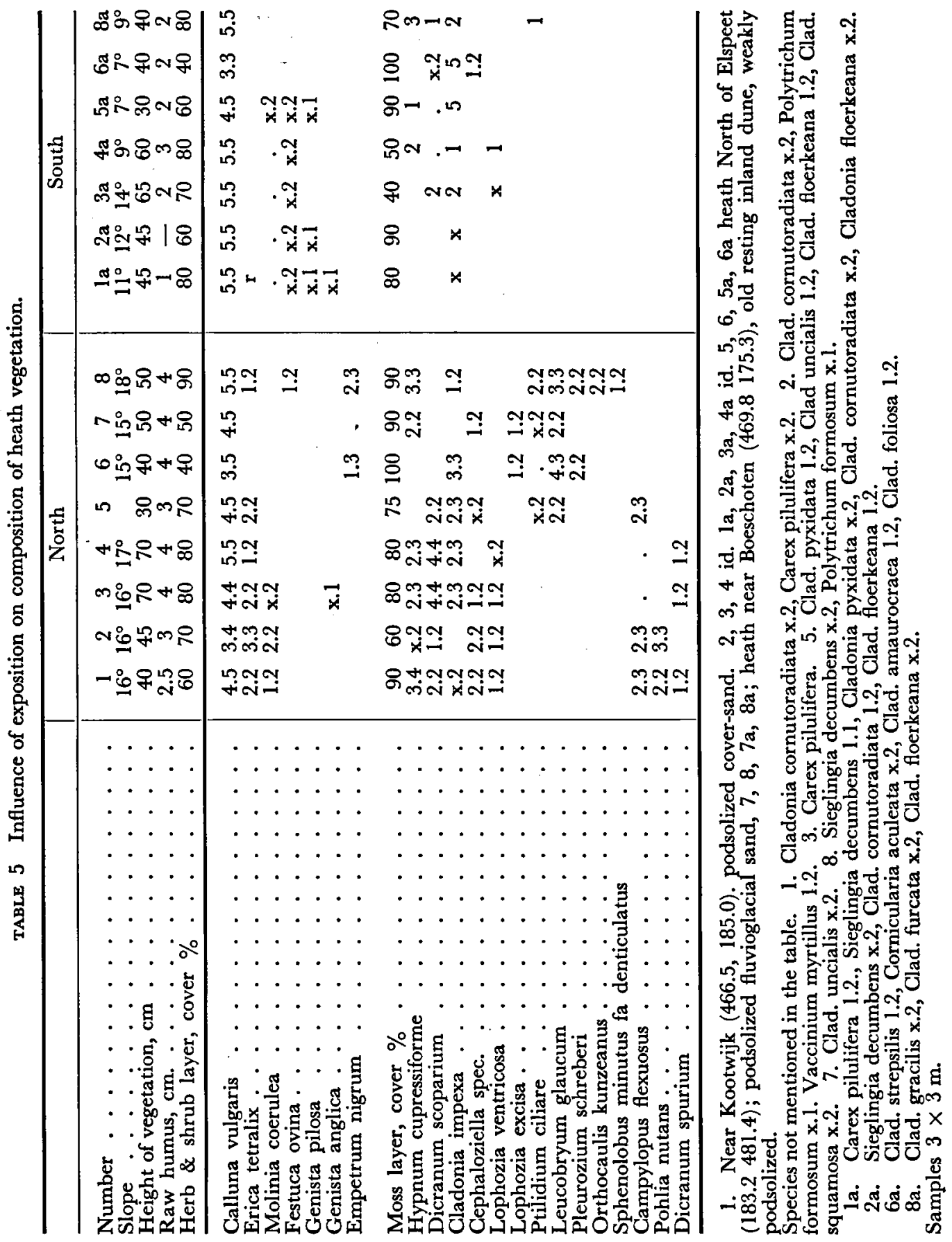


standing, weakly podsolized; fluvioglacial soil, podsolized; cover-sand, podsolized. As compared with the south slopes the north slopes carry a vegetation which clearly demonstrates the presence of a different microclimate. Where Erica is present on flat ground, it becomes more important on the north slopes, whereas it is usually absent from the south slopes. On high, weakly podsolized aeolian sand Erica is usually absent on flat ground, but it is often present on the north slopes. Empetrum shows a preference for north slopes. Molinia, when present, is also more abundant on the north slopes. The moss layer on north slopes is thicker and more lush. Leucobryum glaucum may become dominant here. Pleurozium schreberi is rare in heath vegetations on flat ground, but often abundant on the north slopes. Leucobryum is absent from the slopes on podsolized cover-sand. It is replaced here by Dicranum scoparium and $D$. spurium. Dicranium spurium is very rare in the moss layer of Veluvian heaths, but is is a regular constituent of the moss layer at Kootwijker veld, where much oak shrub is found on the heath (ca $1 / 3$ of the area is covered by it). The shelter given by the oak shrub as well as specific influences of the latter may be of importance. In the vicinity of the hills near Kootwijk radio much oak shrub is found as well, but the distance from the sampling spots is too high to think of a direct influence. Leucobryum seems to prefer places on the north slopes where the vegetation is rather open. Light intensity is relatively high here, without ever reaching extreme values. The reduced radiation may, of course, act indirectly by reducing transpiration.

Hepatics are more frequent and abundant components of the vegetation on north slopes than they are on south slopes or on level ground.

The raw humus layer is not only thicker on the north slopes, but also of a more peaty consistence.

The difference in vegetation between north slopes and flat ground is much greater than that between flat ground and south slopes. This can partly be understood from the calculations of radiation sums (c. Chapter IV. q), but it may partly be due to the fact that the north slopes are steeper.

\section{c. Cyclic development of the heath vegetations}

The rôle of trees in the ultimate development of a heath, i.e. the question whether the presence of scattered trees on a heath means that the latter will finally develop into a forest, will not be discussed here. We have confined our attention to places where trees did not interfere with the development of the vegetation.

When working on problems of heath conservation, we started from the common supposition that a heath vegetation which was not regularly burned and in this way induced to rejuvenate itself, would change into a grass or lichen steppe. This opinion was supported by the observation that Calluna seedlings were never found in a mature heath vegetation. Further study brought out the fact that Calluna recolonizes places where it had been replaced by lichens or grass. 
Apparently two types of vegetation alternate here in a similar way as is known from raised bogs. We made some estimates of the time during which the different stages can maintain themselves in a definite site, by determining the relative size of the surfaces occupied by them throughout the whole area (SToutjesDijk, 1953).

A paper of WATT (1947) revealed to us that cyclic processes are of common occurrence. Watt gives many theoretical considerations supported by observations:

The fundamental unit of the plant community he calls the "patch". Patches of one species or of one species combination alternate with patches of a different constitution. Every cycle consists of an upgrade and a downgrade series.

"Running parallel with the change in vegetation of the cycle, there is change in the factors of the habitat and in total 'habitat potential'. The variable factors of micro-climate and soil e.g. shelter, light intensity, temperature, the amount of litter, the state of the humus and its distribution in the soil, are differentiae of the phases superposed on the original foundation of a uniform habitat. They are closely linked with the phases because they are the effects of the plants themselves; the effects of one phase become partly cause of the next".

"In the upgrade series there is an accumulation of plant material and an increase in habitat potential; in the downgrade a dispersion of these mainly by fungi, bacteria, insects, but also by inorganic agents. At each stage, of course, there is both a building up and a breaking down, but in the upgrade series the balance is positive, in the downgrade negative."

The tendency to produce even-aged populations as a consequence of wholesale killing of the downgrade phase by climatic or biotic factors, and as a consequence of time limits to the colonization of free spaces, is discussed too by Watt.

There is always a tendency to reach an equilibrium in which each phase occupies a part of the area which is proportional to the time during which it can maintain itself in a definite site.

An account of the observations of cyclic processes made on heath vegetations, follows:

On unpodsolized fixed dune sand a community was found in which several stages of development could be observed.

1. High Calluna $(50-60 \mathrm{~cm})$ forms a closed vegetation. The moss layer is dominated by Hypnum cupressiforme, with Dicranum scoparium as an important constituent. Where the heather canopy reaches its greatest density, no moss layer is found.

2. High Calluna, but the shrubs are apparently less vital than those of 1 ; the density of the canopy is less, partly because of the fact that branches tend to sink down. Cladonia impexa may become the major constituent of the "moss" layer. It seems to find its optimum conditions where light is fairly good but where some shelter is still present.

3. Calluna dying, many plants sinking down; Cladonia impexa dominates the "moss" layer.

4. Dead Calluna, with branches sunk down; tips of the branches 
covered with Cladonia pyxidata and Campylopus flexuosus. Cladonia impexa covers the greater part of the soil surface.

5. Calluna rests show a further stage of breakdown. The Cladonia impexa layer becomes thinner, and shows cracks and bare spots. The raw humus layer is much thinner, and often only a layer of black amorphous humus is found. Heather seedlings and young heather plants are found in the spots with Cladonia pyxidata and Campylopus, and in cracks or in bare spots in the Cladonia impexa layer.

6. A young vigorous heather vegetation is formed. In one instance the development of a Cladonia impexa vegetation covering an area of about $100 \mathrm{~m}^{2}$, into an almost closed Calluna vegetation could actually be followed from 1951-1955 (locality: Boeschoten, 469.7 173.0).

Changes in other biotic and physical factors accompany the changes in the vegetation.

Soil temperatures begin to show a slight change when the vegetation becomes less dense, but in the later stages of the latters breakdown soil temperatures become much higher. Surface temperatures become very high in spots where the raw humus becomes exposed and in Cladonia pyxidata-Campylopus patches. Here the surface temperatures may exceed the air temperature with $20-30^{\circ} \mathrm{C}$, while those below the heather plants are at most a few degrees above the air temperature. There is a rapid fall of temperature in deeper layers, but even at $10 \mathrm{~cm}$ depth the temperature is up to $5^{\circ} \mathrm{C}$ higher than it is in heather soil. In spots where Calluna is decaying, the upper soil layers have higher temperatures, and present much more varied conditions, both in time and space, to the soil micro-organisms than those of the soil under healthy Calluna do. The surface layers show enormous variations in temperature. Day temperatures of $50^{\circ} \mathrm{C}$ may be followed by night temperatures below zero. Enders $(1942,1943)$ and HARMSEN (1951) have discussed the importance of such sublethal conditions for the formation of stable humus compounds by soil micro-organisms.

We tried to demonstrate the rapid decay of organic matter in the more open parts by measuring the $\mathrm{CO}_{2}$ production of the soil and comparing it with that of the soil under a dense Calluna vegetation.

The method used by us gave no absolute values nor was it very accurate. Yet it was sufficiently accurate for our purpose. It had the advantage of disturbing the natural situation but slightly and of giving quick results. It was based upon the method used by WaLter (1950) for estimating the $\mathrm{CO}_{2}$ production and consumption by leaves.

A $1 / 1000 \mathrm{~N}$ solution of $\mathrm{Ba}(\mathrm{OH})_{2}$ was prepared and a sufficient quantity of methyl violet added. The solution has a blue colour but becomes yellow when its $p_{H}$ falls below 8 . A brass cylinder of $4 \mathrm{~cm}$ diameter and $12 \mathrm{~cm}$ length with a sharpened edge at one end was pressed $5 \mathrm{~cm}$ deep into the soil. A short test tube filled with $5 \mathrm{cc}$ of the fluid was placed in the upper part of the cylinder. The top of the cylinder was closed by means of a glass dish stuck to it with a little vaseline.

The time necessary to effect the change in colour was taken as a measure of the $\mathrm{CO}_{2}$ production of the soil. The relative velocity of 
the $\mathrm{CO}_{2}$ production in the Cladonia impexa and Cladonia pyxidataCampylopus phase as compared with that in the mature heath phase was calculated.

The $\mathrm{CO}_{2}$ production appeared to be 1.6-4 times higher in the open phases. The ratio for the $\mathrm{CO}_{2}$ produced by microbes will be higher still, as in the Calluna phase part of the $\mathrm{CO}_{2}$ is produced by roots.

Nitrate production of the soil was measured by the brucine-sulphuric acid method.

Samples of the top $5 \mathrm{~cm}$ of the soil were placed for ten days in loosely covered jam pots. As the summer of 1954 was very rainy, this practice was adopted in order to make it possible for the nitrate to accumulate. However, it appeared that in none of the samples a measurable quantity of nitrate was formed.

Biotic factors. Rabbits are nowhere numerous, but they concentrate on the spots which are being recolonized by young heather. They drop their pellets, which are buried by Geotrupes species. Digging and running about of the rabbits cause a desintegration of the Cladonia impexa carpet. By feeding on the young Calluna plants the rabbits retard the development of a dense Calluna vegetation; their other activities, as well as those of the beetles that follow in their wake, undoubtedly facilitate the establishment of Calluna seedlings.

When the Cladonia carpet is broken up in some other way, this also favours the recolonization by heather seedlings, strange enough a tank track may be marked in due course by Calluna seedlings, whereas on both sides of it Cladonia impexa firmly holds its ground.

\section{d. Heaths with Deschampsia flexuosa}

Some vegetations were studied which consisted predominantly of Deschampsia flexuosa with irregularly scattered larger and smaller patches of Calluna.

1. Where Calluna is deteriorating, an increase of Cladonia impexa and the development of Cladonia pyxidata-Campylopus patches may be observed.

2. At the same time, however, Deschampsia enters these places by vegetative propagation.

3. Subsequently the greater part of the area becomes occupied by Deschampsia, which forms a closed mat. Deschampsia is invariably found to cover a $2-4 \mathrm{~cm}$ thick layer of raw humus, which is broken up by roots. In the humus often rests of heather branches can be found. In this connection it is interesting to note that RAmanN (1911) calls Deschampsia a "rohhumus-fresser".

4. In the Deschampsia mat decaying patches of a few dm in diam. are found that are occupied by the combination of Cladonia pyxidata and Campylopus flexuosus which has already been mentioned. Where Deschampsia forms tussocks, the north sides of the latter are the first to succumb. In this stage the breakdown of the raw humus proceeds apparently at the fastest rate; a thinner and more amorphous humus layer is found here. In these decaying patches Calluna seedlings may be found. 
Finally stretches covered by a closed and vigorous Calluna vegetation are found, with a considerable amount of half decayed Deschampsia rests in the litter layer. Calluna has probably entered the Deschampsia vegetation in the spots where the latter was decaying, and the rest of the grass was killed subsequently by the shade shed on them by the expanding heather plants.

Concluding we may say that we have nowhere found a Deschampsia field without Calluna rests in the litter or without patches that were being recolonized by Calluna.

$\mathrm{CO}_{2}$ production in the decaying patches was compared with that under mature heather. The decaying patches showed a $\mathrm{CO}_{2}$ production 2.5 times as high as that of the soil under mature heather.

Nitrate production in the decaying patches was considerable. Samples treated in the way mentioned before, proved to contain $40 \mathrm{mg}$ nitrate per liter soil. Möller found in soils with an Urtica dioica vegetation $40-200 \mathrm{mg} \mathrm{NO} / 1$. In the other stages no nitrate was found.

To the biotic factors already mentioned the activity displayed by ants must be added. Ants make their nests in the Deschampsia, especially where it grows more or less in tussocks. The Deschampsia is killed in these places, and decays in the normal way. The ants certainly are an important factor in accelerating the transition from the Deschampsia stage to the Calluna one.

\section{e. Molinia vegetation with Calluna and Erica}

The elements of this vegetation are:

1. Molinia tussocks standing wide apart but nevertheless completely covering the ground by their overhanging leaves. The compact part of the tussocks consists of roots and rhizomes, and is circa $25 \mathrm{~cm}$ high and narrow at its base. Between the tussocks no other vegetation is found. The soil is covered with an up to $6 \mathrm{~cm}$ thick layer of dead grass leaves. Under this litter an about $2 \mathrm{~cm}$ thick layer of black amorphous humus is found.

2. Dead or decaying tussocks with between them the layer of decaying grass leaves. The dead material is overgrown by Cladonia pyxidata and Campylopus flexuosus.

3. Tussocks in the final stages of decay with between them a Campylopus-Cladonia pyxidata vegetation on a black amorphous humus with little grass rests left.

In this stage seedlings and young plants of Calluna and Erica are occasionally found.

Seedlings of Molinia are very rare, and are found only in the stages 2 and 3.

Nitrate production was studied in the way outlined above. A sample taken between the tussocks (stage 1) contained a small amount of nitrate. In a sample from stage 3 nitrate formation was a little higher than it was in the spots with decaying Deschampsia.

Under the closed Molinia vegetation the soil temperatures are even somewhat lower than they are in the heath soil.

Under the decaying patches they are not significantly different 
from those found in similar patches in the Deschampsia vegetation.

The biotic factors are of the same kind as in the two types of vegetation mentioned above. The ants may bite their nests out in the Molinia tussocks too, thus often (but not always) causing their decay.

\section{f. Equilibrium of Plant communities}

Much attention has been given in the botanical literature to the effects of the competition between plants of plant communities, and but little attention has been paid to the fact that there are also plant communities (e.g. climax vegetations) which remain unchanged. In such cases the existence of an equilibrium was taken for granted, and seemed to need no further investigation.

Yet it is easy enough to understand how as a result of competition one plant community may replace another one; but what is the cause that one species does not always gain dominance over the other ones occurring in the same stratum?

If the equilibrium is regarded as the result of a competition, there are two possibilities. The first is that the competing species are of the same strength. However, it seems improbable that the equilibrium will ever be of such a static kind. The other possibility is that the changes brought about by competition or otherwise are counteracted by a force proportional to the change, as happens in all other equilibria known in nature.

What we actually see, can obviously not be explained by assuming that competition is the driving force by which the species reach the state of equilibrium. On the contrary, one component creates by its decay favourable conditions for the development of another one, and this may happen long before the latter is present on the spot, so that there can be no question of competition between them.

Equilibrium in a plant community means that its composition remains unchanged. This is possible only if the total set of habitat factors remains the same. If a species produces changes in the habitat, the latter must be neutralized either by inorganic or by organic agents.

A change in the habitat which is often easily recognizable, is the accumulation of dead organic material.

Apart from the alternation of accumulation and breakdown which takes place in the litter formed by the heath vegetations with the concomitant changes in the latter, there are in the literature several indications which seem to prove that such an alternation is often accompanied by corresponding changes in the development of the vegetation. According to TANSLEY (1939) there are indications that birch and pine are components of a single cyclic succession. Now birch is known to cause a rapid decomposition of raw humus (Edelman), and pine is known to cause the accumulation of the latter.

In damp pine woods Sphagnum growth may cause the accumulation of a peat layer on the soil surface. In open places, i.e. where the pines have succumbed, the peat is decomposed, and pine can settle again (GRAEBNER, 1925).

In the oak forests of Fontainebleau there are indications of an 
PH. STOUTJESDIJK

alternation of oak and beech (Westhoff). It is a known fact that under certain conditions the biological activity in the soil under beech is small compared with that in the soil under oak.

Summarizing we may say that it is essential for the maintenance of an equilibrium in a vegetation that changes in the habitat effected by one component are corrected by another one. A cyclic change of "patches" may satisfy this condition to some extent. However, such processes might run so smoothly, and the interacting of higher plants and micro-organisms might be so perfect that in order to observe cyclic changes, one would be compelled to study ever smaller soil surfaces or volumes. One could for instance imagine that in the case of heath the litter was gradually decomposed by microbial activity, and that together with the old plants young ones were present which gradually replaced the former. In that case the phases of the cycle would have become practically inseparable in space and time, i.e. indistinguishable. Then nobody would see something out of the ordinary in the vegetation. In some cases, however, the parts of the cycle are widely separated in space and time, and then they may be characterized by different vegetations of higher plants.

It might be suggested that the higher the degree of development of a vegetation or of an ecosystem, the smaller the deviations from the equilibrium become. The strongest fluctuations may be expected to occur in the ecosystems that are the poorest in life forms and species. The smaller the number of counteracting forces, the greater the chance that an influence acting on one of them will cause a marked change in the system as a whole.

It is, of course, generally known that great and even catastrophic changes occur mainly in poor ecosystems, both in natural and in artificial ones.

\section{g. Human and biotic influences}

\section{Burning of the heath}

Everywhere where the heath plays a rôle in agriculture, it is burnt regularly to provide the grazing sheep or cattle with fresh and apparently more palatable food. (cf. Weiss (l.c.), Denmark; GraEBNER (1925), Germany; Transly, Frazer, Darling, British Islands).

In the Netherlands only a few herds of sheep are kept now as a folkloristic curiosity.

Planned burning of the heath has been practised but little during the last 40 years. Accidental fires, however, occur more frequently than in earlier days; they usually take place late in spring or in summer.

The effects of planned as well as of accidental fires are discussed below. The regeneration of the heath after a fire may proceed along the following lines.

1. Where the heath which is burnt, grows on a sandy soil without much humus either in or on it, a vegetation regenerates with a moss layer of Polytrichum piliferum. In this moss layer Agrostis canina forms patches of a loose structure. In these patches many seedlings of 
Calluna are found, but where the soil is covered with moss, Calluna seedlings are found as well. Regeneration from the partially burnt plants is noted too. The regenerated plant usually forms a completely new root system and new branches. The rests of the old plant gradually decay.

2. The fire results in a hardening of the soil surface. The raw humus is superficially scorched by the fire, or a vegetation was burnt without a good layer of raw humus. The vitality of the regenerating heath is low. We know heaths of this type which were burnt 16 years ago. The heath is now only $20-30 \mathrm{~cm}$ high, and covers the ground for $40 \%$ only. The stems are only $2-3 \mathrm{~mm}$ in diameter. The amount of flowers that are yearly produced is roughly only $1 / 10$ of what a welldeveloped heather plant can produce. The root system of these weakened Calluna plants is different from that of healthy ones. The young roots are dark brown, strongly and capriciously curled and breakable, in contrast with the light brown, straight and tough ones of a normally developed plant. The roots of these weak heather plants look exactly like those of heather plants grown under sterile conditions. Yet, they are much more densely covered with mycelium than roots of healthy Calluna are. It is true that the same three types of mycelium are found, but in the heather plants of the burnt heath a brown mycelium is the most important one.

Where burnt heath of this type is bordered by oak shrub or by a Deschampsia vegetation its growth is much better. The same effect is found where the heath adjoins a ploughed strip, or another place where the soil is less compact. This applies also to the soil under oak shrub and under Deschampsia.

Heaths of this type are probably meant by Von Benthem (cited by GraEBNER, 1925) when he writes: "Man bezweckte ... die Neubildung eines jungen, schmackhaften Ausschlages. Dieser Zweck wurde auch zunächst erreicht. Meist aber erfolgte sehr bald ein solcher Rückschlag dasz die Brandheiden wegen ihres kankhaften Aussehens und ihres stockenden Wachstums eine traurige Berühmtheit erlangt haben".

Next to the extreme cases there are many instances of a merely somewhat reduced vitality after a fire. In such cases regeneration always is mainly vegetative. In the examples known to us, the heath had not reached maturity when the fire took place, and this explains that this vegetative regeneration is the usual effect of accidental fires. It is noteworthy that the fires which gave rise to this type or regeneration, all took place between April and the end of September.

3. Mature heath is burnt without scorching the sour humus layer, and regeneration takes place mainly by seedlings, which are of good vitality. This type of regeneration usually proved to be the result of planned burning in February or March.

The cases described above all apply to heaths in which Calluna plays the major part. Where plants occur which are more resistant against fire than Calluna is, they spread at the cost of the latter. Bell heather is never severely damaged by fire, and during the first 4 years after the fire the regenerating Erica grows more rapidly than 
Calluna. Seedlings of Erica, however, are not found in spots where before the fire Erica was absent.

Grasses may greatly increase their area after a fire. As a rule, the vegetatively spreading Deschampsia forms a dense vegetation which contains seedlings too, but in such vegetations many heather seedlings were found as well.

Where grasses of any kind are found in the vegetation, the deleterious effects of a fire are never strong. Under these circumstances the grasses decay and provide Calluna seedlings with a foothold. This is especially the case with Sieglingia decumbens. About 8 years after a fire seedlings of Calluna were found in the decaying patches of this grass.

A vegetation table and details with regard to the effect of fires, has been given by Stoutjesdijk (1953).

\section{The heather beetle}

The larvae of the heather beetle (Lochmaea suturalis) may cause serious damage to the heather, in the Netherlands as well as in Western Germany, Denmark and the British Isles (Betrem, 1929; Darling, 1947). A description of the life history of the beetle and an account of years in which serious plagues occurred, is given by Betrem.

We could follow the development of a heather-beetle plague during several years, viz. from 1951 onward. In July 1951 the larvae were found on many heaths, always in old heather growing on a soil with a strong cover of moss and/or litter. In August the larvae pupated as usual under the moss or litter layer. In September the beetles hatched out and hibernated in the same places where the pupae had been found. In the parts that were most severely damaged, 5-10 hibernating beetles were found on $1 \mathrm{dm}^{2}$. In April of the next year the young beetles were flying around freely. Yet the plague clearly spread from the centres of origin. As a rule patches several hundreds of square metres in extent were found where the plants were so severely damaged that they succumbed. Between these patches the heather had suffered too, but it was not killed.

In 1953 the plague spread to less favourable places, such as recently burnt fields, with low heather and without a thick moss or litter layer. In some parts, viz. in those with old heather, about $50 \%$ of the latter was killed. In the spring of 1954 the beetles were flying around in great numbers. In the summer of 1954 , however, only sporadically a few larvae were found. In the next years the beetles became somewhat more numerous, but not to such an extent as to cause serious damage. It is hard to imagine that the sudden and almost complete disappearance of the beetles was due to an attack by a parasite or by a disease. In that case a wholesale elimination throughout the area seems inconceivable. It may have been due to a climatological influence, such as the dry spring of 1954. During that period in many places the layer of raw humus dried out completely, and this may have been deleterious to the development of the eggs. 
h. Biological notes on heath plants

The species are arranged according to the geographical classification developed by Böcher (1943).

\section{Euoceanic species}

Erica tetralix. Distribution map in Walter (1927). Rapid growth mainly in April. Germination mainly in summer. The plants flower when two years old. Erica was never observed to suffer from frost, not even in cases where Calluna did.

Genista anglica. Reaches its northern limit in S. Sweden; and extends southward to Portugal. Young shoots formed by the end of Apr il. Seedlings are rare. Frost damage was not observed, even not by night frosts down to $-10^{\circ} \mathrm{C}$ in May. The root system is strongly branched. In a small plant the roots could be followed to a distance of $60 \mathrm{~cm}$ from the centre and down to a depth of $30 \mathrm{~cm}$.

Ulex europeus. A southern atlantic species, here reaching the northern limit of its area, possibly even planted or subspontaneous on the Veluwe. A typical evergreen in mild winters, but severely damaged by strong frosts. Ulex is absent from most of the larger heath complexes of the Veluwe. There is only one place in the S.E. Veluwe where Ulex is abundant and where it forms larger groups. This has been ascribed to the löss soil found here (WEsTHOFF, 1958). However, there may be another factor of importance. The S.E. Veluwe is an elevated plateau cut by deep gorges. Both factors make for relatively high air temperatures in still, bright nights. Ulex is found on the higher parts of a steep slope which connects the plateau, $100 \mathrm{~m}$ above sea level, with the Rhine valley, $10-20 \mathrm{~m}$ above sea level. On the upper parts of such a slope cold air is drained away very easily (cf. Chapter 4.4). This situation, of course, gives protection only against night frosts, not against frosts that last longer and extend over a wider area. However, higher night temperatures may not only be of importance as a protection against frosts, they may as well have a positive influence. The opinion that the micrometeorological situation is of importance, is supported by the observation that lower down on the löss Ulex is missing, while it is present in the locality indicated above on preglacial sand too.

Suboceanic species

Genista pilosa. From S.W. Sweden to Spain. Young shoots tormed in May. Frost damage was never observed. A main root was found penetrating more or less vertically to a depth of $50 \mathrm{~cm}$. With plants of $20 \mathrm{~cm}$ diameter, near to the surface lateral roots were found up to $1 \mathrm{~m}$ from the centre.

Galium saxatile. Of rather northern distribution according to Böcher (l.c.). From S. Sweden to N. Spain according to Hegi. Wintergreen. No seedlings observed.

Juncus squarrosus. In middle and northern Europe, not in the arctic region. Old leaves gradually die off in autumn, but young green leaves are usually present during the winter. 
Sarothamnus scoparius. From S. Scandinavia to S. Spain. Usually very rare on the heaths of the Veluwe, but locally abundant. Germinating seeds were found in summer. According to Hegi, seeds need a period of 2 years for ripening and they germinate exclusively in light. According to Walter the species is sensitive to night frost. This would explain why it is absent from peaty soil. However, where present in the heath, it is found on spots which are most susceptible to night frosts.

Sarothamnus is sensitive to low winter temperatures, but it was never found to suffer from night frosts. Its distribution on the heath seems to be governed by edaphic factors rather than by micro-climatological ones. On the larger heath complexes it avoids podsolized soil, except where digging has taken place, and prefers preglacial soil. It is most abundant on small stretches of heath which have been spared in a reclaimed area.

Species with oceanic tendencies

Calluna vulgaris. Its distribution has been discussed extensively by W. BEYERINCK (1940). It is found from $71^{\circ} \mathrm{NL}$ to the coastal regions of Morocco. Its eastern boundary reaches $67^{\circ}$ beyond the Ural Mountains. Calluna shows little variability in aspect, but it has a strong periodicity. Beyerinck (l.c.) states that the first cell-divisions in the growing points and the first extension of internodes and leaflets take place sometimes as early as February, by "fits and jolts" depending on weather conditions.

The period of rapid growth during which the young shoots reach their ultimate length, does not start before the beginning of May. Often it does not start before the end of May, and in 1955 the rapid growth of the shoots in parts with a closed vegetation, started only in the beginning of June. Isolated heather plants growing on sandy soil, e.g. on road sides, start much earlier with the development of young shoots than those found in a dense heather vegetation. The same applies to plants in heaths that have been burnt. Isolated heather plants on resting inland dunes are up to one month earlier than heather plants in a heath vegetation. This may be due to higher soil temperatures as well as to higher nocturnal air temperatures. The latter certainly are responsible for the earlier development of heather on a high hill as compared with that on flat ground or in valleys. That the internal periodicity of Calluna is not very strong, is shown by the observation that heather plants kept in a heated room, may form young shoots in January.

Calluna usually passes tne winter without suffering harm. Only solitary plants on which rabbits have fed, are usually killed by frost. The winter Jan.-Febr. 1954 being cold with strong east winds and no snow cover had a strong effect on the vegetation as a whole. Almost everywhere heather turned brownish except where it had been sheltered against the wind by a larger number of trees. However, no permanent damage could be observed later in the year.

The winter of 1955 started late, and brought much snow till well 
in March. Frost was never severe by day, and often day temperatures remained above zero. Night temperatures were very low, owing to the isolating snow cover. At $2 \mathrm{~m}$ height minimum temperatures of $-15^{\circ} \mathrm{G}$ were observed. The snow cover was usually not deep enough to cover the higher heath completely, and during the day part of the snow moreover melted away. It must have been the rather high day temperatures and the strong radiation, direct and reflected, which in combination with the very low night temperatures had the observed deleterious effect on the heather. Lower heather plants and lower parts of larger shrubs remained unaffected. Since the soil was never frozen during this winter, a drying out of the leaves is a very unlikely explanation for the observed damage.

The same remarks that were made with regard of the winter of 1955 , apply to that of 1956.

The conditions necessary for a successful germination and development of Calluna can be summarized as follows. Calluna seed germinates best on a soil which is not extremely poor, somewhat humous and moist. Abandoned arable land, ploughed strips in pine woods, and soil prepared for planting with pine, apparently are excellent seed beds for Calluna. This is an illustration of the rule that the optimum for the development of a species is often not realized in the environment in which the latter is mainly found in nature. On preglacial yellow sand a good development of the seedlings is found. Bleached sand, e.g. ploughed strips in the heath, is very slowly colonized by heather seedlings. The same applies to places in a dry heath where sods have been cut. Where raw humus is left after the sods have been removed, a good development of seeds was observed. Conditions for a successful development of Calluna may differ from point to point, as is illustrated by the following examples. The surface of a burnt pine wood still showed the relief due to the plowing that was carried out just before the wood was planted; the furrows appeared to be colonized by heather, whereas the ridges carried a vegetation consisting of Festuca ovina and Polytrichum piliferum. Paths running east-west through the heath are always quickly colonized on their south-side but not on their north-side.

Experiments with regard to the germination and growth of Calluna on different soils were carried out by UITTIEN and GEERLINGs (1932). Aeolian sand proved to be almost totally unfit for the germination of Calluna seeds, whereas preglacial soil and red sand proved most suitable for the germination and further development of this species. On arable soil or garden soil in an experiment lasting 11 years the competition of weeds was too strong for the heather plants to become successfully established.

According to Greviluus (1928), germination of seeds is favoured by high temperatures $\left(67^{\circ}-70^{\circ} \mathrm{C}\right)$ during short periods. As such temperatures may occur in the normal seed beds of Calluna, e.g. in bare humus patches, this process may take place under normal conditions. These high temperatures also occur when a heath is burnt.

In autumn many seeds germinate on the places mentioned above. A considerable quantity of seed however is retained in the fruits, 
PH. STOUTJESDIJK

and not strewn before the first dry period in March of the next year. These seeds germinate during wet periods in spring and summer, even as late as August.

An impression of the distance over which seeds may be carried away by air currents, can be obtained by the application of a formula given by Rombakis (cf. Geiger l.c.). Heather seeds have a rate of fall of $1 \mathrm{~m} / \mathrm{sec}$. approximately in air. Assuming further that the wind force at the level of the heather tops is $6 \mathrm{~m} / \mathrm{sec}$., and that the exchange coefficient has a value of $50 \mathrm{~cm}$.g.sec., the mean distance of dispersal for heather seeds must be $20 \mathrm{~m}$. This means that $50 \%$ of the seeds do not reach this distance, and that $50 \%$ are carried beyond it. Although this figure shows that dispersal over very great distances is improbable, it certainly leaves room for dispersal of seed over a distance of a few hundred meters. Often, of course, seeds may drift along the surface in the same way as grains of sand.

We found that an area of burnt wood of $400 \times 400 \mathrm{~m}$ received enough seed to become completely covered by heather.

Immediately below the soil surface the root system of Calluna is strongly branched. Where a hardpan is found the roots very rarely penetrate into it; a characteristic felt of fine roots covers the pan. Roots penetrate to a greater depth in soils without a hardpan. In preglacial soil with a brown podsolic profile rather numerous roots were found down to $65 \mathrm{~cm}$, but usually the depth to which heather roots are found in an appreciable quantity, is much smaller. Incidentally roots were found to a much greater depth, viz. where they followed the passages dug out by Geotrupes spec. (cf. W. BEYERINCK, 1938), or where decaying tree roots had been present. KivenHeimo (1947) found in open pine wood Calluna roots down to a depth of $45 \mathrm{~cm}$. SAlisbury (1952) pictures a root system of Calluna going down to $60 \mathrm{~cm}$ in the soil of fixed inland dunes. The isolated Calluna plants on fixed inland dunes have an extensive root system. A plant of $60 \mathrm{~cm}$ diameter had a root system of 2 meter diameter, which went down to a depth of $35 \mathrm{~cm}$.

Carex pilulifera. A boreal species, not found in the arctic region, occurring up to an altitude of $2000 \mathrm{~m}$ (Hegi). Passes the winter in the same way as most of the sedges do with leaves which remain green at their base. Old leaves gradually die off during the winter. Leaf growth begins in February and March. Seedlings are rare; the few I found, had germinated in June.

Sieglingia decumbens. A boreal species with southerly tendencies. Leaves gradually die off during the winter. Growth starts in February or March.

\section{Indifferent species}

Molinia coerulea. A boreal, rather southerly species. Starts sprouting in May, usually even late in May. Vegetative growth is very slow at first, and is not completed before the end of July. In mid-September the leaves gradually turn yellow, and in the first half of October this process is completed. Where Molinia is burnt, sprouting 
is much quicker. This is probably due to the fact that the plant is freed from the dead isolating material, so that higher temperatures can develop in the tussock. Seedlings are rare. They were found in June and July on moist sandy places and on bare humous spots in the heath. KINZEL (1913-1920) found the best germination at $30^{\circ} \mathrm{C}$; at $20^{\circ} \mathrm{C}$ it was already much retarded. This is in accordance with the observation that seeds germinate on bare patches in summer. According to Hegi germination is very slow, and only a small fraction of the seeds do germinate at all. In unpodsolized soil roots were found down to $60 \mathrm{~cm}$.

Deschampsia flexuosa has a wide distribution. According to ScURFIEld (1954) it is cosmopolitan, and it occurs between Gibraltar and $71^{\circ} \mathrm{NL}$. It passes the winter with a fair amount of rather long green sprouts, but in spring the plants strongly change their aspect, and become green all over. The old leaves die off gradually during the winter. Roots may go rather deep, which is possible as the species prefers soils without hardpan formation. We found Deschampsia roots regularly down to $75 \mathrm{~cm}$ in preglacial soil with a brown podsolic profile. The greatest depth to which Kivenheimo found Deschampsia roots, was $115 \mathrm{~cm}$ in open pine wood. Seedlings are rare. We found them plentiful only on a burnt heath.

Nardus stricta has a wide distribution (cf. Hegi). Passes the winter with very short green sprouts which remain concealed between the old dead leaves. Leaf growth begins in April. Most leaves die off early in October; the remaining ones remain green so long as the winter is not too severe.

\section{Species with continental affinities}

Lycopodium complanatum var. chamaecyparissus. Boreal to subcontinental. Rare, known to us only from soil with a brown podsolic profile.

Scorzonera humilis. Subcontinental. An extremely rare species on the Veluwe, except at one place $(466,4184,8)$, where it occurs in a large number in the heath (cf. UrtTien, 1932). Here the soil is of the brown podsolic type. According to Böcher it grows abundantly in some Danish heaths along the more fertile and less acid roadsides. This species has a penroot which goes down to a depth of $40 \mathrm{~cm}$.

CHAPTER III

\section{INLAND DUNES}

a. LANDSCAPE FORMS WHICH OWE THEIR ORIGIN TO WIND EROSION 1. Rests of the original heath soil. In all inland dune areas rests of the original podsol are found. Usually the bleached sand is eroded away, ar least partly, but the hardpan persists. In this way in a denuded plain often miniature table mountains are left. These rests 
PH. STOUTJESDIJK

often have a oblong shape with their main axis in the direction E-W. Long E-W ridges may have been formed in this way.

2. Hills covered with Ammophila arenaria. When they are free from each other, these hills too may have a somewhat oblong shape with their main axis pointing more or less in an E-W. direction. The west side of the hill may have a slope of $18^{\circ}$. At the foot of this slope usually a deposit of coarser material is found. The east side of the hill is steep, up to $30^{\circ}$, i.e. close to the maximum possible for dry sand $\left(35^{\circ}\right)$. These hills usually combine in larger masses or irregular shape, though a tendency exists to form ridges in a direction $\mathrm{N}-\mathrm{S}$, i.e. perpendicular to the direction of the prevailing wind. Next to Ammophila, Festuca rubra var. arenaria plays a rôle (cf. VAlgkenier Suringar, 1926).

3. High dunes without any vegetation. These dunes may be compared with barchanes, but the sickle-shaped form of the latter is not recognizable. A typical barchane develops only when a mass of sand moves over a plain without meeting obstacles (cf. VAN Dieren, 1934). They will doubtless have formed a more important part of the dune landscape before extensive stretches were reclaimed.

4. Small hills covered with Corynephorus canescens. On the leeside of a tuft of Corynephorus canescens very fine sand may be accumulated in the form of a low and oblong pyramid. These mounds show a tendency to combine into ridges with a N-S orientation. Corynephorus may form hills up to 1 meter in height and often still provided with a long "tail" of sand on their leeside.

5. Hills in a state of breakdown. Where the sand supply has stopped, aeolian breakdown may take place, especially when the windforce increases. Such hills have an irregular shape, and when the erosion finally reaches their leeside, dune formation may start anew.

6. Blown-out gullies. In the depressions between the hills the wind force increases and so gullies are blown out. The main direction of these gullies is somewhat south of west. Eventually they may widen out to denuded plains. Because of the prevailing winds the main direction of the sand transport is from east to west. Eventually all the sand is carried away from a certain area. However, wind erosion does not go on indefinitely, as the coarser sand and small pebbles are left behind and form a "desert pavement", which prevents further erosion. The level down to which wind erosion goes on, is usually little more than 1 meter below the original surface, as rests of the original stratification show.

7. Ridges. Where a gully forms, on its sides sand accumulates, and ridges up to $8 \mathrm{~m}$ in height are formed. They may be compared with the arms of the parabole dunes that were described by Van Dieren (l.c.). In the inland dunes there is, however, no evidence that an ordinary dune is changed into a U-shaped one with distinguishable north and south arms.

8. Ground covered with aeolian sand. Extensive stretches of ground, covered with aeolian sand are found on the "Delense Heide". This is a vast, almost flat area which lies at a somewhat higher level than the 
inland dunes to its S.W. Still further to the S.W. lies a vast denuded plain. The high ground carries a rather hygrophilous vegetation, usually dominated by Molinia, which forms an unexpected contrast with the arid stretches of ground in the vicinity, which are found at a much lower level.

Several sheets of water are found here which are situated far above ground-water level. Borings in this area showed that there is a thick layer of aeolian sand which overlies a heath podsol with a very strongly developed hardpan. The pan must be quite impermeable, as the soil above it proves to be completely saturated with water, while the pan itself and the soil below the latter obviously contain no water in excess of their field capacity. Valleys which have been cut out in this area to below the hard pan, have a dry bottom, which carries an arid heath vegetation. When on one of the sides of such a valley a section is made, the water oozes out of the soil just above the pan. That this is usually not so, is due to the fact that from the pan hard concretion layers rise steeply upwards in the overlying sand layers. These concretion layers form the sides of a basin of which the hardpan forms the bottom. They are 3-5 mm thick and of a rusty brown to reddish colour. A similar stiuation was found near Hilversum. Apart from these slablike concretions irregularly shaped tubes are found, which have been formed around the roots of grasses growing on the slopes of the plateaus. As the dead roots are still present in the tubes, the development of the concretions must be a rather rapid process, which is apparently still going on.

Apart from the dry vallies mentioned above, other ones functioning as active drainage channels are present. The aeolian sand deposits on the plateau must have originated from the now denuded areas to the west of the latter, as the main direction of the winds that were responsible for the transport, must have been west-east. In these sands in many places rests of an old heath-soil stratification are found, always well recognizable by the presence of a very typical layer of bleached sand, and of a well developed hardpan. The same tubiform concretions as were found on the slopes of the plateau, are here met with together with the rests of the old heath soil. Thus similar processes as have been active and still are active in the heath area, must have played a rôle here; i.c. stagnation of water on the hardpan and oozing out of water on the slopes of a hardpan plateau.

The rests of the heath stratification permit the conclusion that the sand dunes have originated from a heath. The close association existing between dune areas and rests of heath podsols and eventually sheets of water, is found in all other stretches of inland dunes found on the Veluwe, and not only there but also in the inland dunes of Utrecht (Soester Duinen), Noord Holland (Hilversum), Drente, Overijsel and Noord Brabant. In the inland dunes of Norfolk-Suffolk (Brecklands) too podsol rests are often present, and Weiss gives a description of rests of a very hard podsol found in a sand dune area in Jutland.

Inside the area where heath podsols could be formed, all soils of 
PH. STOUTJESDIJK

TABLE 6

\begin{tabular}{|c|c|c|c|c|c|c|c|c|c|c|c|c|c|c|c|}
\hline $\begin{array}{l}\text { Number } \\
\text { Herb layer, cover \% } \\
\text { Taickness of humous sand, } \mathrm{cm} \\
\text { Loss on ignition, upper } 10 \mathrm{~cm}, \%\end{array}$ & $\begin{array}{l}1 \\
1 \\
2\end{array}$ & $\begin{array}{r}2 \\
2 \\
1-4\end{array}$ & $\begin{array}{l}3 \\
2 \\
2\end{array}$ & $\frac{4}{1-2}$ & $\begin{array}{c}5 \\
<5 \\
\leftarrow\end{array}$ & $\begin{array}{r}6 \\
<5 \\
1-2\end{array}$ & $\begin{array}{c}7 \\
\langle 5 \\
\rightarrow\end{array}$ & $\begin{array}{c}8 \\
<5 \\
4\end{array}$ & $\begin{array}{l}9 \\
5 \\
4\end{array}$ & $\begin{array}{c}10 \\
5 \\
4\end{array}$ & $\begin{array}{c}11 \\
10 \\
4\end{array}$ & $\begin{array}{c}12 \\
5\end{array}$ & $\begin{array}{l}13 \\
15\end{array}$ & $\begin{array}{l}14 \\
30\end{array}$ & $\begin{array}{l}15 \\
20\end{array}$ \\
\hline $\begin{array}{l}\text { Corynephorus canescens } \\
\text { Festuca ovina } \\
\text { Agrostis canina } \\
\text { Spergula vernalis } \\
\text { Carex arenaria } \\
\text { Rumex acetosella } \\
\text { Moss layer, Cover \% } \\
\text { Polytrichum piliferum } \\
\text { Cornicularia aculeata } \\
\text { Cladonia grayi } \\
\text { Cladonia uncialis } \\
\text { Cladonia glauca } \\
\text { Cladonia impexa } \\
\text { Cladonia cf. floerkeana } \\
\text { Cladonia verticillata } \\
\text { Cladonia amaurocrea } \\
\text { Cladonia pyxidata } \\
\text { Cladonia nemoxyna }\end{array}$ & $\overline{\mathrm{x} .2}$ & $\begin{array}{r}50 \\
3.4 \\
2.2 \\
1.2 \\
\times .2 \\
= \\
-\end{array}$ & $\begin{array}{l}40 \\
2.3 \\
2.2 \\
= \\
= \\
=\end{array}$ & $\begin{array}{r}60 \\
2.3 \\
3.3 \\
\times .2 \\
\times .2 \\
1.2 \\
\mathrm{x} .2 \\
\end{array}$ & $\begin{array}{r}40 \\
3.3 \\
2.2 \\
\mathbf{x} .2 \\
\mathbf{x} .2 \\
- \\
-\end{array}$ & $\begin{array}{r}50 \\
3.3 \\
2.2 \\
\mathrm{x} .2 \\
\mathrm{x} .2 \\
- \\
\end{array}$ & $\begin{array}{r}50 \\
3.3 \\
3.2 \\
\mathbf{x} .2 \\
- \\
\mathrm{x} .2 \\
\end{array}$ & $\begin{array}{r}30 \\
3.2 \\
\mathbf{x} .2 \\
\mathbf{x} .2 \\
\mathbf{x} .2 \\
- \\
-\end{array}$ & $\begin{array}{r}40 \\
3.3 \\
1.2 \\
1.2 \\
\times .2 \\
\times .2 \\
\times .2\end{array}$ & $\begin{array}{r}20 \\
2.2 \\
2.2 \\
\times .2 \\
\times .2 \\
- \\
-\end{array}$ & $\begin{array}{l}40 \\
3.3 \\
-2.2 \\
1.2 \\
- \\
-\end{array}$ & $\begin{array}{r}95 \\
3.4 \\
3.3 \\
3.3 \\
2.2 \\
x .2 \\
x .2\end{array}$ & $\begin{array}{r}90 \\
3.4 \\
3.4 \\
2.2 \\
2.2 \\
\mathrm{x} .2 \\
\mathrm{x} .2 \\
1.2\end{array}$ & $\begin{array}{l}85 \\
3.4 \\
\times .2 \\
2.2 \\
- \\
2.2 \\
\times .2\end{array}$ & $\begin{array}{r}75 \\
4.4 \\
-\overline{2.2} \\
- \\
\bar{x} .2 \\
\mathrm{x} .2\end{array}$ \\
\hline
\end{tabular}

TABLE 6

(Legenda)

\begin{tabular}{|c|c|c|}
\hline Number & \multicolumn{2}{|c|}{ Locality } \\
\hline 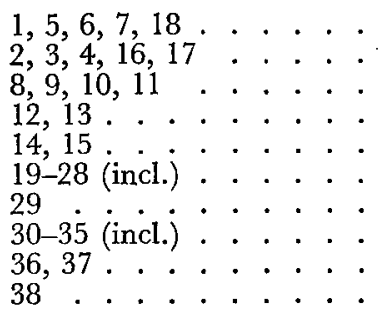 & 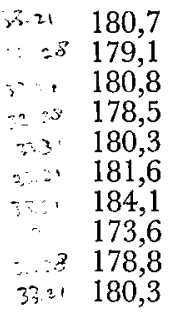 & 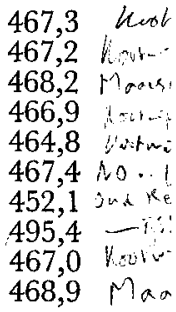 \\
\hline
\end{tabular}

which it might be expected that they would develop dunes, seem to have formed podsols before the aeolian transport was started.

The frequent association of inland dunes with sheets of water or bogs has already been mentioned. Sarimmel and Ter Hoeve (1952) showed that the sheet of water called "Gerritsfles" rests on an impermeable hardpan. VoorwIJ and HARdjoprakoso (1945) showed that the same situation exists near Ommen.

We found several pools resting on a heath podsol covered with a layer of aeolian sand, viz. near Hulshorst, near Boeschoten (Watersmeer) and near Kootwijk. Near Hilversum an impermeable hardpan was found under a bleached sand deposit of great depth. The sheets of water ralled "Laarder Wasmeer" and "Hilversumse Wasmeer" probably rest on a hardpan as well. The level of these waters is much 
Vegetation of denuded plains

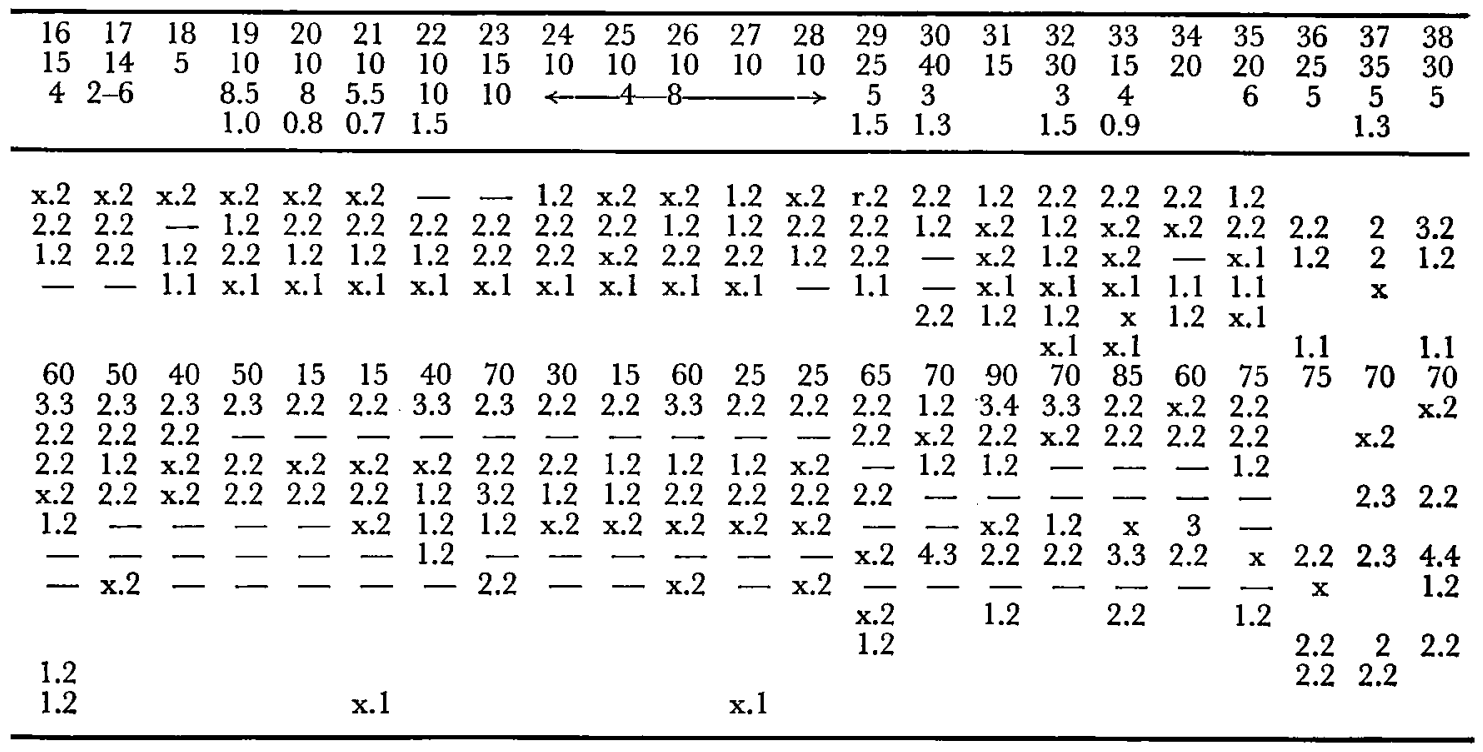

Size of plots: $1 \mathrm{~m}^{2}$

Species not included in the table:

2. Cladonia mitis $\times .2 ; 23$. Cladonia macilenta $\times .2$, Cladonia cornuta 1.2 ;

26. Cladonia macilenta x.2; 30. Hypochoeris glabra x.1, Cladonia gracilis 2.2, Cephaloziella spec. x.2; 32. Cladonia macilenta x.2, Cephaloziella spec. 2.2., Cladonia fimbriata x.2, Hypochoeris radicata x.1, Antennaria dioica r.1, Calluna vulgaris x.1; 33. Calluna vulgaris x.2, Cladonia macilenta x.2; 34. Ammophila arenaria x.1, Cladonia fimbriata x.2; 35. Hypochoeris radicata $r .1$, Calluna vulgaris x.1, Genista pilosa x.1; 36. Calluna vulgaris x.1; 37. Festuca rubra 2.2; 38. Calluna vulgaris 1.2, Hypochoeris radicata x.1.

higher than the blown-out ground found at a small distance trom them. The impenetrable pan could, however, not be reached with an ordinary soil auger. Other pools and bogs which probably rest on an hardpan are: "Koefles", "Kempesfles", "Kootwijkerveen", sheets of water in the "Wekeromse zand".

The formation of sheets of water or of bogs on the hardpan seems to be possible only where the latter is covered with a layer of aeolian sand or where the layer of bleached sand is unusually thick $(8 \mathrm{dm})$. This bleached sand may not have been autochtonous but may have been formed gradually from sand transported by the wind. Whether the hardpan was originally everywhere impenetrable, and lost this property partly where it remained uncovered, or whether the sand by which it was covered, has made it impermeable, could not be decided. A third possibility is that sand dunes have formed in those places only where the hardpan was very hard and impermeable.

Here the question arises whether perhaps the impermeable hardpan was one of the causes that are responsible for the wind erosion. 
On a flat heath provided with an impermeable pan, always drainage channels will form, and these channels will gradually become deeper and finally they will break through the hardpan. In dry periods these drainage channels with their exposed subsoil will form starting points for wind erosion.

We arrive at the conclusion that the higher cover-sands of the Veluwe were originally all covered by heath, and that they posessed a strongly developed podsol stratification with a thick hardpan. The position of the rests of the old surface shows that the landscape must have been weakly undulating, locally with a more marked relief. Thanks to the impermeable hardpan, in depressions pools and bogs were formed.

Of the original heath on coversand only fragments are now left.

\section{b. The vegetation of THE Denuded plains}

Where wind erosion prevails over sand supply, the soil surface is constantly lowered. Under such conditions many tufts of Corynephorus may be found of which the root system has been denuded, and which consequently have died. As a pioneer on places where the soil surface is constantly but slowly lowered (because of the formation of an erosion pavement), the same cone-shaped lichen bodies are found which form pioneer vegetations on bare south slopes. Spergula is present in this vegetation, and rarely some living tufts of Corynephorus canescens and Festuca ovina are met with .The "vegetation" does not cover more than $1 \%$ of the soil surface (Table 6).

Apparently a later stage is the vegetation consisting of Polytrichum piliferum and some lichens, which covers a much greater part of the soil surface. This vegetation shows a mosaic-like distribution of patches consisting of Polytrichum piliferum and of more open patches consisting of Cornicularia aculeata. Cladonia grayi and Cladonia uncialis are found frequently but in small quantities only. The Polytrichum patches form flat elevations rising about $3 \mathrm{~cm}$ above the level of the lichen patches. The Polytrichum patches apparently collect some aeolian sand, either from the bare patches or from outside the area. The cone-shaped bodies of Cladonia are present in this community too, although they usually present a later stage of development, viz. a ramified thallus occasionally provided with podetia.

Corynephorus canescens, Festuca ovina and sometimes Agrostis canina are present in this community, but their total coverage remains usually below $5 \%$.

By means of transitory stages differing in the number of species, in the degree of coverage and in the humus content of the soil, this community develops into the following one, a vegetation dominated by Festuca ovina together with Agrostis canina; Corynephorus is usually still present, but not of any importance compared with the other grasses. In the moss layer Polytrichum piliferum is dominant, and Cladonia uncialis is the next important element. Cladonia glauca and $\mathrm{Cl}$. grayi are always present. Cornicularia aculeata is absent from this community. Hypochoeris radicata is found in this vegetation in a few scattered 
specimens. It has a preference for the immediate neighbourhood of isolated Calluna shrubs. Fasione montana is very rare. Scattered plants of Calluna are present, but usually in the neighbourhood of an old shrub, but neither young plants nor seedlings are found. Germination and the development of seedlings seem to require a set of favourable conditions which is but rarely present.

In this community the Cladonia species find their anchorage invariably on dead remains of Polytrichum and of grasses. On the other hand seedlings of grasses are found in sufficient quantity to replace the tufts that have succumbed, and Polytrichum recolonizes cracks and bare spots in the lichen cover. Thus the same cyclic processes take place as were described by Watt for a somewhat different inland dune vegetation. In order to observe these cyclic processes, one should study a very small area, say a square decimeter or less. In an area of a square meter the succession stages are all already represented, and here the mean composition of the vegetation remains therefore more or less the same.

To a depth of $6-10 \mathrm{~cm}$ the soil under this vegetation is coloured grey by humus. In this stage the loss on ignition of the soil was found to remain below $1.5 \%$ if the samples were taken from the upper $10 \mathrm{~cm}$.

Old single plants or patches of Empetrum are spread far and wide. Pinus silvestris may enter all these communities, but neither seedlings nor older trees are very numerous. The trees have a very shallow but a very extensive root system; that of a sapling of $60 \mathrm{~cm}$ height went no deeper than $30 \mathrm{~cm}$, but roots of up to $4.5 \mathrm{~m}$ in length spread to all sides. That the root system of the pines does not penetrate to a greater depth, is obviously due to the fact that the soil at a depth of ca $35 \mathrm{~cm}$ becomes very hard and compact. It proved almost impossible to force the cylinder used for soil sampling $10 \mathrm{~cm}$ deep into this soil. This can be due only to the close packing of the sand grains, as it appears that they are not cemented together at all.

On denuded plains no higher stage of development of the vegetation was found. On aeolian soil a further stage may be observed, whichis characterized by a thick lichen layer $(3-4 \mathrm{~cm})$ and by the small amount of Polytrichum that is present in the vegetation.

\section{c. Colonization of the fiXed inland dunes}

As long as there is an abundant supply of sand, this supply apparently is the determining factor in the development of the vegetation. The vegetation of the moving inland dunes has been extensively discussed by Valckenier Suringar (l.c.). When the sand supply is stopped, e.g. where hills occupy an isolated position in a denuded plain, the differentiating action of the microclimate becomes visible (Table 7).

With isolated hills in a denuded plain, the north slopes usually have developed into a heath, which may have reached a considerable age when the south slopes still carry a vegetation consisting of Corynephorus, Festuca, Agrostis, and Ammophila. Sand transport now takes place only in a downward direction. Many grass tufts die from lack of sand, 
TABLE 7

\begin{tabular}{|c|c|c|c|c|c|c|c|c|c|c|c|c|c|c|}
\hline \multirow[b]{2}{*}{$\begin{array}{l}\text { Number } \\
\text { Slope } \\
\text { Height of vegetation in } \mathrm{cm} \\
\text { Humous sand, cm } \\
\text { Raw humus, cm } \\
\text { Herbs \& shrubs, cover \% }\end{array}$} & \multicolumn{14}{|c|}{ North slopes } \\
\hline & $\begin{array}{c}1 \\
30\end{array}$ & $\begin{array}{c}2 \\
15^{\circ} \\
20\end{array}$ & $\begin{array}{c}3 \\
41^{\circ} \\
30\end{array}$ & $\begin{array}{c}4 \\
36^{\circ} \\
20\end{array}$ & $\begin{array}{l}5 \\
30^{\circ} \\
45\end{array}$ & $\begin{array}{l}6 \\
38^{\circ} \\
45\end{array}$ & $\begin{array}{c}7 \\
22^{\circ} \\
20\end{array}$ & $\begin{array}{l}8 \\
22^{\circ} \\
60\end{array}$ & $\begin{array}{c}9 \\
25^{\circ} \\
40\end{array}$ & $\begin{array}{l}10 \\
25^{\circ} \\
25 \\
50\end{array}$ & $\begin{array}{c}11 \\
19^{\circ} \\
20 \\
4 \\
3 \\
80\end{array}$ & $\begin{array}{l}12 \\
28^{\circ} \\
20 \\
3 \\
2.5 \\
70\end{array}$ & $\begin{array}{l}13 \\
25^{\circ} \\
40 \\
2 \\
4 \\
60\end{array}$ & $\begin{array}{c}14 \\
26 \\
35 \\
3 \\
3.5 \\
80\end{array}$ \\
\hline $\begin{array}{l}\text { Calluna vulgaris } \\
\text { Empetrum nigrum } \\
\text { Festuca ovina } \\
\text { Agrostis canina } \\
\text { Corynephorus canescens } \\
\text { Hypochoeris radicata } \\
\text { Jasione montana } \\
\text { Ammophila arenaria }\end{array}$ & $\begin{array}{l}2.2 \\
2.2 \\
1.2\end{array}$ & $\begin{array}{l}1.1 \\
\mathrm{x} .2 \\
2.1 \\
\mathrm{x} .2 \\
\mathrm{x} .1 \\
.\end{array}$ & $\begin{array}{l}\mathrm{x} .1 \\
\mathbf{x} .2 \\
1.1\end{array}$ & $\begin{array}{l}2.1 \\
2.2 \\
1.1 \\
. \\
.\end{array}$ & $\begin{array}{c}5.5 \\
2.3 \\
\mathrm{x} .2 \\
\cdot \\
\dot{1.1} \\
\mathrm{x} .1 \\
\mathrm{x} .2\end{array}$ & $\begin{array}{l}4.4 \\
2.3 \\
\times .2 \\
\cdot \\
\dot{1.1} \\
\mathrm{x} .1\end{array}$ & $\begin{array}{l}\mathbf{x} \\
1.2 \\
1.1 \\
1.2 \\
: \\
\cdot\end{array}$ & $\begin{array}{l}3.4 \\
2.3 \\
2.2 \\
2.1 \\
2.2 \\
\mathbf{x} .1 \\
\mathbf{x} .1 \\
1.2\end{array}$ & $\begin{array}{l}4.5 \\
\dot{2.2} \\
\dot{x} .1\end{array}$ & $\begin{array}{c}4 \\
\dot{1.2} \\
\mathbf{x} .1\end{array}$ & $\begin{array}{l}5.5 \\
. \\
.\end{array}$ & $\begin{array}{l}1.2 \\
4.5 \\
\times .2 \\
. \\
.\end{array}$ & $\begin{array}{l}2.2 \\
3.3 \\
\mathrm{x} .2 \\
\cdot \\
.\end{array}$ & $\begin{array}{l}x .2 \\
5.5\end{array}$ \\
\hline $\begin{array}{l}\text { Moss layer, cover \% } \\
\text { Pohlia nutans } \\
\text { Plectocolea hyalina } \\
\text { Scapania compacta } \\
\text { Parmelia physodes } \\
\text { Polytrichum piliferum } \\
\text { Cornicularia aculeata } \\
\text { Pleurozium schreberi } \\
\text { Polytrichum formosum } \\
\text { Cladonia impexa } \\
\text { Hypnum cupressiforme } \\
\text { Dicranum scoparium } \\
\text { Cladonia glauca } \\
\text { Cladonia grayi } \\
\text { Cladonia uncialis } \\
\text { Cladonia "cone-shaped" } \\
\text { Cladonia pyxidata } \\
\text { Cladonia verticillata }\end{array}$ & $\begin{array}{r}30 \\
2.2\end{array}$ & $\begin{array}{r}60 \\
\times .2 \\
.\end{array}$ & $\begin{array}{r}70 \\
3.3 \\
2.3\end{array}$ & $\begin{array}{r}80 \\
3.3 \\
3.3\end{array}$ & $\begin{array}{c}100 \\
5.5 \\
.\end{array}$ & $\begin{array}{l}60 \\
4.4 \\
\cdot \\
1.2 \\
\cdot\end{array}$ & $\begin{array}{l}95 \\
5.5 \\
2.2 \\
1.2\end{array}$ & $\begin{array}{l}100 \\
1.2 \\
3.3 \\
3.3 \\
1.2 \\
\mathrm{x} .2\end{array}$ & $\begin{array}{r}90 \\
3.4 \\
1.2 \\
3.4 \\
1.2 \\
\mathrm{x} .2\end{array}$ & $\begin{array}{c}70 \\
\dot{4.4} \\
\times .2 \\
1.2\end{array}$ & $\begin{array}{l}5.5 \\
\mathrm{x} .2 \\
\mathrm{x} .2 \\
1.2\end{array}$ & $\begin{array}{l}1.2 \\
4.5 \\
\times .2 \\
1.2\end{array}$ & $\begin{array}{l}2.2 \\
2.2 \\
1.2 \\
2.2\end{array}$ & $\begin{array}{l}1.2 \\
1.2 \\
4.5 \\
2.2\end{array}$ \\
\hline
\end{tabular}

apparently because the root system is laid bare by the rainwater that flows down the slope. On the rests of the killed grass tufts a crustlike lichen settles itself, and this lichen spreads over the sand as well. As the level of the sand around it is gradually lowered, the part of the sand which is fixed by the lichens begins to form elevations. These cones show concentric growth rings. They become almost as hard as pebbles and reach a diameter of $5 \mathrm{~cm}$; especially on the gentler slopes they may be present in large numbers. When the sand is fixed, the lichens begin to branch and to form podetia, and then they can be identified as Cladonia nemoxyna and $\mathrm{Cl}$. glauca. These lichens may be washed down the slope and may accumulate at its foot.

Polytrichum piliferum colonizes these retrogressive slopes, starting at the foot. The sand that has been washed down, is fixed by the moss carpet. The growth of the mosses keeps pace with the amount of sand that is deposited on them. It is often seen that the stream of sand splits up into several branches, which when they have been fixed by the moss, look as if they were frozen on the surface of the slopes. 


\begin{tabular}{|c|c|c|c|c|c|c|c|c|}
\hline \multicolumn{8}{|c|}{ South slopes } & \\
\hline $\begin{array}{r}1 \mathrm{a} \\
20^{\circ}\end{array}$ & $\begin{array}{r}8 \mathrm{a} \\
25^{\circ}\end{array}$ & $\begin{array}{r}9 a \\
27^{\circ}\end{array}$ & $\begin{array}{l}10 \mathrm{a} \\
25^{\circ}\end{array}$ & $\begin{array}{l}11 \mathrm{a} \\
12^{\circ} \\
2.5\end{array}$ & $\begin{array}{r}12 \mathrm{a} \\
8^{\circ} \\
4\end{array}$ & $\begin{array}{r}13 \mathrm{a} \\
12^{\circ} \\
2\end{array}$ & $\begin{array}{c}14 \mathrm{a} \\
12^{\circ} \\
10 \\
2\end{array}$ & \\
\hline 30 & 10 & 10 & 10 & 15 & 15 & 5 & 2 & \\
\hline $\begin{array}{l}1.2 \\
2.2\end{array}$ & $\begin{array}{l}x .2 \\
1.2 \\
2.2\end{array}$ & $\begin{array}{l}1.2 \\
1.2 \\
1.2\end{array}$ & $\begin{array}{l}\text { x.2 } \\
\text { x.2 } \\
2.2\end{array}$ & $\begin{array}{l}\text { x.1 } \\
1.2 \\
2.2 \\
\text { x.2 }\end{array}$ & $\begin{array}{l}x .2 \\
2.2\end{array}$ & $\begin{array}{l}1.2 \\
1.2 \\
1.2\end{array}$ & $\begin{array}{l}\mathrm{x} .2 \\
\mathrm{x} .2\end{array}$ & 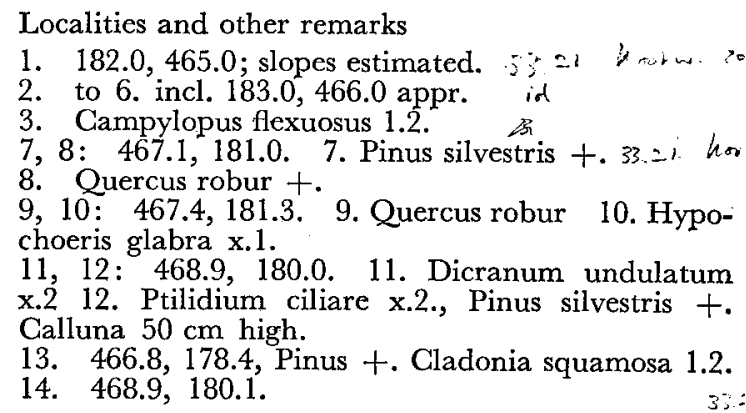 \\
\hline 1.2 & $\begin{array}{l}1.3 \\
1.3\end{array}$ & $\begin{array}{r}1.2 \\
\times .2\end{array}$ & $\begin{array}{r}1.2 \\
\mathrm{x}\end{array}$ & $\begin{array}{l}2.2 \\
3.5 \\
\\
2.2\end{array}$ & $\begin{array}{c}2.2 \\
2 \\
2.2\end{array}$ & $\begin{array}{l}\text { x.2 } \\
2.2 \\
1.2 \\
1.1\end{array}$ & $\begin{array}{l}\text { x.2 } \\
\text { x.1 }\end{array}$ & $\begin{array}{l}\text { la. etc. slopes on the same hills as corresponding } \\
\text { north slopes. } \\
\text { la. slope estimated, Pinus }+., 30 \% \text { of soil covered } \\
\text { by dead grass rests. } 7 \mathrm{a}=8 \mathrm{a} \text {. often dead grass rests } \\
\text { on soil surface and threads of algue. 11a. Webera } \\
\text { spec. } 2.2 \text {, lichens except Cladonia impexa on dead } \\
\text { grasses and Polytrichum. 12a. lichens on dead } \\
\text { grass and Polytrichum. 13a, 14a. lichens, except } \\
\text { cone-shaped bodies, on dead Polytrichum. } \\
\text { Size of samples } 2 \times 2 \mathrm{~m} \text {. }\end{array}$ \\
\hline
\end{tabular}

In this way the south slopes become covered with a dense Polytrichum vegetation which is anchored deep into the sand. It fixes the soil surface very effectively, and protects it against erosion. When dried out, the soil surface is very hard.

When no longer any sand is washed down the slope, in these Polytrichum vegetations spots appear where the moss becomes brown, as if some kind of acid had been spilled over it. In many of these spots Cornicularia and several Cladonia species are found, which use the dead Polytrichum as an anchorage. The more or less circular form of the dead spots suggests that they are caused by an agent which spreads from a centre. However, in many spots no lichens are recognizable but, of course, in that case they may be present in an inconspicuous form, and in both cases the decay of the moss might be due to an influence exercized by the lichen. Gradually a vegetation consisting of Polytrichum, Cornicularia and Cladonia is formed. Polytrichum never disappears altogether. A few tufts of Festuca ovina and Corynephorus canescens may settle in this community. Some of the tufts of Corynephorus and those 
of Ammophila may have persisted from the Ammophila-Corynephorus vegetation that was present on the bare sand.

Eventually a community is formed dominated by Polytrichum piliferum, Cornicularia and Cladonia grayi, and containing much Cladonia glauca and usually some $C l$. pyxidata and $C l$. floerkeana. Spergula vernalis is usually present. Tufts of Festuca ovina and Corynephorus canescens are rare and scattered. This community is rather stable, and not before the soil to a depth of a few centimetres has become grey by humus, seedlings of Calluna begin to invade this community. Polytrichum is never excluded from this community, for during heavy rain showers, the loose layer of lichens is often washed down the slope leaving bare spots. These spots are recolonized by Polytrichum. The lichens are always fastened to rests of dead Polytrichum and/or of grasses, but this anchorage gradually weakens as decay proceeds. Thus, here too the vegetation reaches a certain stability by a cyclic development.

The steep north slopes are far more easily colonized than the flat ground or the south slopes, as radiation and temperature measurements indicate the presence of a more favourable environment on this side. North slopes that are beyond the reach of much aeolian sand, become readily covered with several kinds of mosses and of liverworts; Webera nutans is a major constituent of this vegetation. Almost at the same time seedlings of Calluna make their appearance, and soon a vegetation dominated by Calluna is formed. The colonization must be very quick indeed compared with that of the south slopes, as a dense heather vegetation may be found here even on pure yellow sand without a trace of humus, while the south slope is still completely bare.

The moss layer in these vegetations is formed mainly by Webera nutans and two Hepaticae: Scapania compacta and Plectocolea hyalina. Parmelia physodes is found on dead branchlets as well as directly on the soil. It is interesting to note that Webera here prefers north slopes, while on the oak hills with their humous soil it dominates the south slopes, and in heather on south slopes with humous soil it is also an important feature. Quercus and Pinus seedlings are often found in these vegetations. Fasione montana, which is nowhere numerous, is found rather frequent on the consolidated north slopes, an interesting difference with the situation on the West Frisian Islands where it is characteristic for the Corynephoretum on south slopes (WESTHOFF, 1947).

Where there is some sand drift, the foot of the slope remains covered with grasses to about a height of $1 \mathrm{~m}$.

A hill as described here, can not be regarded as stabilized before its south slope too has been stabilized, as erosion on this slope may result in the top of the north side being attacked as well.

Finally a heath vegetation develops which is similar to that found on north slopes.

The influence exercised by a north inclination on the microclimate is much stronger than that exercised by a south inclination (cf. IV q), and this applies also to the differences that are found respectively 
between the vegetation on flat ground and that on a north slope and between the first and that on a south slope.

It is remarkable that in this stage the humus content of the soil on the north slopes, which were much earlier colonized and which always carry a much greater mass of vegetation, is apparently no higher than it is on the south slopes. The surface of the north slopes, it is true, is covered with a thick layer of raw humus, but the layer of soil. which is coloured grey by the ordinary kind of amorphic humus is here as deep as it is on the south slope.

North of the railway Amersfoort-Apeldoorn Calluna is in this community often replaced by Empetrum, especially in reclaimed dunes planted with conifers. The southern boundary of Empetrum runs across the Veluwe, and approximately coincides with this railway. In older communities of this northern type the moss layer gradually changes into that which is found under a mature heath vegetation on a slope of that exposition; this means that Pleurozium schreberi is found in the moss layer. A heavy layer of raw humus is formed.

In this stage the microclimatic differences between the north and south slopes reach their highest value. Differences in exposition and differences in vegetation are acting in the same direction. When the south slopes too become covered with heath, differences both of vegetation and of microclimate decrease once more, but this probably is a process which takes a very long time.

Seedlings of Quercus and Pinus are found almost exclusively on the top and on the north slope of these hills. The trees show a much better growth here than on the denuded plains, where a few $\mathrm{dm}$ below the surface the sand grains are so closely packed that roots can not penetrate between them.

\section{d. Hills covered with oAK shrub}

A characteristic feature of the landscape formed by the resting inland dunes are solitary dome-shaped hills covered with oak shrub. The base of the thin oak trunks is covered with sand. As the sand is fixed by the numerous trunks it is less easily borne away by the wind, and this explains why these hills may have very steep slopes and differ therefore very markedly in shape from the grass-covered hills. The hills are traversed at their base by the old heath soil or by a layer of red sand. The development of these hills will have proceeded in this way: on a rest of a heather podsol aeolian sand is deposited, and when the latter is sufficiently stabilized, it is colonized by oak. After the oak shrub has settled, it will collect more sand. In this way slopes of $47^{\circ}$ may develop. A slope of pure sand has a maximum steepness of $30^{\circ}$. In their present form the oak hills carry a vegetation which is best pictured by a N.-S. transsect passing over the top of the hill. The plain surrounding the hill carries a vegetation as described before. Just beyond the shadow of the oak shrub the S. part of the hill is fringed by a zône which is dominated by Cladonia uncialis, fa impexoides. Another characteristic component of this vegetation is a Cephaloziella species. The rest of the species, mainly several Cladonia 
species and Polytrichum piliferum, it has in common with the surrounding vegetation. The $S$ slope under the oak shrub is covered with a vegetation which is dominated by Pohlia nutans. Dicranoweissia cirrata is frequent, on the branches of the oaks as well as on the humous soil.

On the $\mathbf{N}$ slopes Dicranum scoparium dominates the vegetation, often accompanied by Pleurozium schreberi and Hypnum cupressiforme; the moss carpet is very dense and thick. Polypodium vulgare is found occasionally.

Parmelia physodes prefers the $\mathrm{N}$ slopes, and is found both on dead branches and growing on the mosses. On the $\mathbf{N}$ side the hill is fringed by a half circle of either Calluna or Empetrum or both.

TABLE 8

Hills grown with oak shrub.

Size of samples $2 \times 2 \mathrm{~m}$. Locality $467,1 \quad 178,8$.

\begin{tabular}{|c|c|c|c|c|c|c|c|c|}
\hline $\begin{array}{c}\text { Exposition } \\
\text { Number }\end{array}$ & 1 & & & 4 & 1a & & $3 \mathbf{a}$ & $4 a$ \\
\hline $\begin{array}{l}\text { Slope } \\
\text { Shrub layer, coverage } \% \\
\text { Quercus robur } \\
\text { Herb layer, coverage } \%: \\
\text { Festuca ovina } \\
\text { Polypodium vulgare } \\
\text { Hieracium umbellatum } \\
\text { Empetrum nigrum } \\
\text { Moss layer, coverage } \%: \dot{:}: \\
\text { Webera nutans } \\
\text { Dicranum scoparium } \\
\text { Dicranoweissia cirrata } \\
\text { Parmelia physodes } \\
\text { Hypnum cupressiforme } \\
\text { Pleurozium schreberi } \\
\text { Aulacomnium androgynum. }\end{array}$ & $\begin{array}{l}43 \\
90 \\
5.5 \\
2 \\
1.2\end{array}$ & $\begin{array}{l}33 \\
90 \\
5.5 \\
40 \\
3.2 \\
\times .2 \\
\times .1 \\
\\
20 \\
2.2 \\
1.2 \\
\times .2\end{array}$ & $\begin{array}{l}26 \\
90 \\
5.5 \\
\mathbf{x . 2}\end{array}$ & $\begin{array}{l}90 \\
3.3 \\
1.2 \\
.12 \\
1.2\end{array}$ & $\begin{array}{l}47 \\
90 \\
5.5 \\
2 \\
\times .2 \\
\\
1.2 \\
100 \\
5.5 \\
1.2 \\
1.2\end{array}$ & $\begin{array}{l}35 \\
90 \\
5.5 \\
10 \\
2.2 \\
2.2 \\
\mathrm{x} .1 \\
60 \\
2.2 \\
4.4 \\
1.2 \\
1.2 \\
\mathrm{x} .2\end{array}$ & $\begin{array}{l}47 \\
90 \\
5.5 \\
\\
1.1\end{array}$ & $\begin{array}{l}27 \\
90 \\
5.5 \\
2 \\
1.2\end{array}$ \\
\hline
\end{tabular}

\section{e. Growth RINGS}

Where the vegetation consists mainly of mosses and lichens, the few higher plants, at least those which reproduce vegetatively, can spread freely in all directions. This explains why the latter form circular patches. When these patches grow older, they die off in the centre and change in rings. This phenomenon can be seen in salt marshes and on mud flats too. Many plant species apparently do not thrive in their own waste products. Watt has described this process for Agrostis canina. Growth rings of this plant are found in the Veluvian sand dunes too; however, as the rings are not very compact, they are not very conspicuous.

Much more striking are the growth rings of $\mathcal{N}$ ardus stricta, a species which occurs locally on the fixed dunes. When the tussocks of $\mathcal{N}$ ardus exceed a diameter of $2 \mathrm{dm}$, the central part begins to wither, while peripherally growth still goes on. Thus rings $60-70 \mathrm{~cm}$ in diameter are formed. A vertical section through the centre of such a ring is shown in Fig. 3. From the periphery to the centre one finds: 
$1^{\circ}$. living leaves and rhizomes,

$2^{\circ}$. dead but still well-preserved leaves and rhizomes,

$3^{\circ}$. several stages in the decay of the dead material.

The decaying material becomes covered with the familiar combination consisting of Cladonia pyxidata and Campylopus flexuosus together with Cladonia floerkeana, Cl. nemoxyna and a lush growth of Rumex
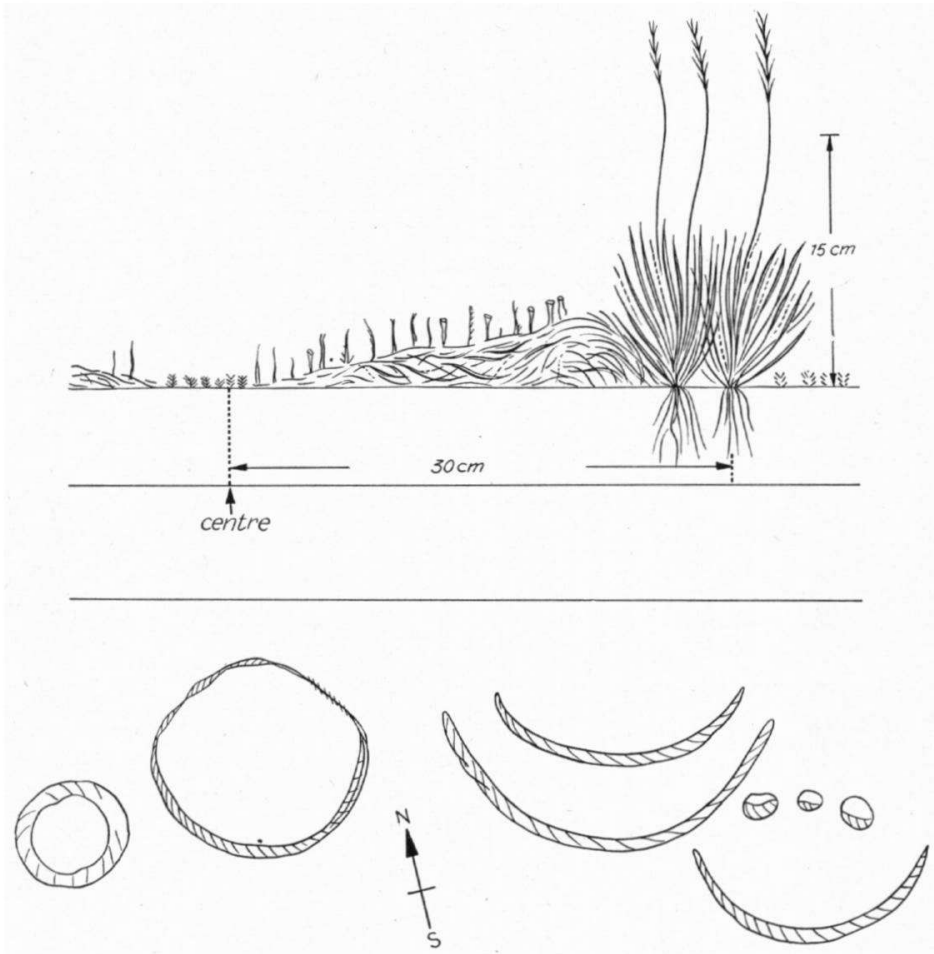

Fig. 3. Above: Section through a growth ring of Nardus stricta.

Below: Various stages in the development of growth rings seen from above.

acetosella. In the centre of the ring the bare ground is once more exposed, and is colonized by Polytrichum piliferum, which is the main component of the vegetation outside the ring. Rings of this size $(60-70 \mathrm{~cm})$ usually are at one side somewhat retarded in their growth. On further extension horseshoe-like structures are formed. The open end of these horseshoes always lies at the north or N.E. side. The only environmental factor whose action is one-sided, seems to be the direct sunlight, and this may therefore be responsible for this kind of development. For the rhizomes and the tufts of leaves at the outer side of the ring, life conditions at the north side are apparently very different from those at the south side, for in spring the number of tufts at the south side is about 3 times as high as that at the north side. At the 
north side of the larger horseshoes some living tufts may survive till the surrounding dead material has decayed. They they start growing in a southward direction, thus forming a new horseshoe inside the old one. From the yearly accretion of these rings and horseshoes their age may roughly by calculated. As the zône of living $\mathcal{N a r d u s}$ tufts is but narrow, there can be only a small yearly accretion, viz. hardly $1 \mathrm{~cm}$. This gives an age of at least 50 years for the largest rings. The time required for a complete decay of the dead leaves and rhizomes must be several decades.

Empetrum nigrum spreads with its shoots to all sides, and forms more or less circular patches. In the centre of these patches some decay is often noted, but no regular rings are formed. By counting the growth rings of dead stems in the centre the age of patches of $2 \mathrm{~m}$ diameter was found to be at least 30 years.

Calluna shows here a habit similar to that of Empetrum.

\section{f. Biological notes on inland dune plants}

Corynephorus canescens has a Central-European distribution with a tendency to spread towards southern and oceanic regions (Böcher). It is very rare in the British Isles; it is e.g. absent from the Breckland communities which are otherwise very similar to those found on our inland dunes, and from most other British inland and sea dune vegetations (WATt, TANSLEY, 1939). Its $\mathrm{N}$ limit of distribution is South Denmark and Sweden.

During the winter it has, as a rule, young sprouts as well as fullgrown green leaves.

In February 1954 on exposed places all leaves were killed by frost. About one half of the plants did not recover. In wind-sheltered places the plants did not suffer from the frost. Growth is very slow; leaves apparently live longer than one year, as even on plants that are several years old, dead leaves are rare; this cannot be due to decay, as the latter proceeds at a very slow rate.

Seedlings were usually not found before the end of October. In the very wet summer of 1954 the first seedlings were found by the middle of August, viz. in shallow depressions on ploughed heath soil where much water collected.

In the communities occurring on resting dune sand seedlings are rare, always solitary and apparently originating from detached caryopses.

In moving sand dunes a much more effective way of propagation could be observed. In October often hundreds of seedlings can be found which originate from spikes that are buried under a few centimetres of sand. In autumn the sand rarely dries out to that depth, so that conditions for germination are very favourable.The spikes may remain connected with the mother plant, or they may become detached from the latter and transported by the wind.

The root system of Corynephorus is not very strongly developed, but it is nevertheless very extensive compared with the space occupied 
by the aerial parts. The very fine threadlike roots spread radially to all sides. As a rule, no roots were found below a depth of $35 \mathrm{~cm}$, and the main mass of roots proved to be situated between 0 and $25 \mathrm{~cm}$.

A Corynephorus tuft of $12 \mathrm{~cm}$ diameter had a root system descending to a depth of $35 \mathrm{~cm}$ and with a radius of $55 \mathrm{~cm}$. Young Corynephorus tufts of $2-3 \mathrm{~cm}$ diameter were found to have a hemispherical root system with a radius of $10-15 \mathrm{~cm}$. Where Corynephorus forms a rather closed stand, as it does on the slopes of the moving sand dunes, a considerable number of roots were found down to $60 \mathrm{~cm}$.

Agrostis canina is a widely distributed species with a tendency to spread in a more or less southern direction (Böcher). During the winter the plants are provided with full-grown leaves and sprouts. In February 1954 the leaves were killed by frost, but most plants recovered. In March to April a large amount of new leaves are developed. The plants spread by rhizomes; roots were found to a depth of $35 \mathrm{~cm}$. Seedlings are extremely rare on the fixed sand dunes. On the moving sand dunes propagation by buried spikes is very effective, and takes place in the same way and at the same time of the year as in Corynephorus.

Carex arenaria was, strange enough, found to be very rare on the inland dunes of the central Veluwe. As it is abundant in the older dunes along the coast of the North Sea, even in those with the poorest soil, its rarity in the Veluvian inland dunes must be caused at least partly by climatic differences. This belief finds support in the fact that Carex arenaria was found to be abundant in the fixed inland dunes that are nearest to the IJsselmeer. The influence exercised by this large sheet of water on air temperature and humidity could be measured (cf. Chapter III).

Böcher regards Carex arenaria as a sub-oceanic species. HÅRD (1935) calls it eu-oceanic. It is frequent and abundant in most of the inland dune communities in the Brecklands (N.E. of Cambridge), but in the poorer ones, which are very similar to those of the Central Veluwe, it is rare (cf. FARRow, 1925; WATT, 1940). It is rather frequent in the Corynephoretum canescentis typicum, in the Corynephoretum agrostidetosum caninae and in the Callunetum genistetum empetrosum on fixed inland dunes of N.W. Germany (cf. Tüxen). As far as the author knows it is rare on the inland dunes in the southern and northern Netherlands.

One might be inclined to think that sensitivity to night frosts might restrict Carex arenaria to the vicinity of seas or of large lakes. This supposition, however, was disproved by a study of the conditions under which this species occurs on the inland dunes of the Central Veluwe. Places where Carex arenaria occurs abundantly, always proved to be exposed by night to a stream of cold air. A typical example of this was a sand dune surrounded by heather but separated from the latter by a deeply blown-out gully. In the latter Carex arenaria proved to be abundant. Night temperatures near the soil were lower $\left(1^{\circ} \mathrm{C}\right)$ than those in the flat heather area and much lower than those in the central part of the sand dune area. Another example is provided by a wide heather-clad valley which begins in the high, preglacial hills 
near Hoog-Buurlo and which ends in a flat sand area, viz. the "Harskamper Zand". By night a stream of cold air runs down the valley, and ends in the "Harskamper Zand". In this valley Carex arenaria is abundant and remains so to about $300 \mathrm{~m}$ beyond the end of the valley. In the rest of the area it is rare. Hence, one might explain the distribution of Carex arenaria in this area by supopsing that high heat sums are unfavourable to its development. There is another observation which points in the same direction. In the "Harderwijker Zand" Carex arenaria becomes the rarer, the larger the distance from the IJsselmeer. Here it retreats to the east side of solitary Scotch pines where it is sheltered against the late afternoon and evening sun. The other explanation for the preference shown by Carex arenaria for these habitats, may be that the radiation fog which enters the outskirts of the dune area, is favourable to its development.

Empetrum nigrum. Circumpolar, north to $77^{\circ}$; southern limit on the Veluwe. Oceanic in the southern part of the area (Böcher). Flowers from March to April. Shoots start their growth late in May (observations made in 1954-1955), but on north slopes somewhat earlier than on flat ground, Empetrum grows best on north slopes of resting inland dunes, especially where the latter are covered with Pinus silvestris. The southern boundary is sharp, regardless of the fact that north and south of this line no constant differences in the edaphic and climatic factors could be detected. Seedlings were not found, and plants of a few years old are extremely rare. According to Kinzel germination is often a matter of years.

Festuca rubra var. arenaria. Central European with a tendency to spread in a northern direction; of wide distribution. Resembles Ammophila arenaria in its growth form. The leaves have the same structure as those of Ammophila, but they are much narrower. Propagation by buried spikes in autumn in the same way as with Corynephorus.

This grass has thin rhizomes, which are usually found $10-20 \mathrm{~cm}$ below the surface. The fine roots were found down to a depth of $50 \mathrm{~cm}$.

Spergula vernalis. A species with a more or less oceanic distribution.

Spergula vernalis is a typical winter therophyte. It germinates in autumn. Some plants form flower buds already in autumn, but most of them do this in spring. Occasionally (in 1954) some plants were found that flowered cleistogamously and even formed ripe seeds in December, but, as a rule, flowering starts in the second half of March or in the beginning of April, dependent on the end of the winter weather. By the end of April most of the plants have spread their seeds, and are dying, but some persist till June or July. The seeds remain dormant during the whole summer, and can be found on the surface of the soil. In its typical habitat the first seedlings usally were found at the beginning of October, but several weeks earlier they were seen already on ploughed strips which traversed the heath. After the very wet summer of 1954 seedlings were found by the middle of August in the ploughed strips and by the beginning of September in their typical habitat. As a rule, frost does not affect the plants, but in 
February 1954 all green parts were killed; most of the plants, however, recovered from buds.

The root system of the largest plants could not be traced deeper than $15-20 \mathrm{~cm}$, and its horizontal extension is not very large either.

\section{CHAPTER IV}

\section{MICROCLIMATOLOGIGAL MEASUREMENTS}

a. VARIATION WIDTH OF THE TEMPERATURE IN THE HEATH SOIL

A good impression of the thermic properties shown by the heath soil may be obtained from the graphs of Fig. 4; these graphs show the changes which the temperature of the soil undergoes during a bright 24-hour period at the end of April. Measurements were taken in the soil of an old heath with a peaty $\mathrm{ca} 4 \mathrm{~cm}$ thick layer of raw humus. The vegetation was a closed $50 \mathrm{~cm}$ high Callunetum with but a thin layer of moss.
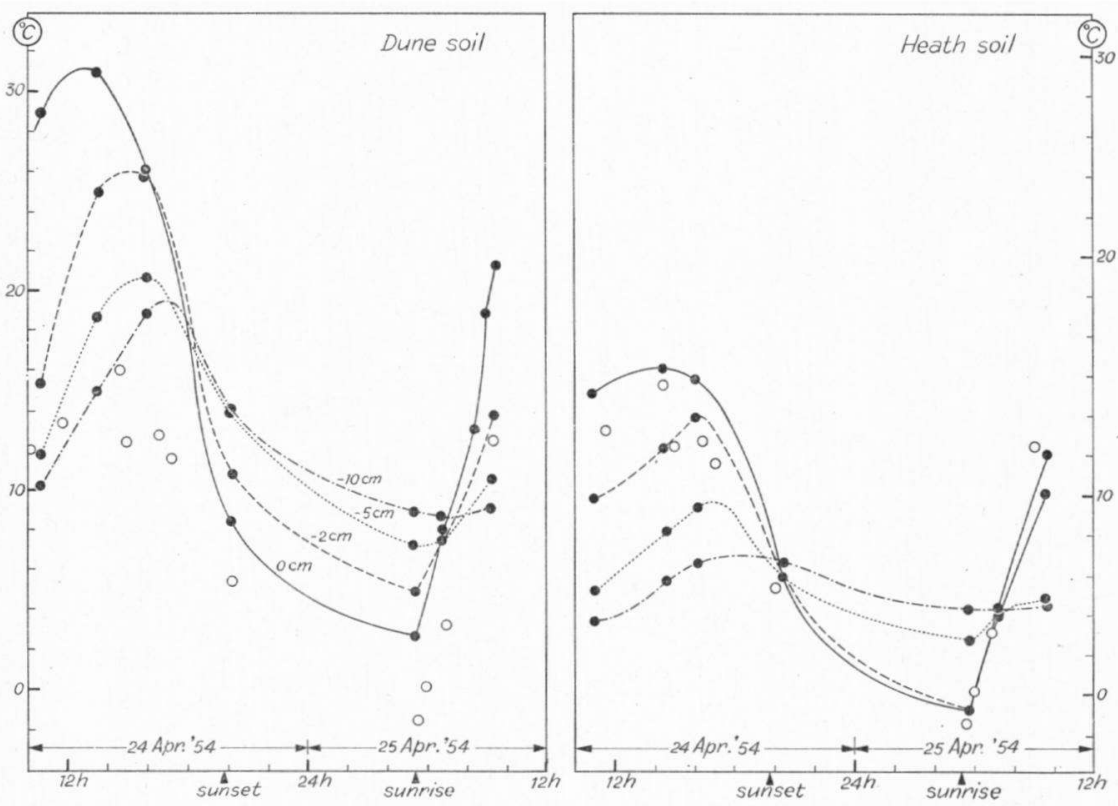

Fig. 4. Soil temperatures in inland dune soil and heath soil during a bright 24-hours period. Open circles: air temperature at $2 \mathrm{~m}$ height.

The surface temperature hardly ever exceeds the temperature of the air, as most radiation is intercepted by the dense vegetation. Down to a depth of $2 \mathrm{~cm}$ the amplitude of the fluctuations shown by the temperature decreases very little, but from 2 to $5 \mathrm{~cm}$ it decreases strongly. That the amplitude at first decreases but slightly must be due to the fact that the upper $2 \mathrm{~cm}$ of the soil are dried out, and 
PH. STOUTJESDIJK

have but a low heat capacity. This means that only a small amount of heat has to be absorbed in order to increase the temperature of this layer to a marked extent. At $10 \mathrm{~cm}$ depth the variation in the daily temperature is reduced to $3^{\circ} \mathrm{C}$, even under conditions of which one may assume that they cause the greatest possible variation. In Fig. 5 the temperatures of the heath soil are set out as a function of the depth for 16.00 o'clock in the afternoon and also for 5.45 o'clock the following morning, i.e. at sunrise. These curves visualize the way in which the temperature changes with increasing depth at two different times of the day, and the difference in temperature at the various levels between the two times. By multiplying the surface between the curves expressed as ${ }^{\circ}$ C.cm, with the specific heat of the soil by volume, we obtain the amount of heat lost per $\mathrm{cm}^{2}$ by the upper $10 \mathrm{~cm}$ of the soil between 16.00 in the afternoon and 5.45 . The same amount of heat must be reabsorbed in the course of the

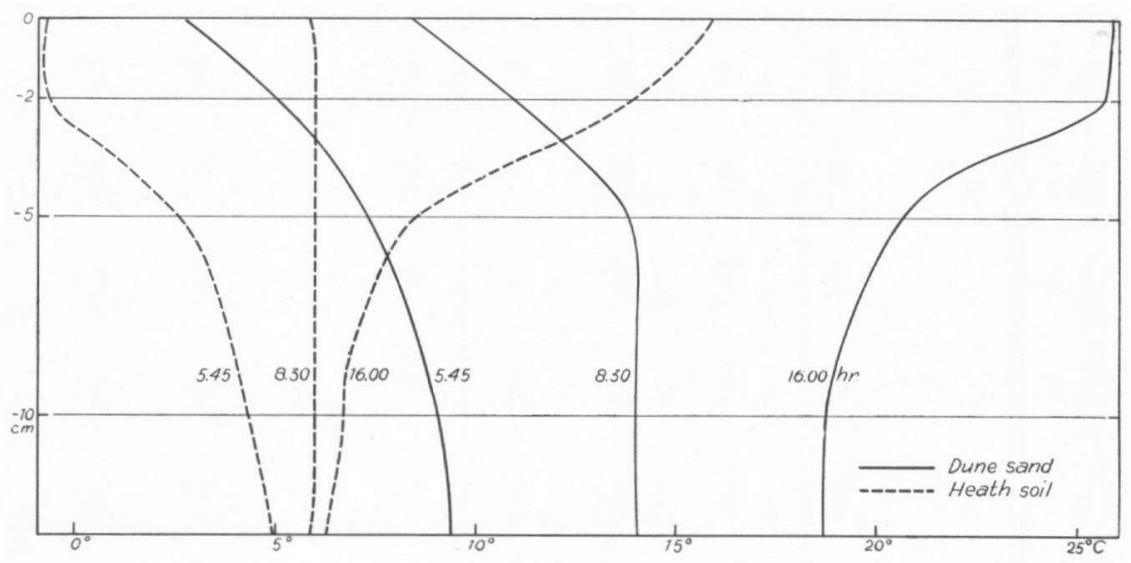

Fig. 5. Temperature as a function of depth in the sand of inland dunes and in a heath soil at three different times of day (April 24, $16.00 \mathrm{hr}$.; $20.30 \mathrm{hr}$.; April 25, 5.45 hr.)

next day, as the changes in the mean daily temperatures are but small. The top two $\mathrm{cm}$ of raw humus are dry and loose, and have the heat capacity of dry peat, viz. $0.1 \mathrm{cal} . / \mathrm{cc}$ or less. The next layer of humid raw humus, which contains at most $20 \%$ water (by volume) has a heat capacity of $0.3 \mathrm{cal} . / \mathrm{cc}$ or less. The sand below it contains $10 \%$ humus, $1.0 \mathrm{~g} \mathrm{SiO}_{2}$ and $0.2 \mathrm{~g}$ water per cc. From these data a heat capacity of 0.44 cal./cc was calculated. By calculating the change in heat content for the different layers separately, we obtain for the upper $10 \mathrm{~cm}$ a total change of 20 cal. between 16.00 and 5.45 the next day. Judging from the rapid decrease which the variation in temperature shows with depth, it is improbable that the total variation of the heat content of the soil can be more than 35 cal.

The values given above can best be appreciated when they are compared with those obtained for other soils. In the first place, Fig. 5 
shows the enormous differences with the sandy soil which below will be discussed more fully. Secondly, the temperatures may be compared with those measured at the Meteorological Station at De Bilt. There the soil consists of a mixture of sand, clay and peat, and is covered with the ordinary short turf (BRAAK, 1943). Readings are taken here three times daily at depths of $3 \mathrm{~cm}, 10 \mathrm{~cm}$, and deeper. In Table 9 temperatures of the soil at De Bilt are compared with temperatures of the heath soil. Judging from the periodic observations the daily

TABLE 9

Soil temperatures at $10 \mathrm{~cm}$ depth in different types of soil.

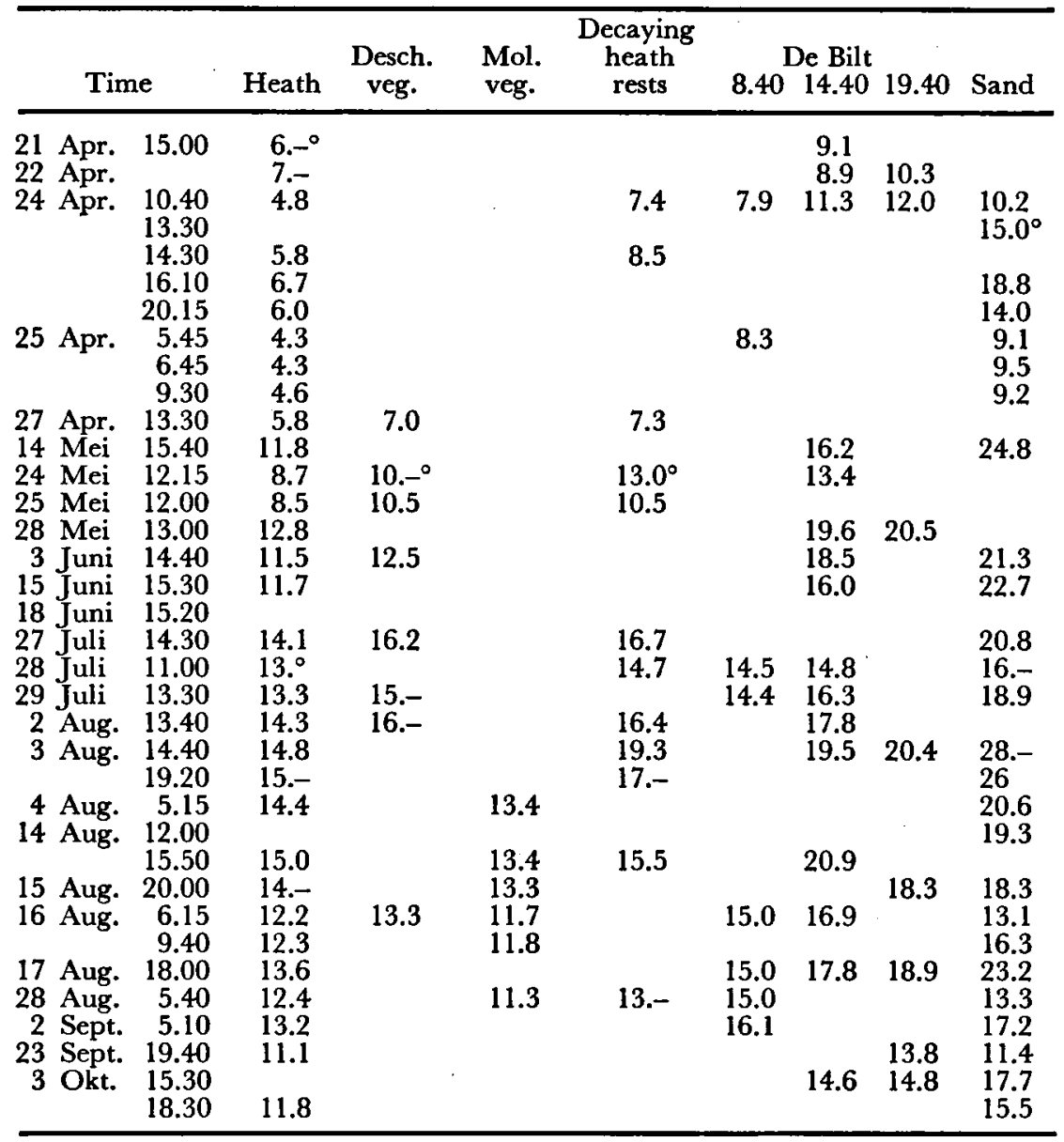

variation in temperature must be considerably higher in the soil at De Bilt than it is in the heath soil. The temperature maxima and the variation width of the temperature measured in the soil at De Bilt are somewhat lower than those found in the soil of clayey pastures 
at Wageningen (Braak 1.c.). The observations made at De Bilt do not permit a calculation of the daily width of variation that is shown here by the heat content of the soil, but it probably is much higher than that calculated for the heath soil. The variation between the periodic observations is larger than the 24-hour variation at corresponding levels in the heath soil. It is not to be expected that the heat capacity of the soil at De Bilt is lower than that of the heath soil; thus the fluctuation of the heat content must be greater in the former soil. Data on the width of variation shown by the heat content of different soil types are given by Homèn (1897). From the data of Homèn it may be concluded that the fluctuation of the heat content of 35 cal. is very low under the relevant conditions; it is of the same order of magnitude as the daily variation found in peat soil. Kreutz has taken measurements in the peat of a raised bog; here too the daily variation found for the soil temperature at $10 \mathrm{~cm}$ depth was comparable with that measured in heath soil.

Table 9 compares heath-soil temperatures at $10 \mathrm{~cm}$ depth with emperatures of the soil recorded at De Bilt. The low temperatures of the heath soil persist throughout the spring and summer months, as can be seen in the table. At $10 \mathrm{~cm}$ depth the temperature rarely exceeds $15^{\circ} \mathrm{C}$, even during or after periods with maximum air temperatures between $25^{\circ} \mathrm{C}$ and $30^{\circ} \mathrm{C}$. Soil temperatures in 1955 did not differ considerably from those in 1954.

All the observed properties of the heath soil, viz. low temperatures in spring and summer, a strong decrease of temperature variation with increasing depth, small changes of heat content of the soil, are typical for a soil of low thermal conductivity. Soils of low thermal conductivity remain relatively warm when the air temperature decreases. Thus in winter, frost will enter the heath soil less deep than it will do a soil with better conductivity. Of course, the water content too plays an important rôle. After severe winters during which, moreover, the heath was not covered with snow, the soil of the latter remains frozen during a longer time than other soils, but in moderately cold winters (1955) the frost penetrates in the heath soil but rarely below the moss and litter layer.

In Fig. $6 a$ temperatures of the soil under a heather vegetation are compared with those under a Deschampsia flexuosa one. The temperature curve of the Deschampsia soil has the same trend as that of a Calluna soil, but the temperatures appear to be somewhat higher than could be expected from the structure of the vegetation.

Fig. $6 b$ shows the temperatures of a soil under Molinia and of soil under heather at sunset as well as just after sunrise on the following day. It shows somewhat lower temperatures for the soil under Molinia; other temperature records obtained during the summer confirm the existence of this difference.

The soil under decaying material respectively in Calluna, Deschampsia, Molinia and Festuca vegetations shows a temperature curve which differs considerably from that under a vigorous heather vegetation. Fig. $6 a$ shows that the differences are highest in the surface layer, and 
even though they decrease rapidly with depth, at $10 \mathrm{~cm}$ depth the temperatures are still up to $5^{\circ} \mathrm{C}$ higher than they are in soil under a healthy Calluna vegetation. Just below the surface the temperatures may be very high. In a patch covered with Campylopus flexuosus once a "surface" temperature of $52^{\circ} \mathrm{C}$ was measured. At the south side of a decaying Molinia tussock a temperature of $64^{\circ} \mathrm{C}$ was recorded.
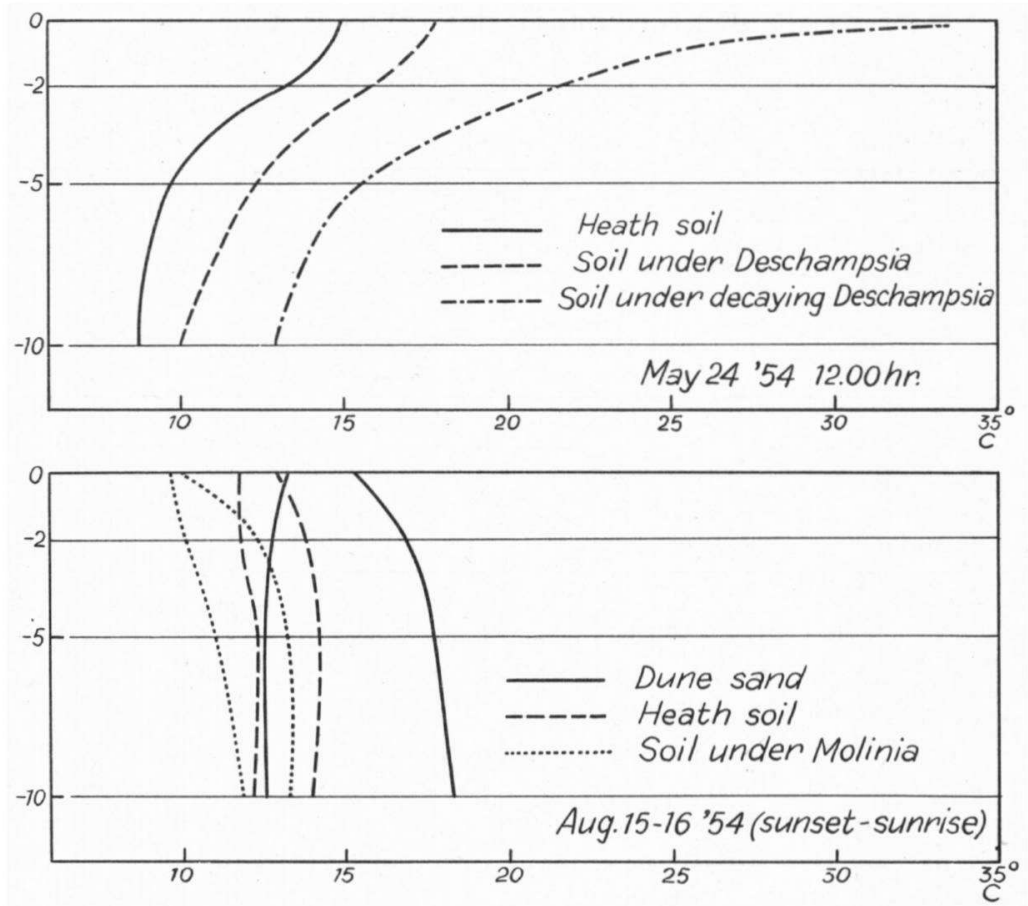

Fig. 6. a. Soil temperatures on a bright day. Air temp. $18.0^{\circ} \mathrm{C}$.

Fig. 6. $b$. Temperatures in three types of soil at sunset and at the end of the night. Air temp. $13^{\circ} \mathrm{C}$ resp. $8^{\circ} \mathrm{C}$.

Both values were obtained under almost ideal conditions, viz. in the middle of a day in the end of May in a sheltered situation. As the air temperature was only $21^{\circ} \mathrm{C}$, on hotter days in both localities higher temperatures may be expected. Further, temperatures measured by means of a mercury thermometer are no true surface temperatures, especially when the material under consideration has a low conductivity. VAartaja (1947) found that for humus the value found for the difference between surface temperature and air temperature by means of a mercury thermometer may be $30 \%$ too low.

b. Heath-soil temperatures in PaRts With DifFerent eXPOSITION

Table 10 shows the effect of different exposition on the temperatures measured in a soil covered by a heath vegetation on a bright summer day and on a day late in autumn. Differences between north and 
PH. STOUTJESDIJK

south slopes appear to be small in comparison with those measured in sand covered with a sparse vegetation. This could be expected, as but very little radiation is absorbed by the surface of the heath soil.

The differences in temperature are doubtless but partly due to the immediate effect of the different amounts of irradiation. On the north slope the isolation provided by a thicker moss layer and by a better developed layer of raw humus tend to keep the temperature of the soil lower, an effect that is not directly dependent upon an exposition effect.

TABLE 10

Effect of exposition on the temperature of heath soil on two bright days.

\begin{tabular}{cccc}
\hline \multicolumn{5}{c}{ June 16 th, $1955,18.00$} \\
\hline Depth & N. incl. 18 & Level & S. incl. $9^{\circ}$ \\
\hline$-2 \mathrm{~cm}$ & $12.9^{\circ} \mathrm{C}$ & $13.0^{\circ} \mathrm{C}$ & $14.2^{\circ} \mathrm{C}$ \\
$-5 \mathrm{~cm}$ & $11.0^{\circ} \mathrm{C}$ & $12.1^{\circ} \mathrm{C}$ & $12.9^{\circ} \mathrm{G}$ \\
$-10 \mathrm{~cm}$ & $10.5^{\circ} \mathrm{C}$ & $11.6^{\circ} \mathrm{C}$ & $12.9^{\circ} \mathrm{C}$ \\
\hline & November $15 \mathrm{th}, 1955,15.30$ & \\
\hline$-2 \mathrm{~cm}$ & $6.6^{\circ} \mathrm{C}$ & $6.2^{\circ} \mathrm{C}$ & $7.2^{\circ} \mathrm{C}$ \\
$-5 \mathrm{~cm}$ & $6.6^{\circ} \mathrm{C}$ & $6.6^{\circ} \mathrm{C}$ & $7.4^{\circ} \mathrm{C}$ \\
$-10 \mathrm{~cm}$ & $6.7^{\circ} \mathrm{C}$ & $6.8^{\circ} \mathrm{C}$ & $7.4^{\circ} \mathrm{C}$ \\
\hline
\end{tabular}

c. Nocturnal temperatures in aND above the heath Vegetation

The measurements of soil temperatures carried out in the heath soil, made it probable that the air temperatures in still, bright nights would be low. Soils in which the diurnal change in the heat content is low, are known to cause in bright, still nights a very strong decrease of the air temperature near the surface. On a bright night the surface of the soil and that of the vegetation lose heat by radiation. So long as the atmospheric conditions remain the same, the value of this radiation is determined only by the mean temperature of that part of the vegetation that is exposed to the sky, as a vegetation behaves in this respect as an almost perfectly black body (FALCKENBERG, 1928). This loss of heat cools the exposed surface below air temperature, with the result that in the immediate vicinity of the plants heat is extracted from the air, and in this way the temperature of the air layer near the surface becomes lower than that of the higher ones (temperature inversion). The temperature gradient indicates that heat must be transported in a downward direction. On the other hand the soil also gives up heat. When under the same conditions one soil gives up more heat than another one, above the latter more heat will be absorbed from the air. Thus it can be understood that on bright, still nights, the air temperatures above soils with a low conductivity may fall to low values. Raised bogs are notorious in this respect. Other examples are given by Geiger (l.c.).

From the curves given in Fig. 5 the change which the heat content of the upper $10 \mathrm{~cm}$ of the soil undergoes during the night, can be 

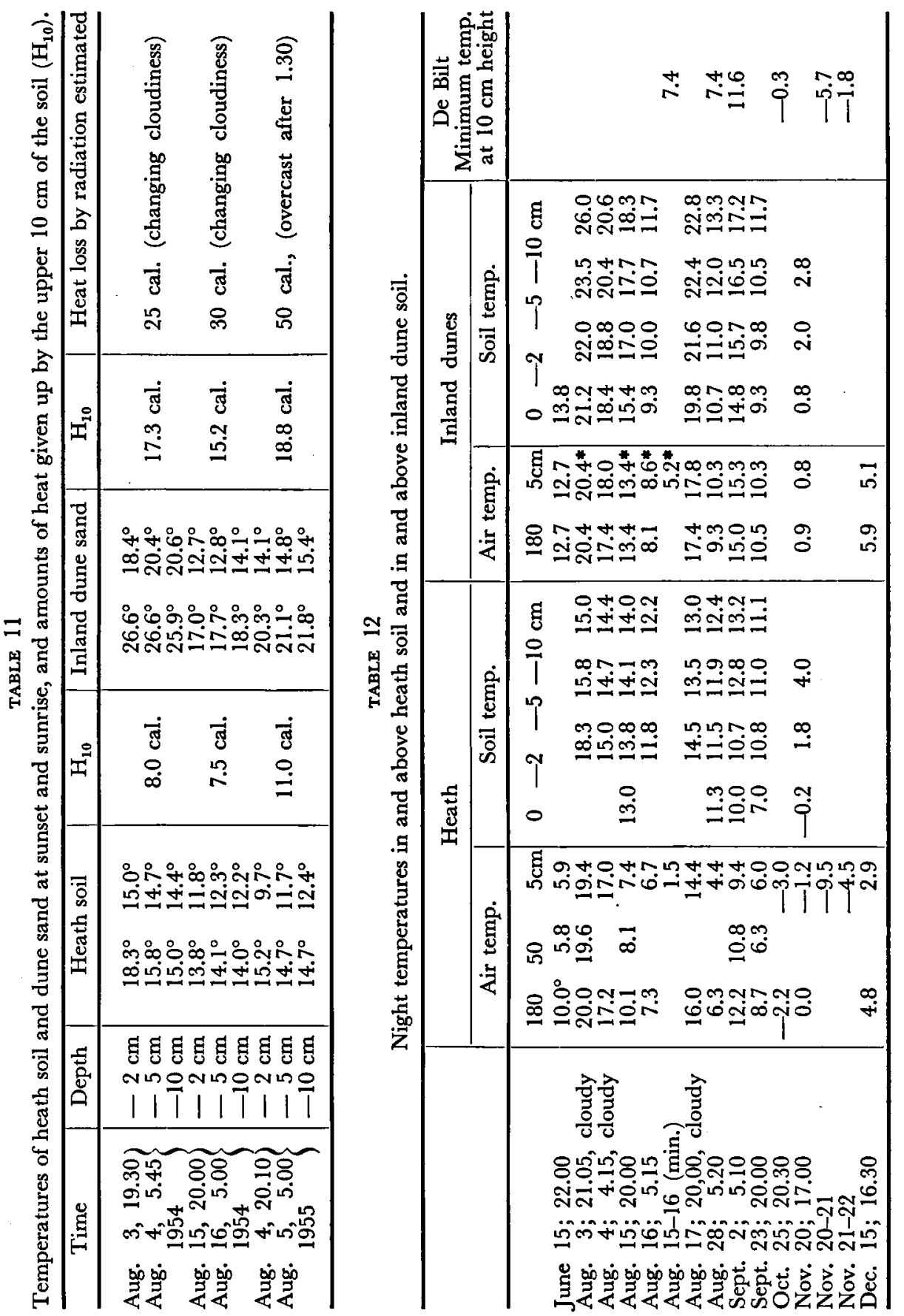
calculated, as has already been expounded. The approximate amount of heat lost by radiation can be obtained by means of a diagram which makes it possible to calculate nightly radiation when temperature and humidity of the air are known. (Geiger l.c.). We calculated for the night for which the fluctuations in the temperature of the soil are shown in the figures, a net total heat loss of $65 \mathrm{cal} . / \mathrm{cm}^{2}$. From these $65 \mathrm{cal}$. only $11.5 \mathrm{cal}$. came from the upper $10 \mathrm{~cm}$ of the soil. The total amount of heat given up by the soil is probably less than two times the amount derived from the upper $10 \mathrm{~cm}$, as the range of soil temperatures decreases rapidly with increasing depth. This means that the part the lower soil layers contribute to the total amount of heat given up, decreases rapidly. Thus we may conclude that about $1 / 3$ of the total loss of heat is restored by heat derived from the soil. A few other examples are given in Table 11 .

In the nights in which the measurements were taken, about the same part of the loss of heat will have been restored by heat derived from the soil. Therefore, about $2 / 3$ of the loss of heat must have been restored by heat absorbed from the air and by condensation heat set free by the formation of dew.

Measurements of air temperature above the heath were taken by means of a small aspirated psychrometer. Minimum temperatures were measured with a sheltered minimum thermometer.

In Tables 12 and 13 temperature measurements above the heath are compared with measurements above sand dunes in the vicinity and with measurements made at the meteorological station at De Bilt. The measurements above the heath were taken in flat parts, and not in depressions, to make sure that the effects measured were not due to differences in relief (frost pockets).

Measurements were taken on two sites, viz. the "Kootwijker Veld" and on the heath near Boeschoten. The "Kootwijker Veld" is an open heath area, weakly sloping to the west and slightly convex at the place where the measurements were taken. The heath near Boeschoten is a plain of $0.5 \times 1 \mathrm{~km}$; on three sides it is sheltered by pine woods. It lies at the foot of a gentle S-facing slope. The slope consists of sandy soil which has recently been planted with pine trees. On a few nights in which comparative measurements were taken, the minimum temperatures on this heath were about $1^{\circ} \mathrm{C}$ lower than those at the "Kootwijker Veld". The measurements at Boeschoten were made in spring and early summer 1955.

On bright, still nights the minimum air temperatures over the heath proved to be several degrees lower than those measured at comparable levels at De Bilt. The highest differences were measured in spring and summer. Of course our measurements are not numerous enough to conclude that there is a marked yearly variation in the differences. Yet the highest differences may be expected when the difference between the temperature of the heath soil and that of the air reaches its lowest value. At such times the air temperature at which the heat emission from the vegetation is balanced by the upward heat transport from the soil and the downward heat transport 
TABLE 13

Minimum air temperatures above heath as compared with those at De Bilt in still, bright nights.

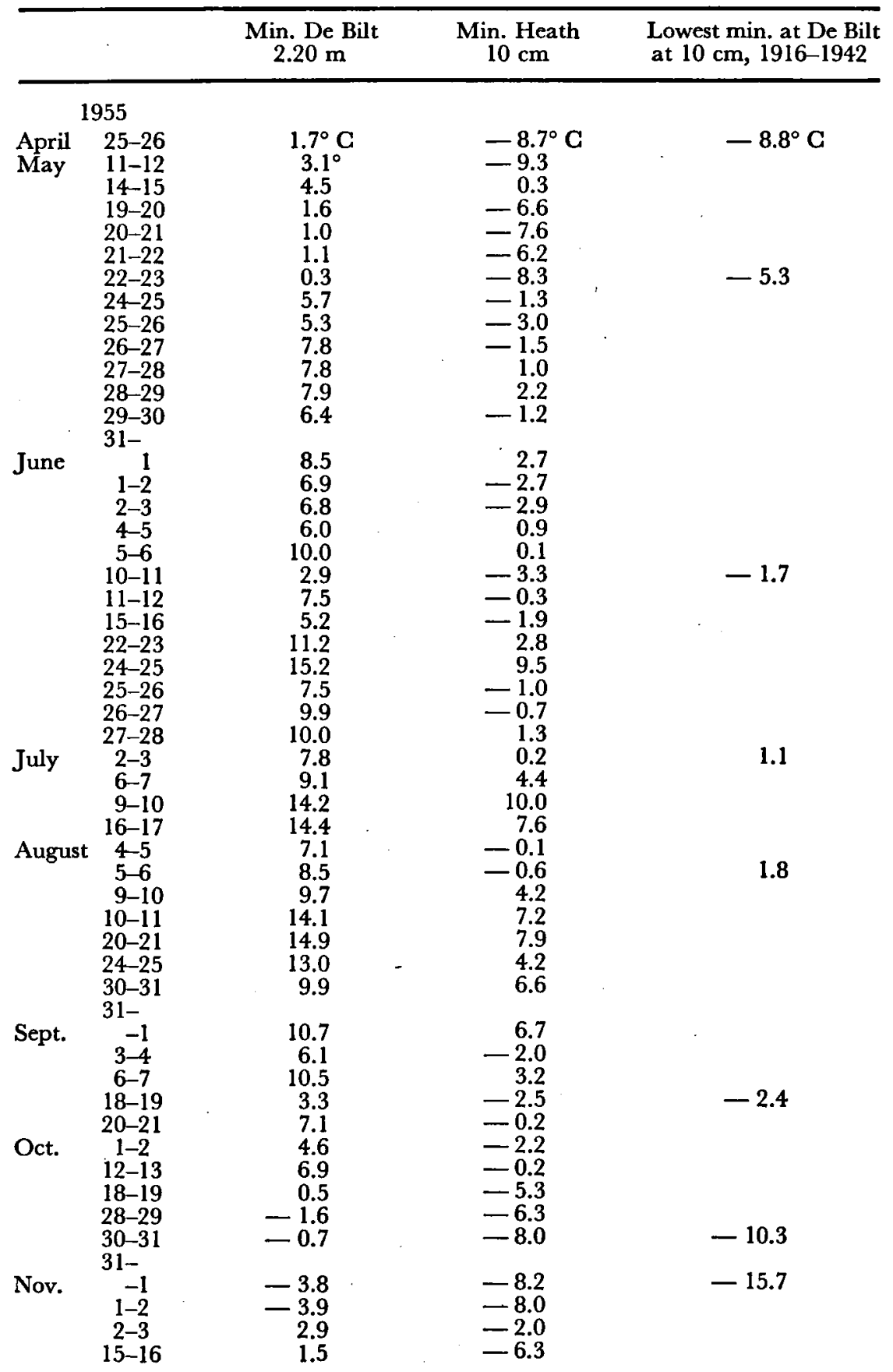


from the air above the vegetation, may be expected to reach its lowest value. Furthermore, in spring, which is usually dry, both conductivity and heat capacity of the heath soil will decrease, and this will cause a still larger decrease of the air temperature above this type of soil.

Temperatures above the heath were found to be up to $9^{\circ} \mathrm{C}$ lower than those at De Bilt. Until late in May 1955 minimum temperatures below $-8^{\circ} \mathrm{C}$ were observed. In 1955 temperatures below zero were measured even in August. These low temperatures can not have been due to local weather conditions as the meteorological station Deelen on the S.E. of the Veluwe measured temperatures that differed but slightly from those at De Bilt.

The low temperatures are entirely an effect of the substrate. Even with severe night frosts on the heath, sensitive crops in nearby gardens showed but rarely any damage. The differences between the heath and the inland dunes are discussed below.

Lower temperatures than were actually measured, may probably occur above the heath. This can be concluded from the fact that the nights during which the very low minima were measured, were not very cold ones; this follows from the regular measurements made at De Bilt and at other stations. These figures also show that the temperatures above the heath fall far below the lowest temperatures measured at De Bilt during the period 1916-1948 (BRAAK, 1949).

With still, bright weather there is, as could be expected, a rapid fall of the air temperature above the heath. One evening at $2 \mathrm{~m}$ height in 45 minutes a temperature drop of $5.5^{\circ} \mathrm{C}$ was observed. On the same evening the rate of fall at De Bilt was only $2^{\circ} \mathrm{C} / \mathrm{hr}$. Near the soil surface the fall in temperature is still more rapid. When the sky becomes overcast, the air temperatures rise as rapidly as they had fallen.

The radiating surface of the dense heath vegetation is formed by the top of the plants: the soil is sheltered by the vegetation from loss of heat by radiation. This means that the coldest part is formed by the tops of the heather plants. In spite of this, air temperatures between the tops of the heather plants were always found to be somewhat higher (about $1^{\circ} \mathrm{C}$ ) than those measured at $5 \mathrm{~cm}$ above the soil. This must be due to the circumstance that the cooled air sinks down and accumulates near the surface of the soil. Temperatures of the soil or of a moss surface were found to be considerably higher than those of the air above it.

For purposes of comparison the measurements of HeLms and JöRGENSEN (1924) are of interest. Helms \& Jörgensen determined the minimum temperatures on a raised bog just above the tops of the heather plants, and also at a height of $2 \mathrm{~m}$, and compared these minimum temperatures with those determined within a screen at the nearby $(5 \mathrm{~km})$ meteorological station at $1.3 \mathrm{~m}$ above a grass mat. The difference between the minimum temperatures at $2 \mathrm{~m}$ above the bog and those at the meteorological station (at $1.3 \mathrm{~m}$ ) was $4-6^{\circ} \mathrm{C}$, and rose occasionally to $8.4^{\circ} \mathrm{C}$. As the minimum temperatures in the bog 
were determined from readings with thermometers which were not sufficiently screened, they may be $1-2^{\circ} \mathrm{C}$ too low.

Differences between the minimum temperatures at $2 \mathrm{~m}$ and those at the level formed by the tops of the heather shrubs usually amounted to $4^{\circ} \mathrm{C}$.

It appears therefore that above a heath and above a raised bog much lower temperatures may be observed than are recorded under normal conditions at a meteorological observatory. In both cases the differences are of the same order of magnitude.

\section{d. Air temperatures in periods with strong insolation}

Measurements of air temperatures were taken with a small aspirated psychrometer. The consecutive measurements were ususally taken at a heights of $1.70 \mathrm{~m}$, at the level reached by the top of the heather shrubs, and at $5 \mathrm{~cm}$ height above the soil surface. The measurements were all taken in and above dense or very dense vegetations.

\section{Comparison of the air temperatures above the heath with those recorded at De Bilt}

The air temperature at the height of $1.70 \mathrm{~m}$ was originally not determined in order to compare it with that recorded at De Bilt, but to have a point of reference for the readings taken inside the vegetation. However, for all days on which these rather occasional readings were taken, the highest record was subsequently compared with the maximum recorded for that day at De Bilt. The days on which only in the early morning or in the late evening readings were taken, were not used for comparison with De Bilt. One should take into consideration that for many days only a few readings were available, and that the latter often were not taken during the warmest part of the day. On the other hand, our readings were taken somewhat nearer to the soil, but this could hardly make a difference of more than a few tenths of degrees. Table 14 shows that only on two days the highest daily temperature measured over the heath was lower $\left(0.3^{\circ} \mathrm{C}\right.$ ) than the maximum temperature for that day taken by the aid of a Six thermometer at De Bilt. The mean difference is $+2.5^{\circ} \mathrm{C}$. This is a conservative estimate of the real difference. In August 1955 some further readings were taken by means of thermometers placed within small screens of white plastic. The screens were devised and tested at the Royal Meteorological Institute at De Bilt. The air temperature can be measured in these screens with a smaller error than within the ordinary Stevenson screen (KRAMER e.a., 1945). These measurements confirmed the conclusions arrived at above. For 17 days, viz. between August 4 and September 5, 1955, a maximum temperature was recorded above the heath that was $0.6-3.4^{\circ} \mathrm{C}$ (mean $2.0^{\circ} \mathrm{C}$ ) higher than that recorded on the same day at De Bilt. The mean difference between Deelen at the S.E. point of the Veluwe and De Bilt was only $0.3^{\circ} \mathrm{C}$, which shows that the difference can not be due to a general increase of temperature in the direction from west to east. A comparison of the thermograph registrations made at De 
TABLE 14

Differences between the highest air temperatures at a height of $1.70 \mathrm{~m}$ above the heath and the maximum at Ermelo and the daily maxima determined at De Bilt, and differences between the vapour pressures (in millibars) above heath and at De Bilt (determined at $14.40 \mathrm{hr}$ ).

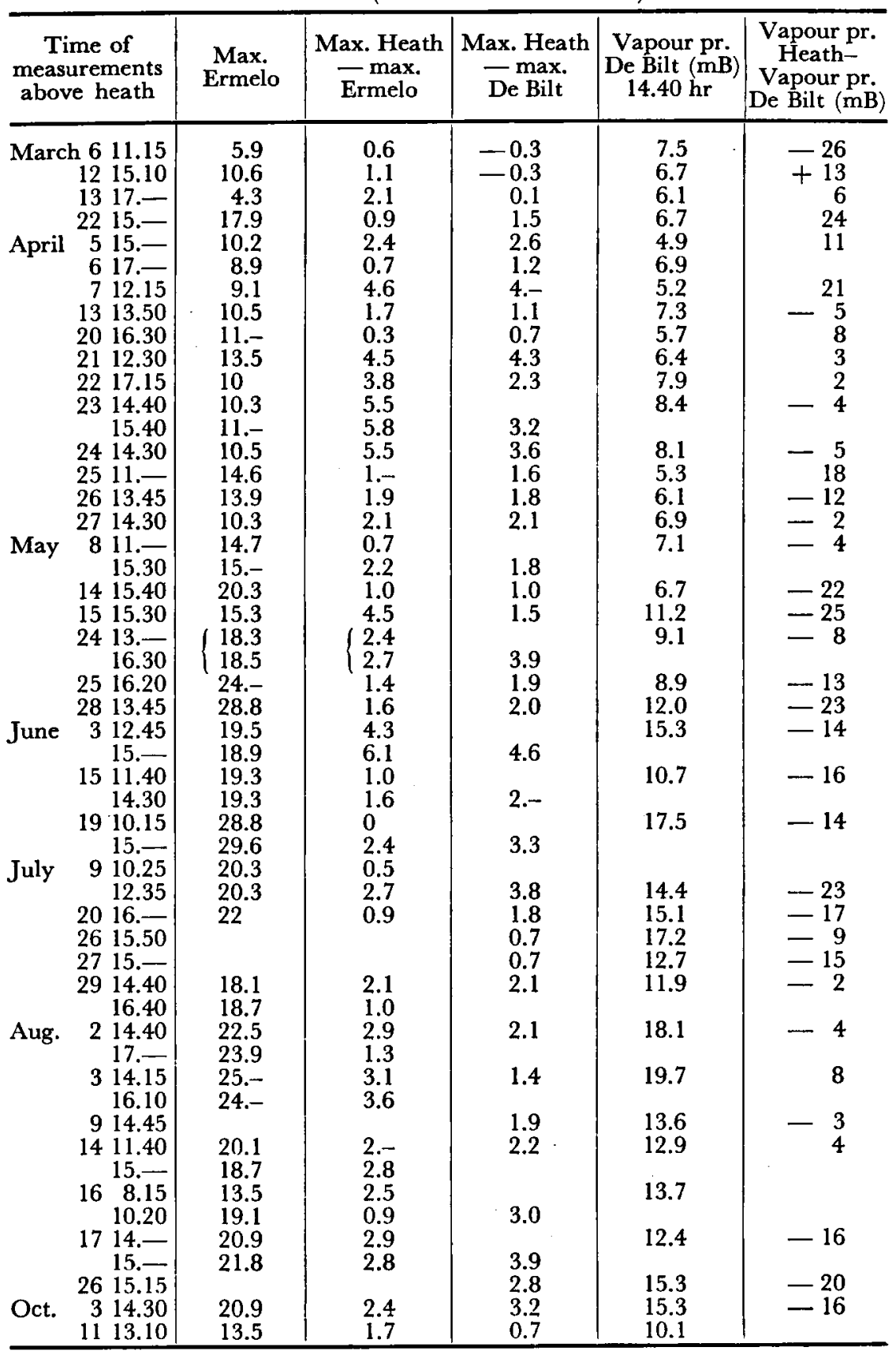


Bilt with temperature readings taken above the heath, shows that the differences which are present in the morning hours, are usually higher than the differences in the maximum temperatures.

\section{Air temperatures within the vegetations}

DeLANY (1953) made temperature measurements within a Calluna vegetation, up to a height of $20 \mathrm{~cm}$, but usually lower. The measurements were made with an unsheltered thermistor, and this means that the effect of radiation was not excluded. The most frequently

observed situation was that the temperature between the vegetation tops was higher (up to $4^{\circ} \mathrm{C}$ ) than that measured at $0.5 \mathrm{~cm}$ above the soil surface, but this difference must partly be due to the use of an unsheltered thermometer.

Fig. 10 gives an impression of the situation inside the vegetation and at the level of the tops of the plants on a cloudless summer day. Each dot represents the mean value of a series of measurements. At a height of $50 \mathrm{~cm}$ the air temperature is nearly $2^{\circ} \mathrm{C}$ higher than at a height of $1.80 \mathrm{~m}$. At a height of $5 \mathrm{~cm}$ the air temperature is $3.4^{\circ} \mathrm{C}$ lower than it is between the heather tops. This type of temperature distribution is found only in a very dense heather vegetation with a wet moss-layer underneath. Apparently the temperature difference can be maintained because the amount of radiation which reaches the soil or the moss layer, is but small, and because the moss surface is damp and absorbs heat in order to replace the heat that is lost by evaporation.

Differences with $1.80 \mathrm{~m}$ height (+ means a value in excess of that measured $1.80 \mathrm{~m}$ )

\begin{tabular}{cccc}
\hline \multicolumn{2}{c}{ Heather tops } & \multicolumn{2}{c}{ Inside the vegetation at $5 \mathrm{~cm}$ height } \\
Temp. & Humidity & Temp. & Humidity \\
\hline$+0.9^{\circ} \mathrm{C}$ & 0.9 & $0.0^{\circ} \mathrm{C}$ & 3.2 \\
$\left(-0.4^{\circ}-3.4^{\circ}\right)$ & $(0.0-2.5) \mathrm{mm}$ & $\left(-2.4^{\circ}-3.5^{\circ}\right)$ & $(1.2-6.6 \mathrm{~mm})$
\end{tabular}

The numbers between brackets are extreme values.

A mean temperature curve for the air above a heath provided with a dry moss layer, is given in Fig. $9 a$.

From readings taken on 13 days, viz. during the period between May the 24th and August the 30th, 1954 between $10.00 \mathrm{hr}$ and $16.00 \mathrm{hr}$, the following mean results were obtained.

When air temperatures in and above the heath are compared with soil temperatures, we see the same large differences as are observed in a bright night, but now they point in the opposite direction (Fig. 10).

Some measurements could be made with a more reliable thermoelectric method. Details of the method will be given in a later paper. Most of the measurements are summarized in Fig. 7, where mean values of 10-20 single readings are plotted. A series of readings took 1-2 minutes. Measurements were taken in a heather vegetation of $50 \mathrm{~cm}$ height and of medium density $(70 \%)$. At the site of the measurements, which was somewhat sheltered, a wind force 2 (scale of Beaufort) was observed. 
When there was a sunny spell, during the first hours of the measurements (cloudiness $4 / 8-5 / 8$ ) the mean air temperatures inside the vegetation rose $6^{\circ} \mathrm{C}$ above the air temperature at $2 \mathrm{~m}$ height. At the level of the heather tops the mean temperatures were somewhat lower, but the temperature peaks were somewhat higher here than those measured between the plants. Temperatures about $8^{\circ} \mathrm{G}$ above the air temperature at $2 \mathrm{~m}$ height were reached. Fig. 7 also shows that
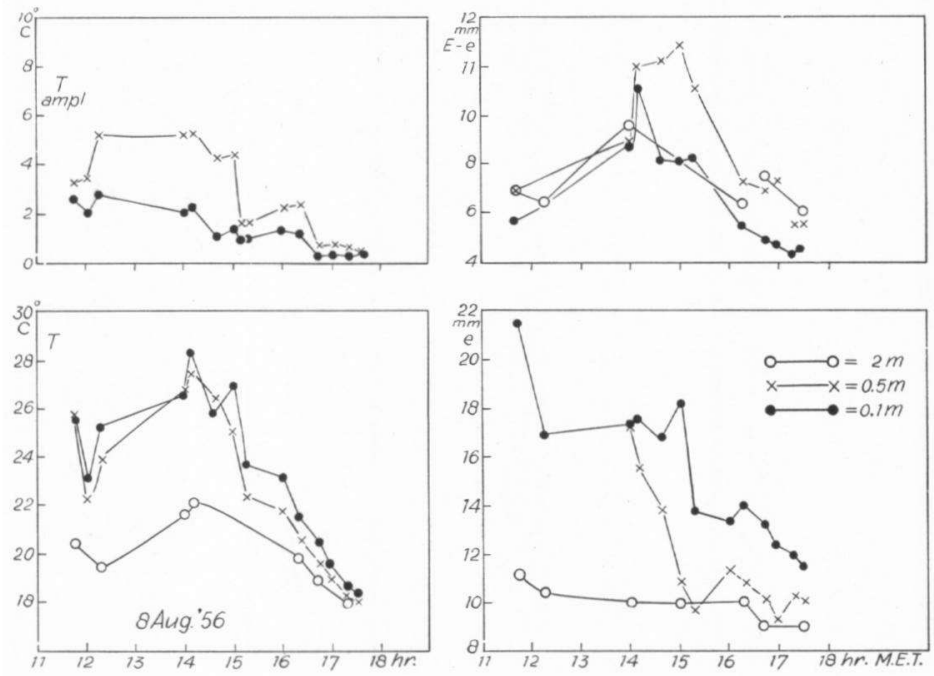

Fig. 7. Temperature ( $T$ ), temperature variation during a short (1-2 min.) series of measurement ( $T$ ampl.), vapour pressure (e) and vapour pressure deficit (E-e) in and above an open heath vegetation.

temperature fluctuations at $40 \mathrm{~cm}$ height are much stronger than at a height of $5 \mathrm{~cm}$. Temperature changes amounting to $2^{\circ}-3^{\circ} \mathrm{C}$ within 5 seconds, were observed. Later in the afternoon cloudiness increases to $7 / 8$ (at $16.00 \mathrm{hr}$ ) and the differences become smaller, but qualitatively the situation remains unchanged.

The observations can be understood as follows. At the level of the heather tops the major part of the sun's energy is absorbed and transformed into heat, but the latter is rapidly carried away by turbulent air movements. Inside the vegetation the movement of the air is strongly reduced, and this explains why the highest mean of the air temperatures is found here, in spite of the fact that the major part of the energy is absorbed at the level of the vegetations tops. The narrower range of the fluctuations can be explained as well by the reduced movement of the air.

The high air temperatures inside the vegetation recorded here are in strong contrast with those measured before with other methods. This must be due to the fact that the latter measurements were taken in a dense heath vegetation where only $1 \%$ of the sun's radiation reached the surface of the soil. 
e. THE EFFECT OF THE RELIEF ON NIGHT TEMPERATURES MEASURED ABOVE THE HEATH

The position of a point on the surface above or below its immediate surroundings, is known to have a considerable effect on the air temperature prevailing on a bright, still night.

Minimum air temperatures were determined at a height of $10 \mathrm{~cm}$ above the surface of a gently undulating plain, and these were compared with temperatures taken at the bottom of a depression in this plain. The depression went down to about $3 \mathrm{~m}$ below the level of the rest of the area, and it was approximately $50 \mathrm{~m}$ wide and several hundred meters long. The slopes were rather steep. The differences in the minimum air temperatures above the plain and in the depression ranged from $0.2^{\circ}$ to $1.8^{\circ} \mathrm{C}$ (mean $0.7^{\circ} \mathrm{C}$ ) in 9 still, bright nights. Measurements made in similar situations elsewhere gave the same results. The differences between the minimum temperatures at a height of $1.70 \mathrm{~m}$ were usually somewhat higher, viz. up to $2.2^{\circ} \mathrm{C}$.

Minimum temperatures measured on elevations of various height were also compared with those measured on the flat part of the heath. The minimum temperatures on an elevation reaching a height of approximately $3 \mathrm{~m}$ above the flat part of the heath and provided with rather steep slopes are given in Table 15.

TABLE 15

The influence of a low hill on the minimum temperature.

\begin{tabular}{|c|c|c|c|}
\hline & & Level heath & Hill \\
\hline $\begin{array}{lll}\text { May } 19-20 & 1955 . \\
\text { May } 20-21 & 1955 \\
\text { May } 21-22 & 1955 \\
\text { May } 22-23 & 1955 . \\
\text { May } 25-26 & 1955 .\end{array}$ & $\begin{array}{l}\dot{ } \\
\dot{.} \\
\dot{ }\end{array}$ & $\begin{array}{r}0.4^{\circ} \mathrm{C} \\
-7.6^{\circ} \mathrm{C} \\
-6.2^{\circ} \mathrm{C} \\
-8.3^{\circ} \mathrm{C} \\
-1.3^{\circ} \mathrm{C}\end{array}$ & $\begin{array}{r}2.2^{\circ} \mathrm{C} \\
-4.0^{\circ} \mathrm{C} \\
-2.0^{\circ} \mathrm{C} \\
-5.3^{\circ} \mathrm{C} \\
0.5^{\circ} \mathrm{C}\end{array}$ \\
\hline
\end{tabular}

The measurements were taken on bright nights and the mean difference amounted to $4.2^{\circ} \mathrm{C}$.

The effect of a high hill ( $30 \mathrm{~m}$ high) is illustrated by observations made on the night of 19-20 May and on the night of 5-6 August 1955. Here the minimum temperatures at the top of a high, gently sloping hill are compared with the minimum temperatures recorded at the station Boeschoten at 1.5 mile distance. The differences were $5.1^{\circ} \mathrm{C}$ and $6.5^{\circ} \mathrm{C}$ respectively.

It appears therefore that the effect of cold air that stagnates in depressions, is at least in this instance smaller than the opposite effect of cold air that is drained off from elevations.

Geiger (l.c.) gives many examples of the effect on the night temperature caused by differences in relief.

Kreutz found on a reclaimed raised bog that differences of a few $\mathrm{dm}$ in elevation were sufficient to cause differences in minimum air temperature (at $10 \mathrm{~cm}$ ) of $3^{\circ} \mathrm{C}$.

PINKHOF (1938) compared nocturnal air temperatures measured at a height of $50 \mathrm{~cm}$ at the foot of a hill and $15 \mathrm{~m}$ higher on the slope. 
Differences in minimum temperature of up to $5^{\circ} \mathrm{C}$ were observed, and when temperatures measured at the beginning of the night were compared, even differences of up to $12^{\circ} \mathrm{C}$ were noted.

VAN Dieren (1934) compared minimum temperatures in a dune valley with those on a dune top.

However, in all these cases, what these authors studied, was the temperature difference between a "frost pocket" and a point from where cold air easily drains away, not between a "frost pocket" and the surrounding flat ground. This is easily conceivable, as in hilly country or on mountains, as a rule, only these two possibilities are present. Further, no attention was paid to the great influence that the thermic properties of the soil may have on the air temperatures.

In the lower parts of the area there is usually a stronger accumulation of dead organic material on the surface of the soil. It is not impossible that this may be responsible for the differences observed in the minimum air temperatures above depressions and elevations.

\section{f. Humidity Within the heath Vegetation}

Humidity measurements in heath and similar vegetations are scarce. STocker (1923) has collected some data with regard to the relative humidity found in heath vegetations, and concluded that the relative humidity in the latter is not higher than that in the air, except where the heath is sheltered by a wood.

In that case the relative humidity in the vegetation exceed that in the free air by about $10 \%$. As the concomitant temperatures are not recorded, his results are difficult to interpret.

Delany (l.c.) measured the relative humidity in a low heath with the help of cobalt thiocyanate paper. Relative humidity tended to be highest and most equable in the lower part of the vegetation. The measurements have the same drawback as those of Stocker, viz. that no air temperatures have been recorded.

Sample measurements were taken under different circumstances. First, measurement were taken after a prolonged dry period during which moss and litter and even the top layers of the raw humus had dried out. The readings showed that under these circumstances there was little or no difference between the vapour pressure in the vegetation and that in the free air. It is quite understandable that in this case but little water vapour was produced by the moss or litter layer. The heath vegetation has but a low transpiration, and the vapour produced by the upper stratum of the vegetation is easily carried away. In wetter periods the vapour pressure at a height of $5 \mathrm{~cm}$ above the soil surface is always considerably higher than that in free air. Vapour pressure at a height of $5 \mathrm{~cm}$ may even be $6 \mathrm{~mm}$ higher than that at $1.70 \mathrm{~m}$, while differences of $2-3 \mathrm{~mm}$ are of frequent occurrence, even after several days without rain. Vapour pressure between the tops of the heather plants is usually but slightly higher than that of the free air. However, differences of 0.5 to $1 \mathrm{~mm}$ were frequently observed. Differences between the air at a height of $5 \mathrm{~cm}$ and at one of $1.70 \mathrm{~m}$ become more obvious when vapour pressure 
deficits are compared. Vapour pressure deficits, i.e. the differences between the actual vapour pressure and the saturation pressure may differ more strongly than the vapour pressures themselves because the temperature within the vegetation may be somewhat lower than that of the free air (Fig. 8a). Vapour pressure deficits of the air between the
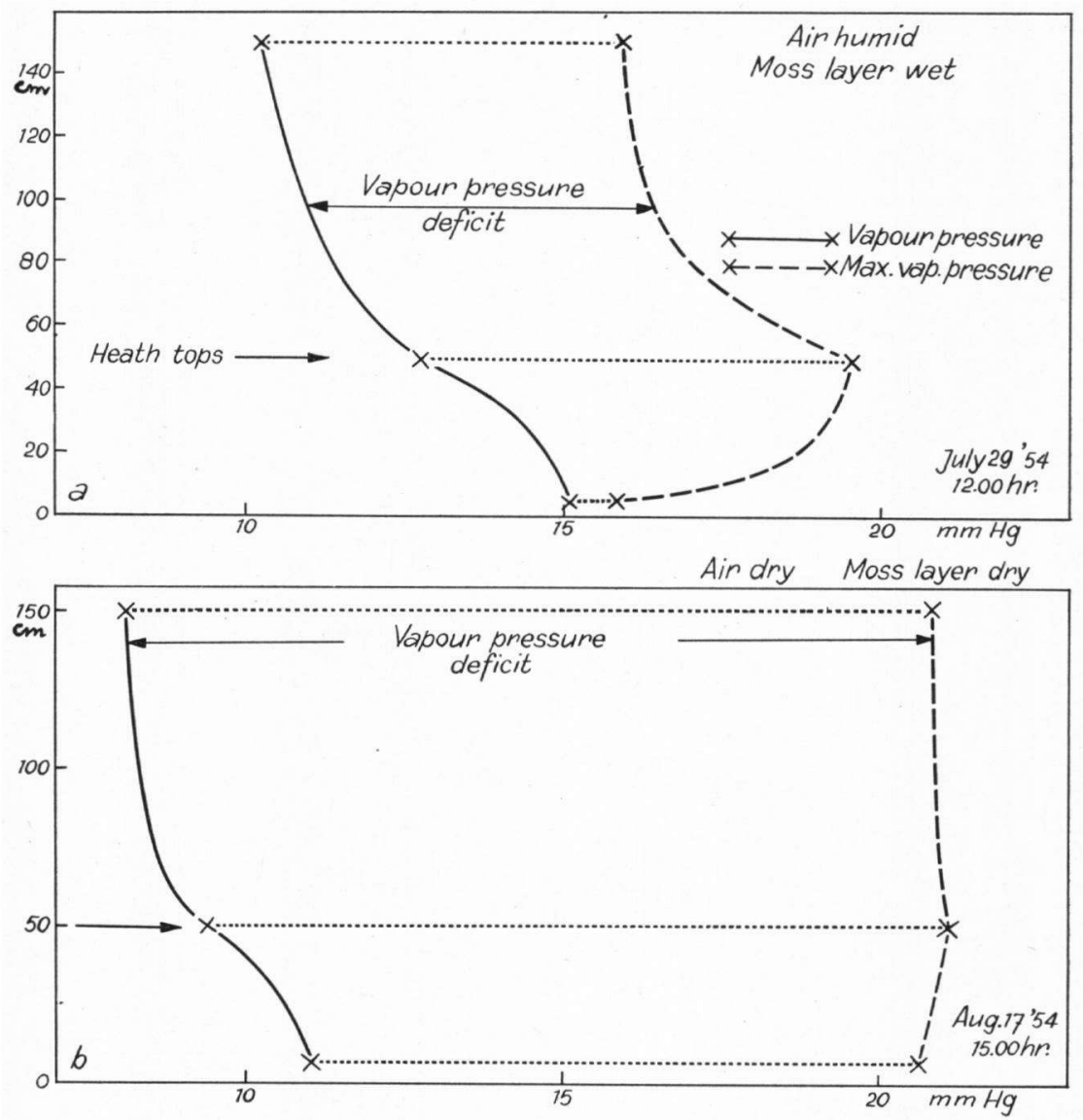

Fig. 8. Two extreme examples of humidity conditions in and above a heath vegetation.

lower parts of the heather plants, viz. at $5 \mathrm{~cm}$ height, may be as low as one-sixth of those measured in the free air.

It seems as if the difference in vapour pressure between the air at $0.05 \mathrm{~m}$ and at $1.70 \mathrm{~m}$ is but slightly influenced by the vapour pressure deficit. This means that when the air at $1.70 \mathrm{~m}$ has a high vapour pressure deficit, the vapour pressure may still be high within the vegetation (Fig. $8 b$ ). The vapour pressure deficit may even be higher within the vegetation owing to a very high temperature in the latter (Fig. 9a). When the free air has but a small saturation 
PH. STOUTJESDIJK

deficit, the saturation deficit of the air between the heather shrubs will be reduced to a fraction of the latter. Thus in dry climates or in dry periods in temperate climates, a vegetation like that of the heath will reduce the effect of the aridity of the climate mainly by the protection it affords against wind and sun. In wetter periods (and in wetter climates) this vegetation is able to maintain an almost saturated atmosphere within its confines.
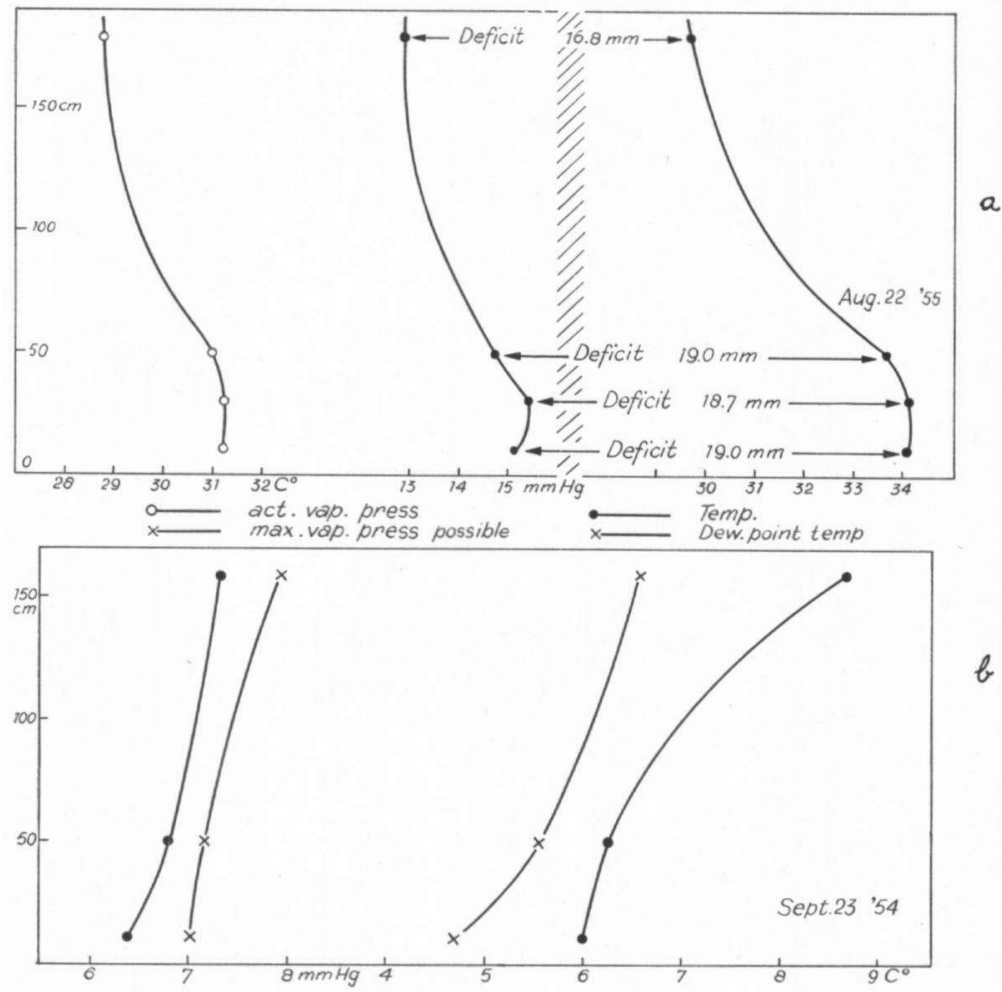

Fig. 9. a. Temperature, vapour pressure and vapour-pressure deficit in and above a heath vegetation with a dry moss layer.

Fig. 9. b. Temperature and humidity in and above a heath on a bright, still evening at sunset. Inversion of the temperature and humidity gradients.

Some measurements were made with a thermo-electric psychrometer which needed no ventilation. The temperature measurements have already been discussed above. Humidity of the air was calculated from mean values of series of dry and wet "bulb" temperatures.

Most humidity data are plotted in Fig. 7.

Inside the heath vegetation extremely high differences with the air at $2 \mathrm{~m}$ height are found, especially during the first hours of the period of observation. Later in the afternoon there is a rapid drop in the value of these differences. Humidity at the level of the tops of the heather plants too is high during the morning. Later in the day it 
decreases to less than $1 \mathrm{~mm}$ above that of the air at $2 \mathrm{~m}$ height. The rapid drop of humidity at $40 \mathrm{~cm}$ and $10 \mathrm{~cm}$ can not be due to the fact that the water vapour is carried away at an increased rate, as wind force and thermic turbulence rather decrease. Hence the production of water vapour must decrease too. The main causes must be the condition of the surface of the moss layer which gradually dries out, and the decreased radiation. The decrease of radiation and the decrease of the air temperature both tend to decrease the temperature of the main evaporating surface, viz. that of the moss and litter layer.

In spite of the high humidity, the vapour pressure deficit inside the heath vegetation is not much lower than that at $2 \mathrm{~m}$ height, owing to the high temperature of the air between the plants. At $40 \mathrm{~cm}$ height the deficit is often considerably higher than it is at $2 \mathrm{~m}$.

The influence of the wind on the humidity is demonstrated by measurements of the humidity that were made respectively in the wind shadow of a group of trees and on a fully exposed heath (Table 16).

Thus we can modify the statement of Stocker by stating that the microclimate of a heath vegetation is dry in periods during which no

TABLE 16

Temperature and humidity in heath vegetation, to show the influence of wind shelter.

\begin{tabular}{|c|c|c|}
\hline Place & Temp. & Vap. press. \\
\hline $\begin{array}{l}1^{\circ} \text { At } 2 \mathrm{~m} \text { height } . \text { ialluna heath } \\
2^{\circ} \text { At } 5 \mathrm{~cm} \text { height in Callu } \\
2 \mathrm{a} \text { id. sheltered by oak } \\
3^{\circ} \text { As } 2^{\circ} \text {, lower heath } \\
4^{\circ} \text {. }\end{array}$ & $\begin{array}{l}20.2^{\circ} \mathrm{C} \\
20.8^{\circ} \mathrm{C} \\
22.4^{\circ} \mathrm{C} \\
20.8^{\circ} \mathrm{C}\end{array}$ & $\begin{array}{l}8.8 \mathrm{~mm} \\
14.6 \mathrm{~mm} \\
16.2 \mathrm{~mm} \\
13.7 \mathrm{~mm}\end{array}$ \\
\hline $2^{\circ}$, not sheltered . . . . . & $20.8^{\circ} \mathrm{G}$ & $11.2 \mathrm{~mm}$ \\
\hline
\end{tabular}

humid substrate is present. The transpiration of the higher plants (Calluna) is not sufficient to maintain a high humidity inside the vegetation. When there is an appreciably increased humidity inside the vegetation, this is due to the evaporation or transpiration of the moss and litter layer. Of course, when a strongly transpiring higher plant is present, the humid microclimate in a vegetation becomes more constant. However, low vegetations in which in dry periods the vapour pressure is much higher than that in free air, are not known to us.

g. The changes Which the hUmidity undergoes DURING THE NIGHT

On a bright night the humidity gradient is inverted in the same way as the temperature gradient. There is a rapid fall of the vapour pressure in the air from a height of $1.70 \mathrm{~m}$ to one of $0.50 \mathrm{~m}$ (i.e. to the level of the heather tops); whereas between $0.50 \mathrm{~m}$ and $0.05 \mathrm{~m}$ the decrease is less rapid (Fig. 9b).

On a bright night when the air temperature within the heather vegetation is below that of the saturation point of the air at a height 
PH. STOUTJESDIJK

of $1.70 \mathrm{~m}$, one would expect that the air within the vegetation would be completely saturated. This, however, is not so; it may even be further removed from the saturation point than it is in the air at a height of $1.70 \mathrm{~m}$. That the air in the vegetation remains below the saturation point, can have only one cause, viz. that there is some colder surface nearby. When the vapour pressure in the vicinity of this surface is above the maximum vapour pressure belonging to the temperature of the latter, a transport in its direction sets in. In our case the colder surface is most likely formed by the heather tops, and then the temperature can not exceed that of the saturation point of the air at a height of $5 \mathrm{~cm}$. That such a situation can be maintained above a damp moss layer, is possible only where the upward transport of water vapour is very slow. This means that the turbulence of the air must be very low, and this doubtless was so when our measurements were taken. Upward transport inside the vegetation must have been mainly by diffusion.

Dew formation on Calluna plants is hardly ever present. Yet the gradient of the vapour pressure indicates a downward transport of water, and other kinds of plants may actually be covered with dew.

\section{h. Evaporation}

In Table 17 figures with regard to the evaporation above the heath are compared with figures obtained at the evaporation stations at De Bilt and Bennekom. (The latter is situated on the S-W border of the Veluwe.) The measurements above the heath were made at a height of $1.40 \mathrm{~m}$ above the tops of a $40 \mathrm{~cm}$ high heath by the aid of Piche evaporimeters provided with disks of green blotting paper.

TABLE 17

Evaporation in 24-hour periods (8.00-8.00).

\begin{tabular}{|c|c|c|c|c|}
\hline & \multicolumn{3}{|c|}{ Evaporation } \\
\hline & & Heath & De Bilt & Bennekom \\
\hline & 1955 & & & \\
\hline Aug. & $10-11$ & 13.4 & 9.0 & 8.6 \\
\hline , & $11-12$ & 27.6 & 12.1 & 14.7 \\
\hline "g & $15-16$ & 9.2 & 5.0 & 7.3 \\
\hline 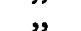 & $16-17$ & 12.05 & 7.95 & 9.0 \\
\hline , & $17-18$ & 14.8 & 8.3 & 12.9 \\
\hline ", & $18-19$ & 12.2 & 5.4 & 10.2 \\
\hline , & $19-20$ & 10.6 & 3.9 & 10.3 \\
\hline 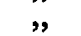 & $20-22$ & 31.4 & 11.15 & 25.6 \\
\hline & $22-24$ & 38.7 & 8.3 & 27.7 \\
\hline & $24-25$ & 16.5 & 3.2 & 12.0 \\
\hline$"$ & $30-31$ & 8.7 & 2.5 . & 6.3 \\
\hline Aug. & 31-Sept. 1 & 11.8 & 2.5 & 7.7 \\
\hline Sept. & $3-5$ & 28.- & 10.15 & 13.6 \\
\hline
\end{tabular}

The diameter of the disks was $3.5 \mathrm{~cm}$. The measurements at the evaporation stations are taken at a height of $30 \mathrm{~cm}$ above a short-cropped lawn. The disks that are used here, have a diameter of $4 \mathrm{~cm}$. To 
make the measurements comparable, our figures were, following a suggestion received by $\operatorname{Dr} \mathrm{P}$. J. M. Woudenberg (Meteorological Institute De Bilt), multiplied by a factor 1.4. In Table 18 the hourly values above and inside the heath vegetation are compared with

TABLe 18

Measured and calculated evaporation. Unless stated otherwise, evaporation . measured at a height of $1.80 \mathrm{~m}$.

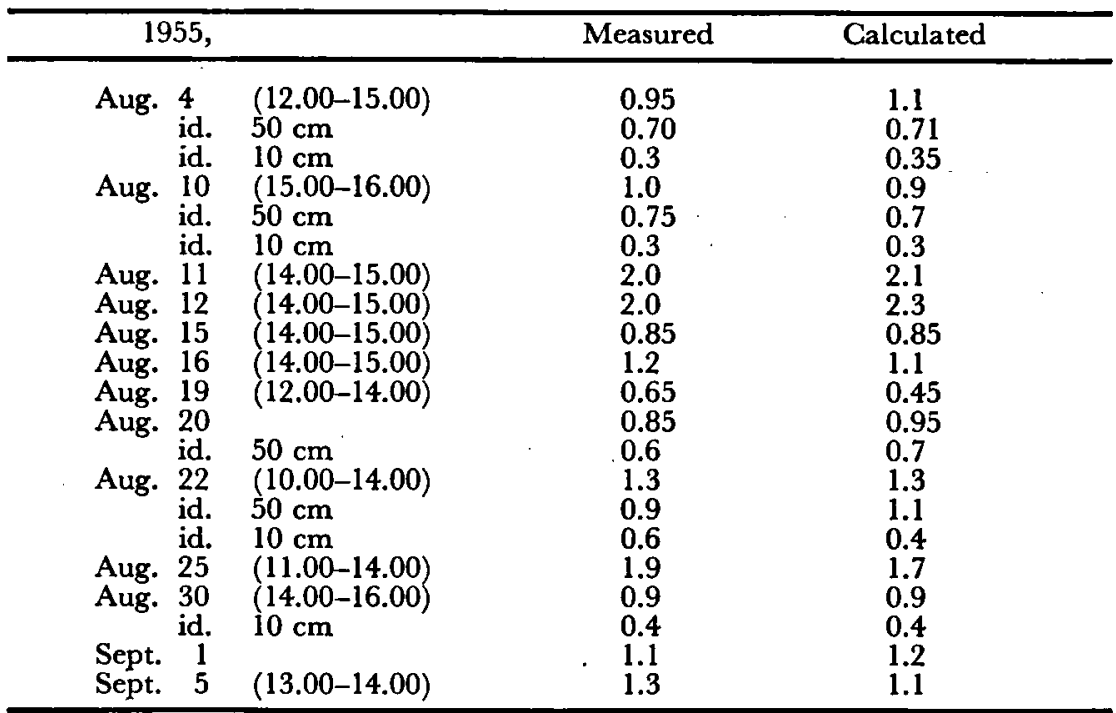

values calculated for periods for which sufficient data were available. The table also gives an impression of the highest hourly values that were measured by us. The calculations were made by the aid of a formula given by De VRIEs and Venema (1954):

$$
\mathrm{E}=\frac{\mathrm{O} . \mathrm{S}}{(\mathrm{S}+0.5) 10}\left(0.5 \mathrm{I}+\mathrm{h}_{\mathrm{w}}\left(\mathrm{t}_{\mathrm{a}}-\mathrm{t}_{\mathrm{d}}\right) \mathrm{S}\right)
$$

In this formula evaporation is expressed as a function of temperature and dewpoint of the air, radiation and wind force. $\mathrm{E}=$ evaporation in $c c / h r, S=\frac{\theta_{a}-\theta_{d}}{t_{a}-t_{d}}, \quad e_{a}=$ saturation vapour pressure at air temperature $\left(t_{a}\right), e_{d}=$ actual vapour pressure, $t_{d}=$ dew point temperature; $\mathrm{O}=$ total evaporation surface of the disks, $\mathrm{I}=$ radiation intensity; $h_{w}=$ coefficient of heat transfer.

The agreement between the observed and the calculated evaporation is as good as could be expected, considering the rather rough data (especially for wind force and radiation intensity) which had to be used.

Reduction of the evaporation above the heath tops is due to reduced wind force. Radiation intensity is the same as at a greater height, and the differences of temperature and humidity existing between the 
two levels are usually such as to cause a slight increase of the evaporation. Wind force above the heath tops was approximately half that at a height of $1.80 \mathrm{~m}$. For the calculation of radiation inside the vegetation wind force was taken to be $1 / 3$ of that at the level of the vegetation tops. The reduction of wind force inside the heath vegetation was supposed to be the same as in a Salix repens vegetation of the same height and of a comparable structure and density for which reliable measurements were available. The relative radiation intensity in the heath was $20 \%$.

The differences between the heath and the evaporation station at Bennekom are as could be expected on account of the higher temperature and of the lower vapour pressure on the heath. Wind force too was probably higher abover the heath, at least at the somewhat greater height on which our measurements were made. The differences in the evaporation figures found for De Bilt and our heath are mostly much higher than could be explained by differences in radiation intensity, temperature, humidity and windforce.

For comparison we may further mention that the highest hourly value measured by us was $2.2 \mathrm{cc} / \mathrm{hr}$. Heilig (1931) measured a maximum evaporation of $2.5 \mathrm{cc} / \mathrm{hr}$; Volk (1931) too found evaporation figures up to $2.5 \mathrm{cc} / \mathrm{hr}$. The measurements of Heilig and Volk were made with $3 \mathrm{~cm}$ disks and to obtain comparable values their data were multiplied by a factor 1.35 .

\section{i. Light INTENSITY IN THE heATH VEgETAtion}

The results of the measurements of the light intensity on the moss layer of a $40-50 \mathrm{~cm}$ high heath vegetation are summarized in Table 19. They are given as relative intensities, i.e. as a percentage of the light intensity measured above the vegetation. The measurements were made with a Weston photo-electric cell (barrier-layer cell). These cells have a maximum sensitivity in the green part of the spectrum.

Where the heath is very dense, a moss layer is absent. The light intensities measured at such places proved to range from $0.2-2 \%$. Dicranum scoparium was found at intensities of $0.5 \%$. As a rule, a well-developed moss layer seems to need a light intensity above $2 \%$.

LUNDEGÅRDH (1957) states that several forest plants grow at relative light intensities of $0.6-0.7 \%$, and that some mosses and algae even

TABLE 19

Mean relative light intensities under heath in relation with the degree of coverage and the composition of the moss layer.

\begin{tabular}{cc}
\hline \multicolumn{1}{c}{ Moss layer } & Mean relative light intensity \\
\hline $1 \%$ Hypnum cupressiforme and & $(0.2-2.5 \%) 1.4 \%$ \\
$70 \%-100 \%$ Dicranum scoparium & $\begin{array}{l}\text { Hypnum cupr. and Dicranum } \\
\text { scoparium }\end{array}$ \\
$60 \%-100 \%$ Cladonia impexa, Dicranum \\
$\begin{array}{l}\text { scoparium, Hypnum cupressiforme } \\
\text { and Pohlia spec. }\end{array}$ & $(4-15 \%) 8.5 \%$
\end{tabular}


grow at intensities of $0.1-0.05 \%$. ShIRLY (1945) had concluded from a survey of the available data that below a relative intensity of $2-4 \%$ plant growth is, as a rule, absent; this applied to measurements on the forest floor as well as to measurements made in lakes and oceans.

\section{f. Heat balance of the heath vegetation}

The peculiar character shown by the microclimate of the heath must, of course, be due to special features of the energy balance.

The energy amounts that play a rôle in the heat economy of a soil surface or of a vegetation, are the following:

(1) direct and indirect radiation received from the sun;

(2) long-wave heat radiation received from the sky;

(2a) heat loss in the long wave-lengths;

(3) reflected radiation in the short wave-lengths;

(4) energy carried downward into the soil;

(5) energy used in evaporation and transpiration;

(6) heat given off to the air.

The processes (1) and (2) supply the energy for (2a) to (6).

(2) depends exclusively on atmospheric conditions.

(2a) depends in the first place on the absolute temperature on the surface of the vegetation, as this behaves in this respect practically as a black body (FALCKENBERG, 1928).

(3) was found for a heath vegetation to vary between 10 and $15 \%$; grassland reflects $20-25 \%$.

Measurements were made with an instrument according to Angström which has a uniform sensitivity for all regions of the solar spectrum.

(4) is, as has been argued, low.

However, while it could easily be shown that the processes (3) and (4) cause a relatively small loss of energy, no direct measurements of the energy quantities involved in processes (5) and (6) were available.

The amount of water used by a heath vegetation can be estimated on the base of the following considerations.

STOCKER (1923) measured the transpiration of potted plants in N.W. Germany under almost natural conditions. The daily transpiration was measured by weighing. The results were expressed in figures representing the transpiration per gram of dried leaf. We ourselves harvested from 1 square meter heath of maximum vigour and density 176 gram of dry leaves. By means of the average transpiration rates determined by Stocker we obtain for this vegetation the following mean daily transpiration figures, viz.

$$
\begin{aligned}
& \text { April . . . } 0.3 \mathrm{~mm} \text { per day } \\
& \text { May . . . } 1.0 \mathrm{~mm} \text { per day } \\
& \text { June . . . } 1.2 \mathrm{~mm} \text { per day } \\
& \text { August . . } 1.3 \mathrm{~mm} \text { per day } \\
& \text { Sept.. . . . } 0.3 \mathrm{~mm} \text { per day }
\end{aligned}
$$

Measurements of the soil humidity after a dry period also permit an estimate of the water used by the vegetation during that period. In a soil situated at a level where the influence of the groundwater 
is no longer noticeable, there is a negligible transport of water when the soil is at field capacity or below it. "When the soil is above field capacity, there is only a downward transport of water" (cf. KRAMER, 1951).

The following table contains data on the water content in three soils measured after a long dry period in comparison with the water content of the same soils at field capacity or above it.

TABLE 20

Water content of heath soil after dry and after wet periods.

\begin{tabular}{|c|c|c|c|c|c|c|}
\hline \multirow[t]{2}{*}{ No } & \multirow[t]{2}{*}{ Depth } & \multicolumn{2}{|c|}{$\begin{array}{l}\text { Water content in } \\
\% \text { by vol. }\end{array}$} & \multirow{2}{*}{$\begin{array}{c}\text { Difference } \\
\text { in } \% \text { by } \\
\text { vol. }\end{array}$} & \multirow{2}{*}{\multicolumn{2}{|c|}{$\begin{array}{c}\mathrm{mm} \text { of water taken from the } \\
\text { layer of soil }\end{array}$}} \\
\hline & & $\begin{array}{l}\text { after dry } \\
\text { period }\end{array}$ & $\begin{array}{l}\text { after wet } \\
\text { period }\end{array}$ & & & \\
\hline $\begin{array}{r}1 \mathbf{a} \\
\mathbf{b} \\
\mathbf{c}\end{array}$ & $\begin{array}{r}0-12 \mathrm{~cm} \\
12-20 \mathrm{~cm} \\
20-29 \mathrm{~cm}\end{array}$ & $\begin{array}{l}9.2 \% \\
20.7 \% \\
23.3 \%\end{array}$ & $\begin{array}{l}17.2 \% \\
28.0 \% \\
35.9 \%\end{array}$ & $\begin{array}{l}8.0 \% \\
7.3 \% \\
12.6 \%\end{array}$ & $\begin{array}{r}9.6 \mathrm{~mm} \\
5.8 \mathrm{~mm} \\
11.1 \mathrm{~mm} \\
26.5 \mathrm{~mm}\end{array}$ & $\begin{array}{l}\text { Aug. } 26 \text { th, } 1955 \\
\text { after rainless } \\
\text { period of } 17 \text { days } \\
(a+b+c)\end{array}$ \\
\hline $\begin{array}{c}2 \\
3 a \\
b\end{array}$ & $\begin{array}{l}0-12 \mathrm{~cm} \\
0-12 \mathrm{~cm} \\
0-12 \mathrm{~cm} \\
0-12 \mathrm{~cm}\end{array}$ & $\begin{array}{l}14.9 \% \\
24.1 \% \\
22.6 \% \\
18.2 \%\end{array}$ & $\begin{array}{l}24.6 \% \\
17.5 \% \\
17.0 \% \\
22.3 \%\end{array}$ & $\begin{array}{l}9.7 \% \\
6.6 \% \\
5.6 \% \\
4.1 \%\end{array}$ & $\begin{array}{l}11.7 \mathrm{~mm} \\
7.9 \mathrm{~mm} \\
6.7 \mathrm{~mm} \\
4.9 \mathrm{~mm}\end{array}$ & $\begin{array}{l}\text { May } 15 \mathrm{th}, 1954 \\
\text { after } 30 \text { days with } \\
12 \mathrm{~mm} \text { of rain. }\end{array}$ \\
\hline
\end{tabular}

In case 1 the soil was sampled as deep as it contained roots. Most of the roots were contained in the upper half of the sample. Probably the amount of water that was actually used by the vegetation, is less than the water content of the soil after the wet period minus the water content after the dry period. The lower layers of the soil were doubtless above field capacity when the second set of samples was taken.

Our data make it possible to give a reasonably accurate estimate of the heat and water balance of a heath vegetation from 6.00 to $18.00 \mathrm{hr}$ on a cloudless summer day, as compared with that of grassland and of inland dunes (Table 21). A water loss of $2 \mathrm{~mm}$ a day was

TABLE 21

Estimated energy balances for soil surfaces with different types of vegetation, on a bright summer day.

\begin{tabular}{|c|c|c|c|c|}
\hline & Heath & $\begin{array}{l}\text { Grass } \\
\text { land }\end{array}$ & \begin{tabular}{|c|} 
Inland \\
dune \\
with \\
vegetation
\end{tabular} & $\begin{array}{l}\text { Inland } \\
\text { dune } \\
\text { bare }\end{array}$ \\
\hline $\begin{array}{l}\text { Incoming short-wave radiation }\left(\mathrm{cal} / \mathrm{cm}^{2}\right) \\
\text { Reflected ", } \\
\text { Net outward radiation (long wave) } \\
\text { Heat absorbed in soil } \\
\text { Heat used in evapotranspiration } \\
\text { Heat given off to air }\end{array}$ & $\begin{array}{r}580 \\
87 \\
150 \\
25 \\
120 \\
198\end{array}$ & $\begin{array}{r}580 \\
145 \\
129 \\
50 \\
180 \\
76\end{array}$ & $\begin{array}{r}580 \\
87 \\
200 \\
60 \\
60 \\
173\end{array}$ & $\begin{array}{r}580 \\
165 \\
150 \\
60 \\
60 \\
145\end{array}$ \\
\hline & 580 & 580 & 580 & 580 \\
\hline
\end{tabular}


assumed for heath, a loss of $3 \mathrm{~mm}$ for grassland, and one of $1 \mathrm{~mm}$ for inland dunes.

Thus, while allowing ample room for possible errors, we may state that great differences exist between the heat and water economy of a heath and of a grassland, and that these differences are in agreement with the microclimatological observations discussed above.

The difference in the loss of heat by radiation is calculated on the assumption that the mean temperature of the heath is $3^{\circ} \mathrm{C}$ higher than that of the meadow.

The low humidity content of the air also fits into this scheme. Not only does the low rate of transpiration produce little water vapour, but the high amount of heat given off to the air must cause a high thermic turbulence. An increased rate of turbulence means an increased upward transport. It is therefore comprehensible that the conditions described above give rise to a high evaporation.

\section{k. Temperatures OF INLAND DUNe SAND}

In botanical literature the following points are stressed:

1. On the surface of sand dunes high temperatures occur, but below the surface the temperatures decrease rapidly;

2 . sand cools very rapidly after sunset, and becomes very cold in a still, bright night; this suggests that sand has a low heat conductivity, cf. Jeswiet (1913), Vagakenier Suringar (1926), Van Dieren (1934), Salisbury (1952).

Dune sand may indeed reach high temperatures at the surface. It should, however, be realized that other dry and bare soil surfaces reach temperatures which may be as high as those of a sandy soil or even higher. On dry dark garden soil higher temperatures were measured than on dune sand. Surface temperatures of bare raw humus were also considerably higher than those of sand. What makes a sand surface different from other soil surfaces, is that it dries out very rapidly. This means that high surface temperatures occur much more frequently here than e.g. on a humous soil. Surface temperatures of bare inland dunes regularly rise to $20^{\circ} \mathrm{C}$ above the air temperature at $2 \mathrm{~m}$ height. Temperatures up to $30^{\circ} \mathrm{C}$ above the air temperature occur under favourable conditions, i.e. with strong insolation and low wind. This refers to level surfaces; on steep S-slopes even higher temperatures are reached.

The graphs of Fig. 4 give a good impression of the thermic properties of an inland dune soil as compared with a heath soil. Striking are the high amplitudes of the fluctuations in the temperature as compared with those found in the heath soil, especially at greater depths. Temperatures at different depths fluctuate round a mean which lies about $8^{\circ} \mathrm{C}$ higher than that found in the heath soil. This is comprehensible as the mean heat content of both kinds of soil increases, but more strongly and more rapidly in sand.

Sand temperatures are, both during the day and at night, much higher than the corresponding temperatures in a heath soil. During the larger part of a twenty-four hour period soil temperatures, even 
PH. STOUTJESDIJK

at $10 \mathrm{~cm}$ depth, are far above the air temperature. Only in the morning hours the temperatures in the sand at $10 \mathrm{~cm}$ depth are somewhat below the air temperature. Compared with the soil at De Bilt the dune soil also has high day temperatures and probably high night temperatures as well, cf. Table 9.

The change in heat content of the sand can be calculated in the same way as has been done for the heath soil. The sand proved to consist of almost pure quartz grains, and the soil had in its undisturbed state a volume weight of 1.45 (water excluded) and a water content of $5 \%$ by volume. The top $2 \mathrm{~cm}$ were bone-dry. The heat capacity of $1 \mathrm{cc}$ of the top soil thus becomes $0.29 \mathrm{cal} /{ }^{\circ} \mathrm{G}$ (quartz has a heat capacity of $0.2 \mathrm{cal} / \mathrm{gram})$. The heat capacity of the humid soil is $0.29+0.05$ (for the water) $=0.34 \mathrm{cal} /{ }^{\circ} \mathrm{C}$. The total change in heat content as calculated from these data and the graphs of Fig. 5 was 49 cal.

Thus the daily fluctuation of the heat in the sand is for the upper $10 \mathrm{~cm} 49 \mathrm{cal} / \mathrm{cm}^{2}$, i.c. nearly 2.5 times as high as that for the heath soil. If the total changes in heath content (i.e. to a depth where no more temperature changes can be observed) had been compared, the ratio would have been still higher, as in the sand the amplitude of the fluctuations in temperature decreases less rapidly with depth than it does in heath soil.

What has been said on the observations of the 24th April, is true for all spring and summer measurements. However, the differences with the heath soil, especially if night temperatures are considered, gradually become somewhat smaller. Further, in summer the temperature of the sand at a depth of $10 \mathrm{~cm}$ does not rise considerably above the air temperature. In autumn the sand reaches higher temperatures by day than the heath soil does, but night temperatures fall below those of the latter.

There was no equipment available for temperature measurements in frozen soils, but the good thermal conductivity and, even more, the low water content of the sand facilitate the penetration of frost into the soil. By the end of the winter and in early spring, dune sand may alternately be freezing and thawing.

\section{ArR TEMPERATURES ABOVE THE DUNES \\ 1. Night temperatures}

The same reasoning which led to the conclusion that low night temperatures may be expected in the air above the heath, can be applied to the dune area, but here it leads to the conclusion, that the night temperatures of the air above the sand will be much higher.

In Table 12 temperature measurements in the air above dune areas are compared with the measurements above the heath which have already been discussed, and with measurements made at De Bilt. Some of our measurements were made in the interior of the extensive sand dune area "Kootwijkerzand". Other measurements (marked with an asterisk) were taken above a smaller dune area immediately adjoining the heath where comparative measurements were made. 
The level of the last-meant denuded area was somewhat lower than that of the adjoining heath.

A striking characteristic of the air temperatures measured above the sand is that there is little or no difference between those at $1.70 \mathrm{~m}$ and those at $0.05 \mathrm{~m}$. While above the heath and at De Bilt the temperatures near the soil are several degrees lower than they are at $1.70 \mathrm{~m}$, respectively $2.20 \mathrm{~m}$, above the sand the situation is more or less reversed, for here the temperatures at a height of $0.05 \mathrm{~m}$ may even be somewhat above those at $1.70 \mathrm{~m}$, cf. Fig. 10. The differences between heath and sand are most marked in bright, still weather and

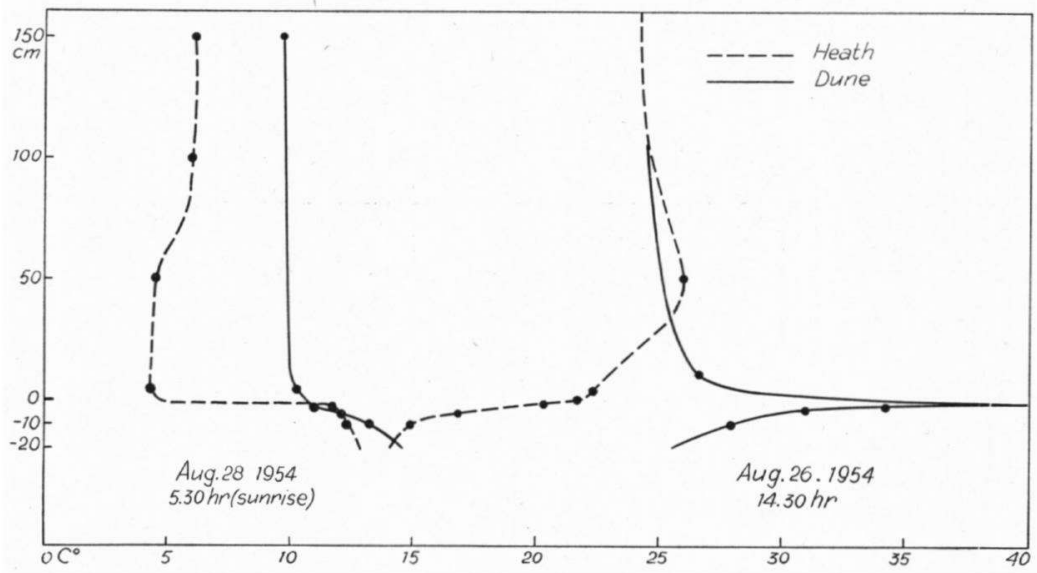

Fig. 10. Air and soil temperatures of heath and inland dune after a bright night and on a bright day.

at times when the sand is relatively warm. Yet the differences are still noticeable when the sand is colder than the heath soil and when the weather is cloudy. On extensive inland dune areas the minimum temperatures near the soil are markedly higher than those found at De Bilt. At $5 \mathrm{~cm}$ height the temperature differences with the heath often amount to $6^{\circ} \mathrm{C}$, occasionally to $10^{\circ} \mathrm{C}$. At $1.80 \mathrm{~m}$ height the differences are still considerable. Air temperatures measured in the smaller sand dune area adjoining the heath are partly lower than they are at De Bilt. Yet the peculiarity that there is no or only a weak inversion of the temperature gradient remains the same, and there is still a considerable difference with the air temperature above the heath.

The inland dune area "Kootwijkerzand" is bordered by mature pine plantations. There proved to be a marked increase in temperature from the periphery of the sand area towards the centre. In nights in which a radiation fog was observed above the heath and the pastures, the air above the inland dune areas remained almost entirely clear, the fog penetrating only into the marginal part of the latter.

The situation in still, bright nights characterized by a strong inversion of the temperature gradient above the heath and none above 
PH. STOUTJESDIJK

the inland dune area, is very similar to that described by Knochenhauer (cf. Geiger l.c.). Knochenhauer took temperature measurements above concrete and on an adjoining lawn. At $1.50 \mathrm{~m}$ temperature differences of $4-5^{\circ} \mathrm{C}$ were observed, while the temperature differences near the soil were $7^{\circ} \mathrm{C}$. Above the lawn an inversion of the temperature gradient had developed, while above the concrete the temperature was highest near the surface.

The higher minimum temperatures are not restricted to the season in which the soil temperatures of the sand are high. Even in autumn and winter there is a considerable difference. Even when soil temperatures of the sand sink to a much lower value than those of the heath soil, the air temperatures above the sand remain higher.

\section{Air temperatures in cases of strong insolation}

Measurements made with an Assmann psychrometer showed that the temperature of the air above a strongly overheated sand surface must undergo a very rapid decrease in the higher layer. The instru-

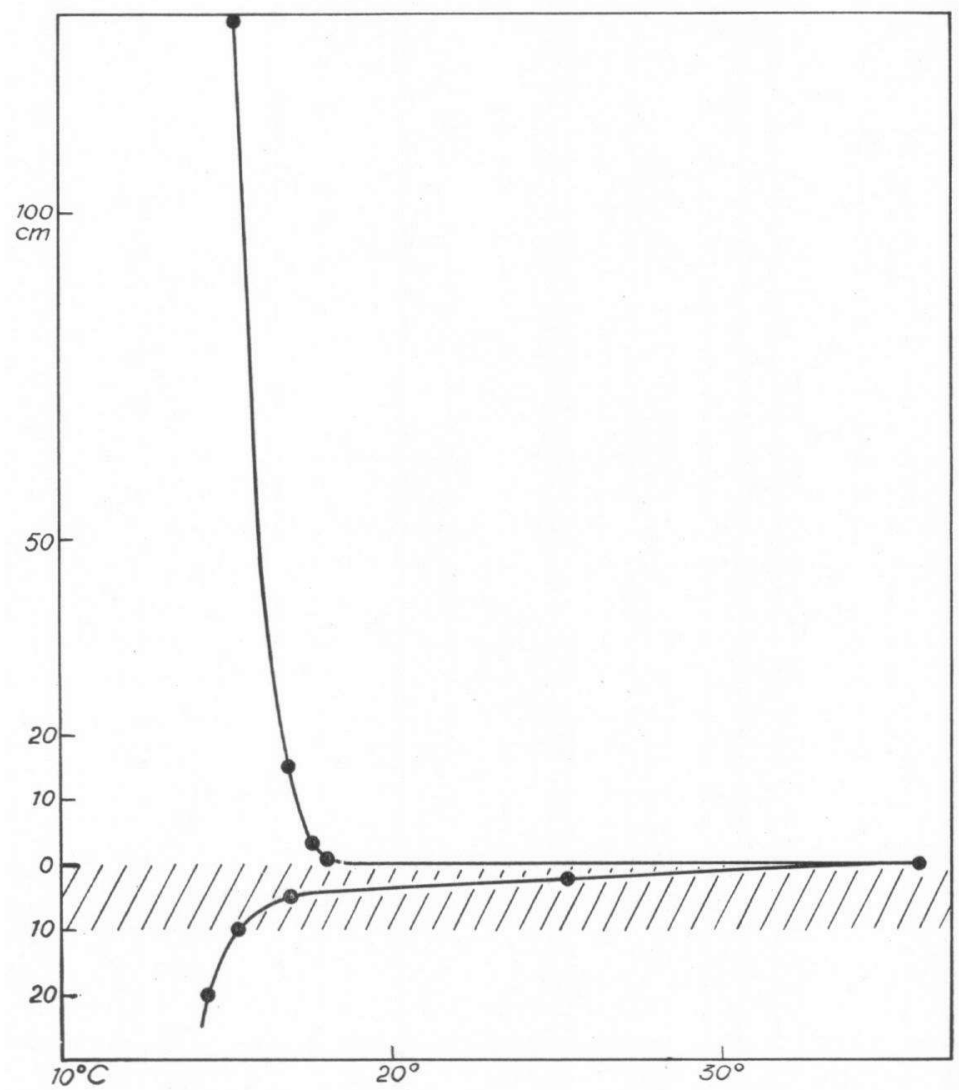

Fig. 11. Temperatures in and above dune sand; strong insolation. 
ment, however, is unsuitable for measurements at places where the temperature gradient is very strong.

Measurements under desert conditions were taken by SINCLAIR (1922) and by HaUde (1934). They show a very rapid fall of the air temperature in the first few milimeters above the surface. In Fig. 11 some results of measurements with fine thermocouples above coastal dunes have been plotted. There is no reason to suppose that the situation above inland dunes will differ significantly from that found in the coastal ones. Measurements were taken above a greyish dune sand with a reflection of $14 \%$. The reflection was measured with an instrument that had the same sensitivity throughout the whole range of the solar spectrum. Radiation intensity $\left(1.2-1.3 \mathrm{cal} / \mathrm{cm}^{2} / \mathrm{min}\right)$ was close to the maximum possible; wind force was low, viz. $1.3 \mathrm{~m} / \mathrm{sec}$ at $1 \mathrm{~m}$ height. The points that have been plotted in Fig. 11, are mean temperatures registered during a period of 10 minutes.

Remarkable is the extremely rapid fall of the air temperatures in the upward direction. At $1 \mathrm{~cm}$ above the surface the air temperature is already far below the soil temperature at $2 \mathrm{~cm}$ depth.

\section{Comparison between the nightly heat balance of dune sand and that of heath soil}

When in a clear night in the dunes surface temperatures and air temperatures near the surface are higher than the temperatures measured at a greater height, this means that the soil does not absorb heat from the air, but that, on the contrary, heat is given off to the air. The heat that is lost in this case is that which is lost by radiation, and also a certain amount that has served to warm the air directly above the soil. To answer the question whether this fits in with the other available data, we may use the results of the measurements brought together in Table 11 . In this table the calculated changes of the heat content of the upper $10 \mathrm{~cm}$ of sand and heath soil are compared with the estimated net loss of heat by radiation for that night. The net radiation was calculated by means of the aforementioned diagram of Philips. To interpret the table, it should be taken into account that the fluctuation in the temperature of the soil decreases but little in the downward direction. This means that the total amount of heat that is given off by the soil during the night, may be several times that given off by the upper $10 \mathrm{~cm}$. The total amount may safely be estimated at three times that given off by the upper $10 \mathrm{~cm}$. Therefore, it does not seem unjustified to assume that the larger part of the nightly loss of heat is made good by heat given off by the soil. That under favourable conditions the upward stream of heat from the deeper layers of the soil may overcompensate in the surface layer the loss of heat due to radiation, seems probable as well. Later, more extensive measurements made in the sand of coastal dunes proved that the sketched situation may be present here. The sand of the coastal dunes differs little in its thermic properties from that of the inland dunes.

To make an estimate of the total amount of heat given off by the 
heath soil, we must taken into consideration that here the amplitude of the fluctuations in the soil temperatures decreases rapidly with depth. Here the amount of heat given off by the upper $10 \mathrm{~cm}$ probably is more than half the total amount that is given off by the soil.

\section{m. Dew Formation}

Dew formation and condensation of water vapour in the soil are often supposed to be of importance in the water economy of sand-dune species (SAlisbury, 1952; Van Dieren, 1934). Leick (1933) has discussed the ways in which condensation of vapour may take place.

Water transport from deeper to higher soil levels can take place when the latter are cooler than the former. As the vapour pressure will be lowest in the colder layers, in this case water will destillate from deeper to higher soil layers. When the vapour pressure at the soil surface is below the dew-point of the air above it, there will also be a transport of water vapour from the air to the soil surface (dew formation). The opposite process takes place by day; then there is a transport of water vapour from the heated upper soil layers to the air as well as to the deeper layers of the soil with their lower temperature.

The sucking in of warm air in the cold soil as the soil temperature falls or as the barometric pressure changes, can be left out of discussion here, as the amount of vapour contained in these small amounts of air is negligeable.

When the temperature of the upper layers of a soil is higher than that of the air, dew formation is impossible. During the night the dune sand is often warmer or only slightly cooler than the air.

Thus, during the warmest time of the year dew formation can not be expected to be of much importance, and this indeed agrees with the observation.

There will be some destillation from deeper to higher layers, but as the vapour pressure increases in the higher layers, more water vapour will pass from the latter to the surface and from there into the air than the deeper layers can supply, and for this reason the dew-point is not reached in the higher ones. Our next argument is that by day the opposite processes, viz. transport from the soil surface to the air as well as transport to deeper layers take place, and when heat uptake is very strong, these processes may prevail. In summer all processes which depend on a transport of water from warmer to colder layers of the soil, will result in a downward transport of water, as in summer the mean soil temperatures decreases in the downward direction.

In nights in which the dew formation in other areas proved to be very strong, it proved to be wanting on the sand (when the surface of the sand was warmer than the air above it) or very weak, only about $1 \mathrm{~mm}$ sand being wetted, the rest remaining as dry as it was before.

We may conclude that dew formation can be of no importance to sand-dune plants which take up water by the roots. This does not mean that no dew is formed on the aerial parts of the plants: the 
latter are not in direct contact with the soil, and may cool below the temperature of the surrounding air. Corynephorus indeed is often covered with fine dew drops, Ammophila less so, but this can not be of much importance to these plants as the amount of dew is very small, and moreover deposited on the strongly cuticularized outer side of the leaves. Lichens and Polytrichum piliferum may be dew-covered even when the sand remains dry. For these plants the wetting may be of importance as they absorb moisture by means of their whole surface. It may permit them to assimilate $\mathrm{CO}_{2}$ during a part of the next day. But often, when elsewhere the dew formation was strong, the mosses and lichens remain in their desiccated state, in which they are unable to perform their vital functions. In cloudy nights, when no dew is formed, lichens which had become brittle during the day, become pliable by the hygroscopic absorption of water vapour. According to STocker (1924) this does not permit assimilation, though it increases the respiration.

Dew formation may also be considered in relation with the nightly heat balance. As has been discussed before, the greater part of the nightly heat loss of the vegetation is made good by the soil. The rest is replaced from the air or, exceptionally, obtained in the form of condensation heat set free with the formation of dew. Thus in the heat balance dew formation plays but a very subordinate part.

\section{n. Light REFLECTION BY BARE DUNE SAND}

The "white" dune sand reflects a high amount of visible radiation, as is already proved by its appearance.

BüTTNER and SïTTER (1935) measured the amount of visible and ultraviolet radiation that is reflected by dune sand on the German North-Sea coast. When the angle of incidence of the rays exceeded $40^{\circ}$, the dry sand reflected $17 \%$ of the U.V. radiation and $37 \%$ of the visible light. With an angle of incidence of less than $40^{\circ}$ the reflection in the visible part of the spectrum increased rapidly, and when the sun approached the horizon, the reflection was nearly total.

The direct as well as the reflected radiation were measured by us by means of a flat Weston photo-electric cell. For measuring the reflected light, the cell was placed at $30 \mathrm{~cm}$ above the soil surface. With a sun at $50^{\circ}$ the following reflection coefficients were measured:

Dry sands of increasing whiteness

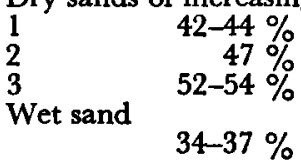

With a clouded sun the reflection decreased in one case from $47 \%$ to $35 \%$.

o. Heat emission by dune sand

At a temperature of $21^{\circ} \mathrm{G}$ the soil emits heat to a value of 0.607 $\mathrm{cal} / \mathrm{cm}^{2} / \mathrm{min}$. Of special interest is the amount of extra radiation 
PH. STOUTJESDIJK

emitted by a superheated soil surface. With an air temperature of $21^{\circ} \mathrm{C}$ a soil surface that is superheated to $41^{\circ} \mathrm{C}$, which is of common occurrence, emits about $0.2 \mathrm{cal} / \mathrm{cm} / \mathrm{min}$. extra; and at noon on a summer day this is about $20 \%$ of the irradiation that is received directly from the sun.

As the leaves of the plants absorb this kind of radiation completely, their temperature ought to rise, and if it does not do this, the surplus heat must have been used for transpiration or it must have been given off to the air.

The open vegetation on grey dune soil does not receive high amounts of reflected short-wave radiation. However, because of the open character of the vegetation, the leaves receive a high amount of direct radiation and a high amount of heat radiation per unit of leaf surface.

\section{p. WATER RELATIONS OF THE INLAND DUNE VEgEtation}

As expounded before, dew formation cannot be of much importance as a source of water supply to the vegetation of the inland dunes, at least not for the vascular plants. For this reason we will consider the possibility that the vegetation covers its water needs from the water stored in the soil.

\section{Evaporation from bare sand}

BARTELs (1933) found in his lysimeter experiments that in comparison with a grass-covered surface bare sand loses only a small amount of water. In dry periods, when the upper centimeters of the soil were dried out, the daily loss of water decreased to $0.26 \mathrm{~mm}$. The yearly evaporation from the sand surface appeared to be $177 \mathrm{~mm}$, whereas for short turf a value of $366 \mathrm{~mm}$ was found. The loss of water was strongest after rain, when the surface of the sand was wet. Evaporation from sand differs from that of a free water surface and also from the transpiration of a crop with plentiful water supply by the rapidity with which it decreases in the course of a dry period.

DEY (1956) gives the following figures for the sand of the Dutch coastal dunes. When the yearly evaporation from sand is put at 1 , the transpiration by a low vegetation varies between 2.1 and 2.66, from a deciduous wood between 1.91 and 2.48 , from a coniferous wood between 2.38 and 3.38. Between 1948 and 1953 the average annual evaporation from sand was $196 \mathrm{~mm}$.

In the open grass vegetations described in chapter III.b, the consumption of water will certainly exceed the amount that is lost by evaporation in bare sand. Yet the total transpiring surface of the markedly xeromorphic leaves is certainly only a fraction of that of the more luxurious vegetation of wetter soils. The field capacity of inland dune sand, both bare and covered with vegetation in the later stages of development, varied between $5.7 \%$ and $9.8 \%$ (mean $7.3 \%$ by volume). When we assume that $5 \%$ by volume of the soil water is available to the plant, and that the roots penetrate to a 
depth of $35 \mathrm{~cm}$, we find that the available amount of water in this layer must have a height of $17.5 \mathrm{~mm}$.

In soils with a very high water-storing capacity about five times as much water may be available in the upper $30 \mathrm{~cm}$ (cf. Kramer, 1951), yet, considering the sparse and xeromorphic character of the vegetation on the inland dunes, there seems to be no reason to suppose that this vegetation employs other means to overcome the difficulties of a dry period than other vegetations do.

After a dry period of 13 days in August 1955 the soil humidity was measured under a vegetation of Festuca ovina which was of much higher density than it usually is. The upper $5 \mathrm{~cm}$ of the soil were bone-dry. From 5-15 cm depth the humidity content was $5.8 \%$ (field capacity $9.0 \%$ ). From $15-25 \mathrm{~cm}$ the humidity content was $4.9 \%$ (field capacity $7.5 \%$ ). Assuming that at the start of the dry period the soil was at field capacity, we calculate the total amount of water used by the upper $25 \mathrm{~cm}$ of the soil at $10.3 \mathrm{~mm}$. Assuming that another $3 \mathrm{~mm}$ of water is extracted from the deeper layers in which but few roots penetrate, we find a total transpiration of $13.3 \mathrm{~mm}$, i.e. about $1 \mathrm{~mm}$ per day. With longer dry periods the evaporation probably decreases.

\section{Energy balance}

With the help of the data on soil temperature, reflection and evapotranspiration, an approximate picture of the energy balance may be developed (Table 21). For bare sand an emission of 0.89 for long-wave radiation was assumed (cf. FALCKENBERG, 1928). The mean surface temperature of the inland dunes was assumed to be $12^{\circ} \mathrm{C}$ higher than that of a grassland. The picture of the energy balance arrived at by indirect methods, does not differ considerably from one that was based on actually measured data obtained from coastal dune sand.

\section{Influence of vegetation on climate}

Our study of the energy balance and of the water balance in heath and in inland dunes, lead to the following considerations.

It leaves no doubt that the heat and the water balance of the surface differ greatly owing to differences in the vegetation and to edaphic conditions. It is in our opinion on these lines that we must try to understand the way in which the vegetation may exercise an influence on the climate.

It has been recognized for a long time that in different climatic zones the heat balance of the surface differs greatly, and that this has important climatological consequences (GEIGER, 1950). Yet, inside a limited area differences in the vegetation may already cause considerable differences in the heat and water economy of the surface. When we assume that heath and inland dune originated from oak wood, it is certain that in both cases the heat and water balance of the surface was changed in such a way that more heat and less water vapour was given off to the atmosphere. This means that the local 
PH. STOUTJESDIJK

climate became warmer and drier. On the other hand, when heath and inland dune are reclaimed and planted with trees, changes in the opposite direction are to be expected.

q. The effect of exposition on the temperature of the soll

The effect that is exercised on the vegetation by different expositions, is most striking and has often been discussed in botanical literature (Braun-Blanquet, l.c., Van Dieren, l.c.). However, strange enough, but few actual measurements have been published (GEIGER, 1.c., KerNer, 1891, Schade, 1917).

As the vegetation has such an enormous influence on the temperature of the soil, measurements made on different slopes without paying attention to the vegetation are of little value to explain the differences in temperature observed in the soil.

KERNER (1.c.) has compared the temperature of the soil at a depth of $70 \mathrm{~cm}$ on different sides of a hill, i.e. at a depth where the effect of the daily variation in the temperature is negligeable.

WoLlNy (1878) has taken measurements at a depth of $15 \mathrm{~cm}$ on artificial slopes with an inclination of $15^{\circ}$ and consisting of garden soil. The amounts of radiation received by slopes of various inclination and exposition was calculated from astronomical and meteorological data.

ScHUBERT (1928) has given diagrams and tables showing the amount of direct solar radiation that reaches surfaces of different exposition and inclination at various times of the year and of the day.

As an example some data calculated for the climate and the latitude $\left(52^{\circ}\right)$ of Potsdam may be cited. As the climate of Potsdam is bright and continental, in our climate the differences would be somewhat smaller and the highest values somewhat lower.

$\begin{array}{ccccc}\text { Mean daily amounts of radiation }\left(\mathrm{cal} / \mathrm{cm}^{2}\right) & \text { received in the months: } \\ \text { exp. } & \text { incl. } & \text { Jan. } & \text { April } & \text { June } \\ \text { level } & 0^{\circ} & 20 & 196 & 319 \\ \text { north } & 30^{\circ} & -54 & 91 & 228 \\ \text { south } & 30^{\circ} & 54 & 248 & 326 \\ \text { east } & 30^{\circ} & 18 & 182 & 289 \\ \text { west } & 30^{\circ} & 19 & 175 & 281\end{array}$

Differences between flat ground and the north slope are much higher than those between flat ground and the south slope. The amount of radiation received by the east and west slopes remains slightly below that received by flat ground. The differences reach their highest values with a low sun. The data, however, refer to direct solar radiation. The indirect radiation, which is $20-40 \%$ of the direct radiation, is not taken into account, and for this reason the differences look higher than they really are. Data on the irradiation received by different slopes in which the diffuse radiation has been taken into account, are not available.

The following measurements give an impression of the actual temperature differences found between slopes of different exposition under various weather conditions. If not stated otherwise, the data 
HEATHS AND INLAND DUNES OF THE VELUWE

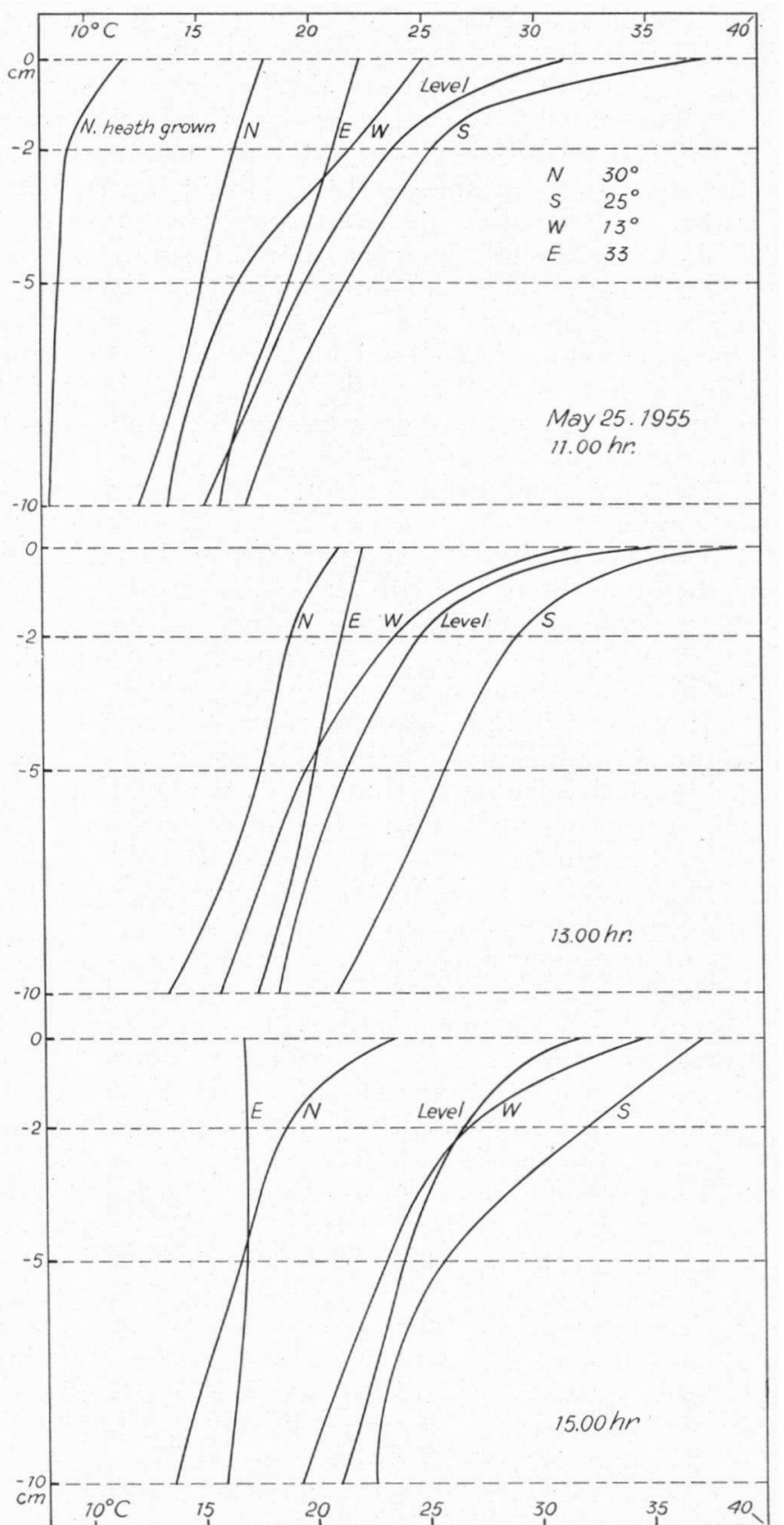

Fig. 12. Influence of exposition on the temperatures in the sand of inland dunes; air temperature $11.00 \mathrm{hr} .: 15^{\circ} \mathrm{C}, 15.00 \mathrm{hr} .: 18^{\circ} \mathrm{C}$. 
PH. STOUTJESDIJK

refer to bare soil. The graphs of Fig. 12 show the differences between $\mathrm{N}, \mathrm{E}, \mathrm{SSE}$ and $\mathrm{W}$ slopes and level ground. Measurements were made on a cloudless day by the end of May. At this time of the year the sun reaches a height of $58^{\circ}$. With the first series of measurements at $11.00 \mathrm{hr}$ the differences between $\mathrm{N}$ and $\mathrm{S}$ slope are already very strong, especially in the upper centimeters. In the lower layers the east slope is considerably warmer than the west one. The upper centimeters of the west slope are already warmer. The sun stands, of course, still east from south, but the steep east slope already receives less radiation than the gently sloping west one.

Where the north slope is covered with heather, the temperatures are much lower than were the soil is bare, which illustrates clearly that next to the exposition the vegetation has a considerable influence on the temperature of the soil.

The next series of measurements (at $13.00 \mathrm{hr}$ ) shows a further increase in temperature at all depths and for all slopes except the east one. The $\mathrm{E}$ slope shows a temperature increase in the deeper layers only. Below a depth of $5 \mathrm{~cm}$ the temperatures of the $W$ slope are still below those of the $\mathrm{E}$ slope.

At $15.00 \mathrm{hr}$ the temperatures in the upper layers of the western slope are higher than those in the upper layers of the level ground. The temperatures of the upper soil layers of the $N$ slope are higher now than those of the $\mathrm{E}$ slope. The temperatures that the $\mathrm{W}$ slope has reached, are at all depths higher than the corresponding ones on the E slope. The upper soil layers now have a higher temperature than those of the level ground, but the lower layers are colder. The temperature gradient on the E slope indicates that the downward transport of heat has stopped almost completely here.

It appears to be a general rule that the temperatures in the upper layers of the soil reflect the mean radiation intensity of a short period, while at $10 \mathrm{~cm}$ depth the mean effect of several hours irradiation becomes apparent. Thus, while on the north slope the superficial layers may become warmer than they do on the east slope, at $10 \mathrm{~cm}$ depth the temperature appears to be dependent on the amount of radiation received during the whole day.

That the differences in temperature between level ground and a south slope are much smaller than those between level ground and a north slope, is in good agreement with the radiation measurements cited above.

That the west slope attains higher temperatures than the east one is not exclusively due to the fact that it is less steep. A steeper $\left(25^{\circ}\right)$ W slope nearby appeared to reach even higher temperatures. An explanation of the differences between $E$ and $W$ slopes is given by Geiger. The $W$ slope receives its strongest insolation at a time of day when the air temperature is highest, and when the soil has already taken up some heat from the air and from diffuse radiation. The difference between east and west slopes which already exists on cloudless days, may be increased by the diurnal variation in the sunshine. In our country the afternoon hours receive a markedly 
higher amount of sunshine than the morning hours, except in October, November and December.

The effect of the inclination of the sun is clearly recognizable when the measurements of May 25th are compared with those of October 12th that were made on the same slopes (Table 22a), for now the differences between the temperatures measured on the south

TABLE 22

The effect of exposition on soil temperatures in the sand of inland dunes under different conditions.

\begin{tabular}{rccc} 
a. & \multicolumn{3}{c}{ October $12,1955,13.30 \mathrm{hr}$. Air temp. $18^{\circ} \mathrm{C}$} \\
& North $\left(30^{\circ}\right)$ & South $\left(25^{\circ}\right)$ & Level \\
$0 \mathrm{~cm}$ & $13.6^{\circ} \mathrm{C}$ & $31.4^{\circ} \mathrm{C}$ & $24.8^{\circ} \mathrm{C}$ \\
$-2 \mathrm{~cm}$ & $12.9^{\circ} \mathrm{C}$ & $25.3^{\circ} \mathrm{C}$ & $23.0^{\circ} \mathrm{C}$ \\
$-5 \mathrm{~cm}$ & $11.8^{\circ} \mathrm{C}$ & $22.0^{\circ} \mathrm{C}$ & $19.2^{\circ} \mathrm{C}$ \\
$-10 \mathrm{~cm}$ & $10.9^{\circ} \mathrm{C}$ & $18.3^{\circ} \mathrm{C}$ & $16.9^{\circ} \mathrm{C}$
\end{tabular}

b. October $31,1955,14.30 \mathrm{hr}$. Air temp. $10^{\circ} \mathrm{C}$

North $\left(28^{\circ}\right)$ South $\left(28^{\circ}\right) \quad$ Level

$\begin{array}{rlll}0 \mathrm{~cm} & 4.4^{\circ} \mathrm{C} & 25.0^{\circ} \mathrm{C} & \\ -2 \mathrm{~cm} & 4.2^{\circ} \mathrm{C} & 18.0^{\circ} \mathrm{C} & 10.8^{\circ} \mathrm{C} \\ -5 \mathrm{~cm} & 4.2^{\circ} \mathrm{C} & 15.3^{\circ} \mathrm{C} & 9.4^{\circ} \mathrm{C} \\ -10 \mathrm{~cm} & 4.2^{\circ} \mathrm{C} & 11.0^{\circ} \mathrm{C} & 7.7^{\circ} \mathrm{C}\end{array}$

c. July $20,1954,16.00 \mathrm{hr}$. Air temp. $22.7^{\circ} \mathrm{C}$

$\begin{array}{rcccc} & \text { North }\left(30^{\circ}\right) & \text { South }\left(25^{\circ}\right) & \text { West }\left(13^{\circ}\right) & \text { East }\left(33^{\circ}\right) \\ 0 \mathrm{~cm} & 25.0^{\circ} \mathrm{C} & 25.8^{\circ} \mathrm{C} & 29.5^{\circ} \mathrm{C} & 21.8^{\circ} \mathrm{C} \\ -2 \mathrm{~cm} & 21.7^{\circ} \mathrm{C} & 24.6^{\circ} \mathrm{C} & 27.3^{\circ} \mathrm{C} & 22.0^{\circ} \mathrm{C} \\ -5 \mathrm{~cm} & 19.9^{\circ} \mathrm{C} & 23.4^{\circ} \mathrm{C} & 23.6^{\circ} \mathrm{C} & 21.8^{\circ} \mathrm{C} \\ -10 \mathrm{~cm} & 17.6^{\circ} \mathrm{C} & 21.0^{\circ} \mathrm{C} & 20.2^{\circ} \mathrm{C} & 20.8^{\circ} \mathrm{C}\end{array}$

d. Sept. 2, 1954, $5.00 \mathrm{hr}$. Air temp. $15^{\circ}$. After still, bright night.

\begin{tabular}{rccccc} 
& North & South & West & East & Level \\
$-2 \mathrm{~cm}$ & $14.8^{\circ} \mathrm{C}$ & $16.1^{\circ} \mathrm{C}$ & $16.0^{\circ} \mathrm{C}$ & $15.0^{\circ} \mathrm{C}$ & $15.7^{\circ} \mathrm{C}$ \\
$-5 \mathrm{~cm}$ & $15.4^{\circ} \mathrm{C}$ & $16.5^{\circ} \mathrm{C}$ & $16.7^{\circ} \mathrm{C}$ & $15.4^{\circ} \mathrm{C}$ & $16.5^{\circ} \mathrm{C}$ \\
$-10 \mathrm{~cm}$ & $16.0^{\circ} \mathrm{C}$ & $17.5^{\circ} \mathrm{C}$ & $17.7^{\circ} \mathrm{C}$ & $16.2^{\circ} \mathrm{C}$ & $17.2^{\circ} \mathrm{C}$ \\
\hline
\end{tabular}

slope appear to be smaller than those between the temperatures measured on the north slope, and the differences between the north and south slopes are accordingly in October greater than they are in May.

These changes in the differences are as could be expected from the radiation data.

The increase in the difference between north and south slopes is especially important when looked at from a biological point of view. In May both north and south slopes have a surface temperature which is higher than the air temperature, and also a completely dry topsoil. In October there is a qualitative difference; the south slopes still has a dry surface with a temperature $13^{\circ} \mathrm{C}$ above the air temperature, but the north slopes has a damp surface, even after several days of dry sunny weather. The surface temperature is several degrees below the air temperature, which will partly be due to evaporation from the damp surface. Under these conditions dew formation may help to keep the surface damp. 
Another example of strong differences found in autumn between north and south slopes is given in Table 22b. From a biological point of view the differences are greater still than on October 12th. The most favourable soil climate is now certainly found on the south slope.

The differences between the slopes are smaller on partially cloudy days, as Table $20 c$ shows. Yet even on July 20th, 1954, when direct radiation was restricted to the afternoon hours, marked differences still did develop, and the steep north slope attained surface temperatures which were higher than the air temperature.

An extreme difference was measured by the middle of March 1955 after a period of snow and frost. Patches of snow persisted on the north slope; the sand of the south slope was superficially dry. With an air temperature of $7^{\circ} \mathrm{C}$ surface temperatures on the north. slope ranged from $0^{\circ} \mathrm{C}$ to $6.4^{\circ} \mathrm{C}$; whereas on the south slope a surface temperature of $33^{\circ} \mathrm{C}$ was measured.

The highest soil temperatures were measured on a steep south slope with a dense vegetation of Polytrichum piliferum.

Aug. 22th, 1955, $14.00 \mathrm{hr}$. Clouds: 1/10; wind: $1.5 \mathrm{~m} / \mathrm{sec}$; air temp: $30^{\circ} \mathrm{C}$.

$\begin{aligned} 0 \mathrm{~cm} & 59.0^{\circ} \mathrm{C} \\ -2 \mathrm{~cm} & 52.7^{\circ} \mathrm{C} \\ -5 \mathrm{~cm} & 40.8^{\circ} \mathrm{C} \\ -10 \mathrm{~cm} & 29.7^{\circ} \mathrm{C}\end{aligned}$

As most of the radiation is not absorbed by the soil surface but by the moss layer, the latter must have had a considerably higher

TABLE 23

Lowest and highest temperature and vapour pressure measured in various distances from the IJsselmeer.

\begin{tabular}{|c|c|c|c|c|}
\hline \multicolumn{2}{|c|}{$\begin{array}{l}\text { Distance from } \\
\text { IJsselmeer }\end{array}$} & \multirow{2}{*}{$\begin{array}{c}\begin{array}{c}\text { Temp. } \\
{ }^{\circ} \mathrm{C}\end{array} \\
13.6-15.4 \\
13.5-14.7 \\
14.0-15.0 \\
13.9-15.0 \\
13.7-15.6 \\
16.0-17.2\end{array}$} & \multirow{2}{*}{$\begin{array}{c}\begin{array}{c}\text { Vapour pressure } \\
\mathrm{mm}\end{array} \\
4.9-5.8 \\
5.5-6.3 \\
6.0-6.6 \\
5.5-5.9 \\
5.8-6.9 \\
5.9-6.2\end{array}$} & \multirow{2}{*}{$\begin{array}{c}\begin{array}{c}\text { Time } \\
\text { May, 8, 1954 }\end{array} \\
10.45-11.25 \\
12.10-12.20 \\
13.10 \\
13.50-14.00 \\
14.40-14.50 \\
15.30\end{array}$} \\
\hline $\begin{array}{l}8 \\
2 \\
2 \\
2 \\
8 \\
8\end{array}$ & $\begin{array}{l}\mathbf{k m} \\
\mathbf{k m} \\
\mathbf{k m} \\
\mathbf{k m} \\
\mathbf{k m} \\
\mathbf{k m}\end{array}$ & & & \\
\hline $\begin{array}{l}8 \\
2 \\
2 \\
0,3 \\
2 \\
8\end{array}$ & $\begin{array}{l}\mathbf{k m} \\
\mathbf{k m} \\
\mathbf{k m} \\
\mathbf{k m} \\
\mathbf{k m} \\
\mathbf{k m}\end{array}$ & $\begin{array}{l}27.0-28.8 \\
25.0-26.3 \\
27.2-27.4 \\
25.1-25.5 \\
27.3-27.8 \\
28.4-31.8\end{array}$ & $\begin{array}{l}11.6-12.4 \\
13.4-14.2 \\
12.6-13.0 \\
15.2-16.7 \\
13.1-13.2 \\
11.6-12.7\end{array}$ & $\begin{array}{c}\text { June } 19,1954 \\
10.00-10.15 \\
10.50 \\
12.15 \\
13.15-13.45 \\
14.00 \\
14.50-15.05\end{array}$ \\
\hline $\begin{array}{l}8 \\
2 \\
0.3 \\
2 \\
8\end{array}$ & $\begin{array}{l}\mathrm{km} \\
\mathrm{km} \\
\mathrm{km} \\
\mathrm{km} \\
\mathrm{km}\end{array}$ & $\begin{array}{l}20.8 \\
18.8-19.3 \\
18.8-19.4 \\
20.3-20.7 \\
20.8-23.0\end{array}$ & $\begin{array}{c}8.9 \\
9.9-10.3 \\
10.5-11.3 \\
10.0-10.1 \\
9.1\end{array}$ & $\begin{array}{l}\text { July } 9,1954 \\
10.25 \\
10.35-10.50 \\
12.00-12.15 \\
12.20 \\
12.35\end{array}$ \\
\hline
\end{tabular}


temperature than the soil immediately below the surface. As the measurements were taken late in summer, it is probable that higher temperatures may occur when the sun occupies a higher position.

\section{r. INFLUENCE OF THE IJSSELMEeR}

It is well known that a large surface of water has a measurable influence on the temperature and on the humidity in a narrow zone of the surrounding country.

In order to find out whether such an influence is recognizable in the inland dunes that are nearest to the IJsselmeer, we measured the temperature and the humidity on bicycle rides to the IJsselmeer to and fro. The data in Table 23 show that on the days on which these measurements were made, such an influence was indeed present. In interpreting the results we should take into account that between the inland dunes and the IJsselmeer an area of grassland with a plentiful water supply is found. When the inland dunes reached the shore of the IJsselmeer, the measurable influence of the latter would probably not extend as far as $2 \mathrm{~km}$ inland.

CHAPTER V

\section{CONCLUDING REMARKS ON THE RELATIONS BETWEEN VEGETATION AND HABITAT}

\section{a. The heath vegetation}

It is interesting to note that heath vegetations find their optimum development in the Atlantic region. The Atlantic climate with its damp, cloudy and windy weather, offers relatively little opportunity for microclimatic differentiation. In contrast with such a vegetation as a lawn, a heath vegetation will in this region not cause the development of very cold nights of or very warm days. The general macroclimate on which such effects would have to be superimposed, also does not tend to extremes. In a bright continental region, on the other hand, the differences between the microclimate of the heath and that of a normal station may become more accentuated as in this case the effects of the vegetation are superimposed on a macroclimate that is already more extreme. Under continental conditions microclimatic differences in soil temperature will be more considerable too.

The same considerations apply to the raised bogs that are so typical for the Atlantic region.

Plant geographically continental elements are practically absent in the flora of the heath. The most important species in the vegetation have a wide distribution, a particularity which may be seen in connection with the wide range of variability shown by the temperature.

The root system of the plants which constitute the vegetation, is often confined to the upper $20 \mathrm{~cm}$ of the soil, viz. when a well-developed hardpan is present. When the latter is absent, roots may be found 
PH. STOUTJESDIJK

down to a depth of $75 \mathrm{~cm}$. However, in this case too the major part of the roots is confined to the upper 5 to $10 \mathrm{~cm}$ of the soil.

Where the roots are confined to the upper $20 \mathrm{~cm}$ of the soil, transpiration must necessarily be small, as otherwise the vegetation would not be able to survive dry periods on the limited amount of water that is available in the soil.

As the last section of Chapter I shows, nearly all species remain more or less green during the winter. In this respect Molinia coerulea is an interesting exception. Where this species dominates, the habitat factors which usually find their expression in the life form, are the same as in places where Calluna dominates, yet instead of an evergreen vegetation we find in this case a vegetation which is green only during 3-4 months.

The vegetation is formed without exception by perennial species, and all species end their period of rest rather late, some even very late (Calluna, Molinia). Empetrum flowers very early in the year, and this is the only species which flowers before it begins to form new leaves and stems, which means that the flower buds have been formed already in the preceding year.

None of the species is sensitive to night frosts so long as the temperature does not sink below $-10^{\circ} \mathrm{C}$; even with night frosts late in May, i.e. in the period when young shoots are formed, they are not damaged. The severeness of the microclimate, is however, clearly seen in the behaviour of the oak shrub, which occurs in patches on several heaths. Oak is known to be rather sensitive to night frosts, and to be retarded in its growth by low temperatures (Pinkhof, 1938). The oaks on the heath, the lower shrub as well as the few higher trees, are very late in their development. In comparison with the oaks in the woods, they are three to four weeks late with leafing. In this respect they resemble winter oaks. However, their morphological characteristics prove that they are Quercus robur. The oaks on the inland dunes are, in their growth habits and morphology, identical with those on the heath. However, they are much earlier, be it somewhat later than those growing in more favourable spots, viz. along roadsides and in woods.

That the low night temperatures really are the cause of the late leafing, becomes clear when oaks in elevated stations are compared with those growing on flat ground. In 1954 the leafing of oak on the "Kootwijkerveld" (a flat heath area) started in the last week of May. In a nearby sand dune area, the "Otterlosezand", the leafing began about May the 15th. In 1955, on May the 10th on the sand dune area "Kootwijkerzand" all stages, from swelling buds to young $3 \mathrm{~cm}$ long leaves could be observed. On May the 22th on a high hill called "Bergsham" (cf. for temperature measurements Chapter IV) most oak shrubs had young soft leaves and the most backward ones had strongly swollen buds. The oaks in another elevated heath area, the S.W. part of the "Ermeloseveld", showed about the same stage of development. On May the 25th the buds began to swell on the heath called the "Kootwijkerveld". On June the 2nd on the heath 
near Boeschoten oaks had small leaves of $1-2 \mathrm{~cm}$ in length on the higher branches whereas often hardly swollen buds were observed on the lower ones.

In autumn the oaks did not show differences with respect to the time at which they changed their colour and shed their leaves. Leaves of oak trees which grow on the heath, change their colour earlier in the autumn than individuals of the same species elsewhere do.

Strange as it may seem, oaks growing on the heath suffer sometimes less from night frosts than those in less frost-susceptible habitats. This is due to the late development of the oaks on the heath. However, some damage can usually be observed, since night frosts of $2-3^{\circ} \mathrm{C}$ (measured at a height of $10 \mathrm{~cm}$ ) are of frequent occurrence at the end of May and at the beginning of June. Occasionally an individual may open its buds earlier in the season, and such a one may suffer more strongly.

The oaks start leafing on the highest branches. This is at variance with what has been observed with other species. Usually development is most rapid near the soil where by day the highest temperatures are measured and where the air movements are weakest. Apparently it is only with oak that the influence of the low night temperatures is of more importance than that of the high day temperatures.

The late development of the oaks on the heath must partly be due to genetic factors. This follows from the fact that on the inland dunes too the oaks are late in putting forth their leaves. Yet here the prevailing temperatures would suggest the opposite effect.

Further oak saplings taken from a nursery and planted on spots where night frosts may be expected, do not put forth their leaves so late. Accordingly they may be severely damaged by night frosts, and they often are killed.

Betula, Sorbus aucuparia, and Prunus serotina show hardly any retardation of the leafing process. Night frosts of $9-10^{\circ} \mathrm{C}$ at the beginning of May did some damage to these three species, but only a few of the lower leaves were killed.

All species are more or less xeromorphic. As most species are confined to the heath and eventually to some other dry habitats, no comparison with less extreme habitats is possible. Again Quercus robur permits a comparison of the heath with other, less extreme habitats. Fig. 13 shows sections through leaves taken from the south side of solitary oak shrubs on heath and on medium dry grassland.

Firbas (1931) has drawn attention to the fact that in a raised bog the soil is cold in contrast with the often high temperature of the air; the species living in such a habitat must be specially adapted in order to be able to absorb water from such a soil. The same applies to heath plants. For Calluna and other raised bog species Firbas has shown that water uptake at $1^{\circ} \mathrm{C}$ was reduced by only $10 \%$ as compared with water uptake at $20^{\circ} \mathrm{C}$.

Finally it must be said that the work of WENT (1944) has only recently shown that more subtle effects of the microclimate are to be expected. To many species periodical changes in temperature are of 
great importance. It may be expected that the amplitude of the fluctuations in temperature in the soil and in the air is of importance too.

Concluding, we may say that all species of the heath vegetation which were studied by us, are well adapted to the extreme conditions under which they have to live. At first sight this may seem to be a
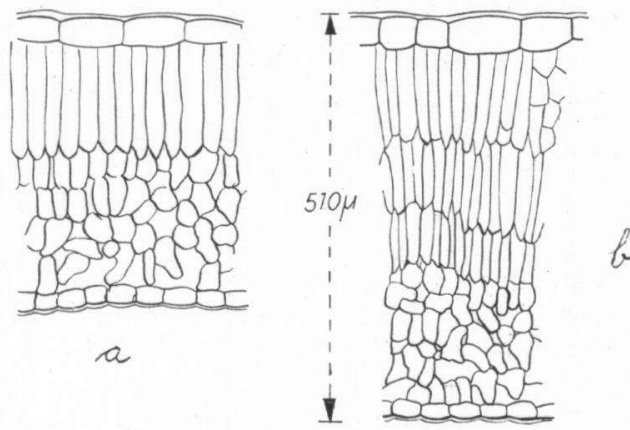

Fig. 13. a. Section of a leaf taken from the South side of an oak on medium dry grass land at $2 \mathrm{~m}$ height.

Fig.13. b. Same as $13 a$, from an oak on a heath.

trivial statement; however, experience in dune vegetations showed that this need not be so. This adaptation to conditions of life which in many respects may be called extreme, doubtless indicates that these conditions must have been in operation for a long time. While pollenanalytical evidence seems to prove that the great expansion of the heather was due to human activity, it is very probable that vegetations similar in composition, and adapted to similar habitat conditions must have existed already at a much earlier time.

\section{b. INLAND DUNES}

The properties of the microclimate, viz. higher soil temperatures in spring and summer and a protection against late spring frosts, would justify the expectation that species with southern or continental affinities might be found here. That this is not so, must be due, in the author's opinion, to the fact that the edaphic factors are by no means similar to those of warmer areas. The expremely poor, leachedout soil is typically North-Atlantic. The poverty of the soil makes it impossible for thermophilous species to avail themselves of the thermic possibilities of the habitat.

The root system of the plants of which this vegetation is composed, usually does not reach a great depth, except that of Ammophila arenaria, which is confined to moving sand. In the fixed inland dunes roots do not penetrate deeper than $35 \mathrm{~cm}$, reflecting in this way the fact that the climate is humid. When the small volume of the aerial parts is considered, the quantity of roots is very large. The severe conditions 
in the upper centimeters of the soil are doubtless responsible for the fact that in these layers roots are but scarce.

All species may be called wintergreen, but the use of this term is somewhat flattering in the case of Ammophila arenaria and of Carex arenaria, of which only the leaf bases are green during the winter. In the resting inland dunes there is hardly any change in aspect in the course of the year, except for the flowering of the grasses and the absence of the winter therophyte Spergula vernalis in summer. On the inland dunes Spergula vernalis is the only representative of the winter therophytes, which are better represented in similar habitats on richer soil. On the sea dunes whith a richer soil the wintertherophytes, prevail while on the sea dunes with poorer soil perennials predominate. On the inland dunes of Norfolk and Suffolk a great number of winter annuals are found, often with southern and continental affinities (steppeflora, cf. TANSLEy, 1939) on richer soil. On the poorest soils a flora like that of our inland dunes is found. The biennial plants Hypochoeris glabra and fasione montana are restricted to north slopes. The remaining species are perennial.

As can be seen from the preceding exposition, all species that germinate in sand (either bare or fixed) do this in autumn, and then continue their growth till their further development is stopped by the sinking temperature. Another time of the year in which seedlings could successfully develop, is difficult to imagine. A seedling germinating at the beginning of October has but two months of mild humid weather at its disposition. Germination by the end of the winter or at the beginning of spring would expose the seedling to a period of increasing dryness and heat.

In 1954 all species were rather strongly affected in the later part of the winter with its strong winds, but only part of the individuals of Corynephorus were killed. None of the species present in the inland dune vegetation is sensitive to night frost.

The mosses and lichens have to be adapted to the high temperatures and the frequent dry periods that occur in summer. LaNGe (1953, $1954,1955)$ made extensive studies on the heat and drought resistance of a great number of mosses and lichens. He found that lichens and mosses from hot and arid habitats could resist in a dry state temperatures up to $90^{\circ} \mathrm{C}$ approximately. This means that their tolerance is with an ample margin sufficient to cope with the situations they meet with in nature. The same applies to drought resistance, although photosynthesis will often be impossible for long periods. To lichens and mosses dew formation doubtless may be of importance, as it makes photosynthesis possible in the early morning hours. However, in summer dew formation is slight or absent even when it is elsewhere strong. Stocker has shown that the lichens studied by him have to be wet, and not merely humid, for an effective photosynthesis to take place (cf. also Butis, 1954). Thus a very weak dew formation might be more harmful than beneficial. However, dew formation may be of importance in autumn.

As mentioned already, Calluna and Quercus show a much earlier 
development on the dunes than on the heath. Remarkable is that the sprouting of Empetrum on steep north slopes was not later, but rather earlier, than on level sand.

\section{REFERENCES}

Aaltonen, V. T., 1935, 1939. Zur Stratigrafie des podsolprofils. Communicationes instituti forestalis Fenniae, 20: nr 6; 27: $\mathrm{nr}$. 4 .

Bartels, J., 1933. Verdunstung, Bodenfeuchte und Sickerwasser. Zeitschrift für Forst- und Jagdwissenschaften 65: 204.

Beijerinck, W., 1938. Over driehoorns en hun werk. De Levende Natuur 47 : 358.

194i. Enkele beschouwingen over de geografische verspreiding van het z.g. podsolprofiel en den samenhang tussen de lagen in dat profiel. Besprekingen over het heidepodsolprofiel. Arnhem.

BraAK, C., 1929-1943. Het klimaat van Nederland. Kon. Ned. Met. Inst., Med. en Verh. 32, 33, 34a, 34b, 39, 40, 41, 42, 43, 46.

Butin, H. 1954. Physiologisch-ökologischen Untersuchungen über den Wasserhaushalt und die Photosynthese bei Flechten. Biologisches Zentralblatt 73: 459.

BüTtNer, K. und E. SuTTER, 1935. Rückstrahlung verschiedener Bodenbedeckungen für u.v. und gesammte Sonnenstrahlung. Strahlentherapie 54: 156.

Darling, F. F., 1947, Natural history in the highlands and islands. London.

DEB, D. C., 1949. The movement and precipitation of iron-oxides in podsol soils. The Journal of Soil Science 1: 1

Delany, M. J., 1953. Journal of An. Ec. 22: 227.

DimblebY, 1952. Soil regeneration on N. E. Yorkshire moors. Journal of Ecology 10: 313 .

Enders, C., 1942, 1943. Uber den Chemismus der Huminsäurebildung unter physiologischen Bedingungen. Bioch. Zeitschr. 312: 339; 313: 174; 313: 325 ; 315: 259.

FalckenberG, G., 1928. Absorptionskonstanten einiger meteorologisch wichtigen Körper für infraroten Wellen. Met. Z. 45: 334.

Farrow, E. P., 1925. Plant life on East-Anglian heaths. Cambridge.

FAvelJEe, J. CH., 1950. Over het voorkomen van ijzeroxyden in de bodem. Tijdschr. Kon. Ned. Aardr. Gen. 67: 684 .

Frrbas, F., 1931. Untersuchungen über den Wasserhaushalt der Moorpflanzen. Jb. für Wiss. Bot. 74: 459.

FloRschütz, F., 1941. Resultaten van het microbotanisch onderzoek van het complex loodzand-oerzand en van daaronder en daarboven gelegen afzettingen. Besprekingen over het heidepodsolprofiel. Arnhem.

Gallagher, P. H., 1943. The mobile colloidal humus of podsolic soils and its relation to the process of podsolisation. Proc. Roy. Irish Ac. 48B: 213.

Geiger, R., 1950. Das Klima der Bodennahen Luftschicht. Braunschweig.

Giffen, A. E. van, 1941. De tijd van vorming van heidepodsolprofielen aan de hand van archeologische waarnemingen. Besprekingen over het heidepodsolprofiel. Arnhem.

Grevilius, Y. 1928. In Lebensgeschichte der Blütenpflanzen Mitteleuropas. Stuttgart.

Hard, F. 1935. Pflanzengeographische Studien im nordwestlichen Teil der Eichenregion Schwedens. Ârkiv. f. Bot. 27A : 1.

Harmsen, G. W., 1951. Die Bedeutung der Bodenoberfläche für die Humusbildung. Plant and soil 3: 110.

Haude, W., 1934. Temperatur und Austausch der Bodennahen Luft über eine Wüste. Beitr. Phys. d. fr. Atm. 21 : 129.

Helmus, A. \& C. A. Jörgensen, 1924. Temperaturforholdene paa Maglemose og deres Betydning for Vegetationen. Bot. Tidsskr, 38: 269.

Hiltner, 1930. Der Tau und seine Bedeutung für den Pflanzenbau. Wiss. Arch. für Landwirtsch. 3: 1 . 
Homen, TH., 1897. Der tägliche Wärmeumsatz im Boden und die Wärmestrahlung zwischen Himmel und Erde. Acta Soc. scient. Fennicae, 23, nr. 3: 1.

Jenny, H., 1934. The clay content of the soil as related to climatic factors, particularly temperature. Soil science 40: 2 .

-1 1930. Gesetzmäszige Beziehungen zwischen Bodenhumus und Klima. Die Naturwissenschaften 18: 41.

JeswIET, J., 1913. Die Entwicklungsgeschichte der Flora der holländischen Dünen. Thesis, Zürich.

KAMPFERT, W., 1942. Sonnenstrahlung auf Ebene, Wand und Hang. Reichsamt für Wetterdienst, Wiss. Abh. 9: nr. 3.

Kerner, A., 1891. Änderung der Bodentemperatur mit der Exposition. Sitz. Ber. Wien Akad. 100: 704.

KinzeL, W. 1913-1920. Frost und Licht als beeinflüssende Kräfte der Samenkeimung. Stuttgart.

Krvenhermo, V. J., 1947. Untersuchungen über die Wurzelsysteme der Samenpflanzen in der Bodenvegetation der Wälder Finnlands. Ann. Bot. Vanamo, 22: nr. 2.

Kramer, P., 1951. Plant and soil water-relationships. New York.

Kramer, C., J. J. Post en J. P. M. Woudenberg. 1954. Nauwkeurigheid en betrouwbaarheid van temperatuur- en vochtigheidsmetingen in buitenlucht met behulp van kwikthermometers. Kon. Ned. Met. Inst., Med. en Verh. nr. 60.

KreUtz, W., 1943. Beitrag zur Erforschung des Boden- und bodennahen Klimas im Emslandmoor. J. für Landwirtsch. 81 : 81.

Lange, O. L., 1953. Hitze- und Trockenresistenz der Flechten in Beziehung zu ihrer Verbreitung. Flora. 140: 39.

. 1954. Einige Messungen zum Wärmehaushalt poikilohydrer Flechten und Moose. Arch. für Meteor. Geoph. und Biokl. ser. B. 5: 182.

1955. Untersuchungen über die Hitzeresistenz der Moose in Beziehung zu Ihrer Verbreitung. Flora 142: 381.

Leick, E., 1933. Der Tau als Standortsfactor. Ber. d. Deutschen Bot. Ges., 51 : 409.

LinkolA, K. und A. TirRIKKA, 1936. über Wurzelsysteme und Wurzelausbreitung der Wiesenpflanzen auf verschiedenen Wiesenstandorten. Ann. Botanici Vanamo, 6: nr. 6.

LundegardH, H., 1957. Klima und Boden. Vienna.

Mattson, S. and Y. Gustafrson, 1933. The chemical characteristics of soil profiles. Lantbrugs Hogsk. Ann. 1: 209.

Modderman, P. J. R., 1954. Grafheuvelonderzoek in midden-Nederland. Ber. van de Rijksd. voor het Oudheidk. Bodemond. 5: 7.

Moerman, J. D., 1947. Rood zand en praehistorische bewoning. Tijdschr. Kon. Ned. Aardr. Gen. 44: 537, 680 .

Muller, P. E., 1887. Studien über die natürlichen Humusformen.

, 1924. Bidrag til de jydske Hedesletters Naturhistorie. Det. Kgl. Danske Vidensk. Selsk. Biol. Medd. 4: 2.

NizLSEN, S. E., 1940. Über die Bedeutung der sogenannten xeromorphen Struktur im Blattbau der Pflanzen auf nährstoffarmen Boden. Dansk. Bot. Arkiv 10: 1 .

Pinkhof, M., 1938. Hemel en Dampkr. 36: 260.

Raman, M. E., 1911. Bodenkunde. Berlin.

RoBinson, G. W., 1949. Soils. London.

SalisBury, E., 1952. Downs and dunes, London.

SCHADE, A., 1917. über den mittleren jährlichen Wärmegenusz von Webera nutans und Leptoscyphus taylori im Elbsandsteingebirge. Ber. D. Bot. Ges. 35: 490.

Schimmed, H. J. W. en J. TER Hoeve, 1952. Bodemgesteldheid van de Gerritsflesch bij Kootwijk. Tijdschr. Kon. Ned. Aardr. Gen. 69 : 16.

Schuffelen, A. C. and G. H. BolT, 1950. Some notes on the synthesis of humus compounds. Landbouwkundig Tijdschr. 62: 333 .

SchuYlenborgh, J. van and A. M. H. SANGER, 1949. The electrokenetic behaviour of iron- and aluminiumhydroxides and -oxides. Rec. des Trav. Chim. des Pays Bas, 68: 999. 
Scurfield, G., 1954. Deschampsia flexuosa. J. of Ec. 42 : 225.

SHIRLEY, H. L., 1945. Light as an ecological factor and its measurement. Bot. Rev.

Sinclair, J. G., 1922. Temperature of the soil and air in a desert. M. W. Review $50: 142$.

Stocker, O., 1923. Klimamessungen auf kleinstem Raum an Wiesen. Wald. und Heidepflanzen. Ber. der Deutschen Bot. Ges. 41 : 145.

, 1927. Physiologischen und ökologischen Untersuchungen an Laub- und Strauchflechten. Flora N.F. 21 : 334.

, 1923. Die Transpiration und Wasserökologie nordwestdeutscher Heideund Moorpflanzen am Standort. Ztschr. für Bot. 15: 1.

Stoutjesdijk, Ph., 1953. Vegetatiekundig onderzoek van Veluwse heidevelden. In: Heeft onze heide nog toekomst. Arnhem.

TAmm, O., 1920. Bodenstudien in der nordschwedischen Nadelwaldregion. Medd. fr. St. Skogsforsoksanstalt, 17: 277.

TANsLeY, A. G., 1939. The British islands and their vegetation.

Uitrten, H. and L. C. Geerlings, 1932. Cultuurproeven met struikhei (Calluna vulgaris Salisb.) Korte med. van het Rijksbosbouwproefstation.

_. 1932. Enige plantengeografische opmerkingen over de Veluwe. Ned. Kruidk. Arch. 1932: 278.

VAaRTAJA, O., 1949. High surface temperatures. Oikos $1: 6$.

VAlCKENIER SURINGAR, J., 1926. De planten in het zandverstuivingsterrein bij Kootwijk en hunne groeiwijze. In: zandverstuivingen bij Kootwijk. Utrecht.

Veenenbos, J. S., 1953. Heterogenisatie van het bodemprofiel in Nederland. Boor en Spade 6.

ViNk, A. P. A., 1949. Bijdrage tot de kennis van löss en dekzanden, in het bijzonder van de Zuidoostelijke Veluwe. Thesis Wageningen.

VIIEGER, J., 1941. Oecologische voorwaarden der podsolvorming. Besprekingen over het heidepodsolprofiel.

Volk, O., 1931. Beiträge zur Okologie der Sandvegetation der oberrheinischen Tiefebene, Ztschr. für Botanik, 24.

Voorwijk G. en S. Hardjoprakoso, 1945. De vennen te Eerde bij Ommen. Tijdschr. Kon. Ned. Aardr. Gen. 62: 105.

VRIEs, D. A. DE and H. J. Venema, 1954. Some considerations on the behaviour of the Piche evaporimeter. Vegetatio 5-6, 225.

Waterbolk, H. T., 1953. De praehistorische mens in zijn milieu. Assen.

WATT, A. S., 1936, 1937, 1938, 1940. Studies in the ecology of Breckland. Journ. of Ec. 24: 117; 25: 91 ; 26: 1 ; $28: 42$.

, 1947. Pattern and process in the plant community. Journal of Ec. 35: 1. and E. W. Jones, 1948. The ecology of the Cairngorms. Journ. of Ec. 36: 283.

WErss, Fr., 1929, 1933. Fysiske og kemiske Undersogelser over Danske Hedejorder. Det Kgl. Danske Vidensk. Selsk. Niol. Medd. 7: nr. 9; 10: nr. 3.

WENT, F. W., 1944. Thermoperiodicity in growth and fruiting of the tomato. Am. Journ. of Bot. 31: 135.

Westhopr, V., 1947. The vegetation of the dunes and salt marshes on the Dutch islands of Terschelling, Vlieland and Texel. Thesis Utrecht.

- 1958. De plantengroei van het nationale park Veluwezoom. Wet. med. K.N.N.V. 26.

Wollsy, W., 1878. Untersuchungen über den Einflusz der Exposition auf die Erwärmung des Bodens. Forsch. a.d. Geb. der Agrikulturphysik, 1 : 263.

ZEIST, W. vaN, 1955. Pollenanalytical investigations in the northern Netherlands, Thesis Utrecht.

Zinderen Bakker, E. M. van, 1948. Palynologisch en stratigraphisch onderzoek van Veluwse venen. Tijdschr. Kon. Ned. Aardrijksk. Gen., 65: 174. 